\title{
A Method for Selecting FBR Development Strategies in the Presence of Uncertainty
}

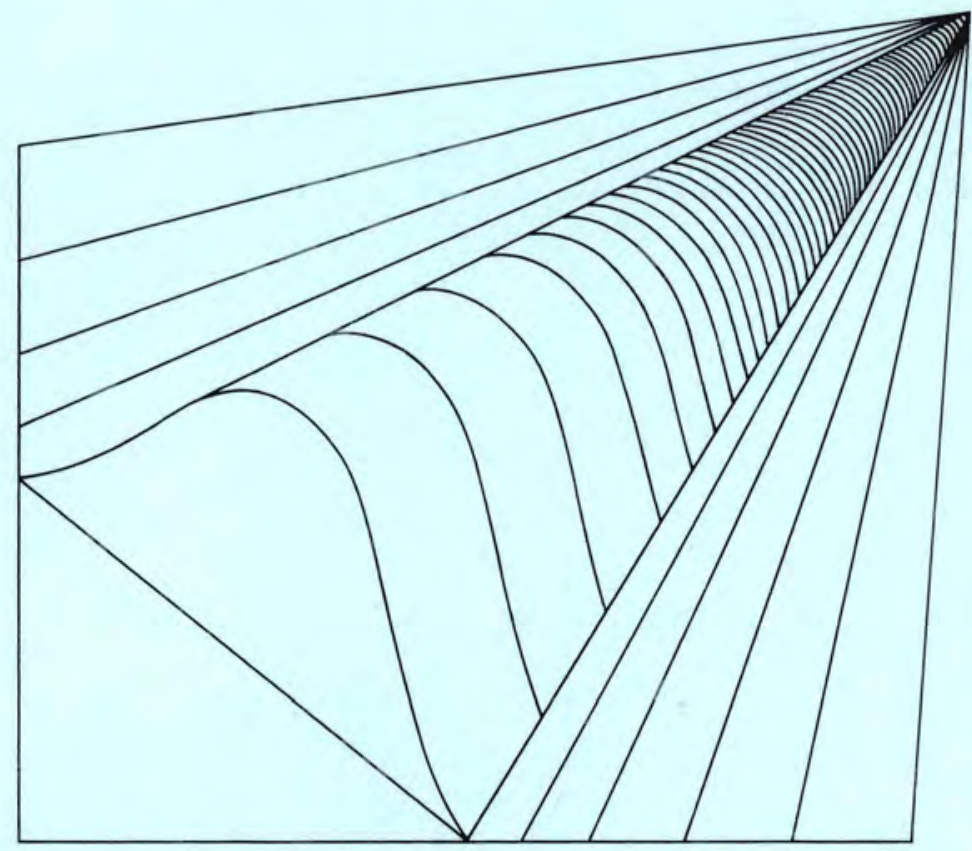

Prepared for the U.S. Department of Energy under Contract DE-AC06-76RLO 1830

Pacific Northwest Laboratory Operated for the U.S. Department of Energy by Battelle Memorial Institute 


\title{
NO T I C E
}

This report was prepared as an account of work sponsored by the United States Government. Neither the United States nor the Department of Energy. nor any of their employees, nor any of their contractors, subcontractors, or their employees. makes any warranty. express or implied, or assumes any legal liability or responsibility for the accuracy. completeness or usefulness of any information, apparatus. product or process disclosed, or represents that its use would not infringe privately owned rights.

The views. opinions and conclusions contained in this report are those of the contractor and do not necessarily represent those of the United States Government or the United States Department of Energy.

\author{
PACIFIC NORTHWEST LABORATORY \\ operated by \\ BATTELLE \\ for the \\ UNITED STATES DEPARTMENT OF ENERGY \\ Under Contract DE-AC06-76RLO 1830
}
Printed in the United States of America
Available from
National Technical Information Service
United States Department of Commerce
5285 Port Royal Road
Springfield. Virginia 22151

Price: Printed Copy $\$$

$\therefore$ Microfiche $\$ 3.00$

NTIS

- Pages Selling Price

001-025 \$4.00

026-050 \$4.50

051-075 \$5.25

076-100 \$6.00

$101-125 \quad \$ 6.50$

$126-150 \quad \$ 7.25$

$151-175 \quad \$ 8.00$

$176.200 \quad \$ 9.00$

201-225 \$9.25

226-250 \$9.50

251-275 \$10.75

$276-300 \quad \$ 11.00$ 


\section{5}

PNL -3598

UC $-2,16$

$51,78,79$

$79 i$

A METHOD FOR SELECTING FBR

DEVELOPMENT STRATEGIES IN

THE PRESENCE OF UNCERTAINTY

D. W. Fraley

J. B. Burnham

December 1981

Prepared for

the U.S. Department of Energy

under Contract DE-AC06-76RLO 1830

Pac if ic Northwest Laboratory

Richland, Washington, 99352 



\section{ACKNOWLEDGMENTS}

The authors wish to acknowledge the considerable efforts of

R. M. Fleischman and J. P. Thereault for their technical contributions and review of this work. We also wish to thank Lonnie Foley for her able assistance in the editing. 



\section{EXECUTIVE SUMMARY}

The development of the Fast Breeder Reactor (FBR) will require expenditure of significant time and monies. Key decisions must be made on the best strategy for the government to pursue to bring the FBR from its present state to the point at which it will be an economic energy alternative. Three key issues must be considered in making these decisions:

timing - Ideally, the strategy should be planned such that its development is complete at the same time the FBR is commercially competitive.

benefits - The estimated net benefits to society of its development must be significant.

risks - The economic risks of the development strategy being too early or too late must be specifically included in the analysis.

A number of factors influence these issues. The major considerations are the capital cost of a mature FBR, the U.S. uranium supply, the growth of the light water reactor (LWR) industry, the time and cost required to complete a development strategy, and the economic benefits that will accrue from the FBR.

Many others have analysed this problem. Unlike other studies, this one explicitly treats the uncertainties of the major factors cited above. The methods developed for this analysis treat all data variables simultaneously as opposed to parametric analysis, which tends to treat the variables singularly.

This report describes the methods used to probabilistically analyze data related to the uranium supply the FBR's competitive dates, development strategies' time and costs, and economic benefits. It also describes the econometric methods used to calculate the economic risks of mistiming the deve lopment.

Seven strategies for developing the FBR are analyzed. The various measures of a strategy's performance--timing, costs, benefits, and risks--are combined into several criteria which are used to evaluate the seven strategies. Methods are described for selecting a strategy based on a number of alternative 
criteria. The major criteria and the strategies' rankings are shown in Table 1. As seen in the table, the compressed schedules that result in $a$ large (1457 MWe) FBR rank highest with the criteria shown. The net benefits criterion is calculated by subtracting from gross benefits the sum of development costs and risks. The risk-averse criterion considers the total risk of a strategy being "too early" and "too late" and looks for a minimum of this sum. The maximum late risk criterion selects the strategy that results in the least impact of the earliest commercially competitive date coinciding with the latest probable completion date.

\section{TABLE 1. Sumary of Strategy Rankings}

\begin{tabular}{|c|c|c|c|}
\hline Strategy $(a)$ & $\begin{array}{c}\text { Net } \\
\text { Benefits }\end{array}$ & $\begin{array}{c}\text { Risk } \\
\text { Averse } \\
\end{array}$ & $\begin{array}{c}\text { Maximum } \\
\text { Late } \\
\text { Risk } \\
\end{array}$ \\
\hline A--Sequential & 3 & 6 & 6 \\
\hline B--Delayed Sequential & 7 & 7 & 7 \\
\hline C--Compressed & 1 & 1 & 1 \\
\hline D--Delayed Compressed & 1 & 1 & 5 \\
\hline E--Component Testing & 4 & 1 & 1 \\
\hline F--Direct Prototype & 4 & 4 & 1 \\
\hline G--Direct Replicate & 4 & 4 & 1 \\
\hline
\end{tabular}

(a) Strategies A-D result in a 1457-MWe FBR; E-G in 1000 -MWe plants.

The magnitude of benefits and risks increases as the discount rate used in the analys is is decreased. However, in spite of this change, the strategy rankings did not change. The analysis concluded that, in the case of the more highly ranked strategies, the income from the sale of energy from the development plants results in an internal rate of return of about $3 \%$ without any consideration of future benefits from the FBR's development.

Strategies were also examined for the flexibility they afforded in decisions to be made in later years when more data are available. Those strategies that comitted to a demonstration plant within the next few years were found to have an advantage from this point of view. 


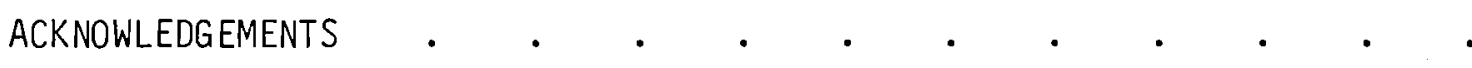

EXECUTIVE SUMMARY

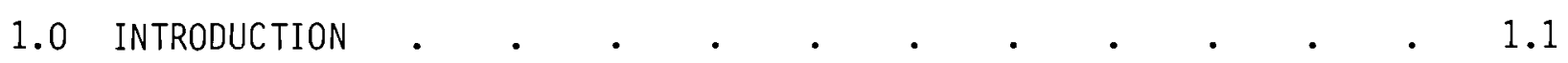

1.1 IMPORTANT FACTORS FOR THE DECISION

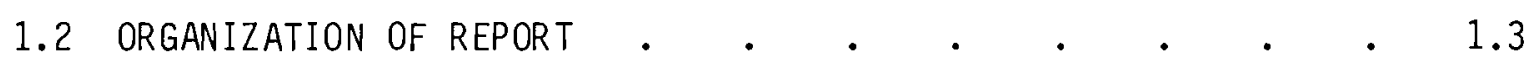

2.0 APPROACH

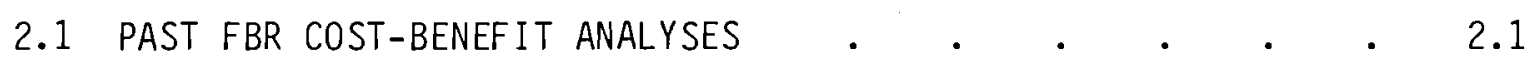

2.2 SUMMARY OF THE APPROACH

Step 1. State the objective . . . . . . . 2.2

Step 2. Describe the Alternative Strategies . . . . 2.3

Step 3. Identify Key Data . . . . . . . . 2.3

Step 4. Design Measures for Characterizing Strategies . $\quad 2.3$

Step 5. Model the Decision . . . . . . . . 2.4

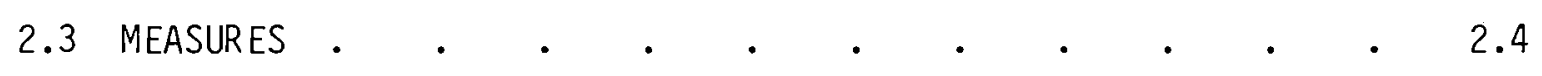

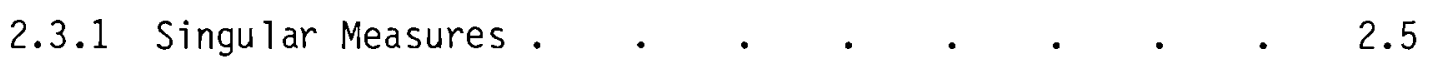

2.3.2 Combination Measures . . . . . . . . . 2.7

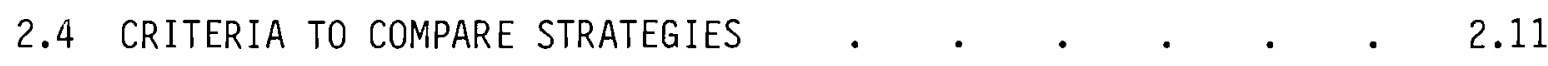

3.0 DATA FOR STRATEGY COMPARISON

3.1 COMPLETION DATES, COMPETITIVE DATES, AND COSTS . 3.1

3.2 CALCULATION OF BENEFITS

3.2.1 Principal Variables $. \quad . \quad . \quad . \quad . \quad . \quad . \quad 3.5$

3.2 .2 FBR Benefits • • . . . . . . . 3.12 
4.0 STRATEGY COMPARISON •

4.1 STRATEGY COMPLETION DATES, FBR COMPETITIVE DATES,

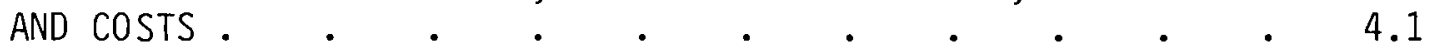

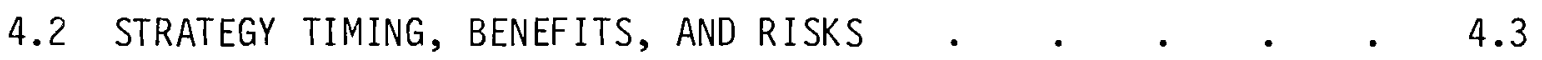

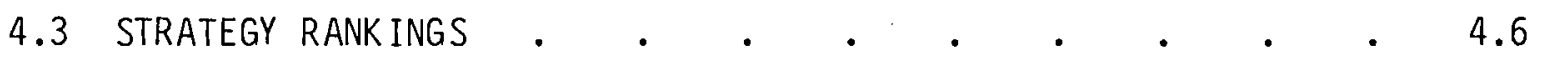

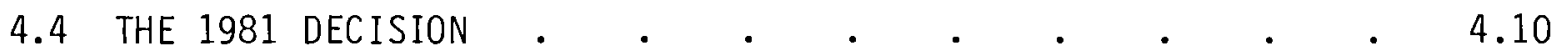

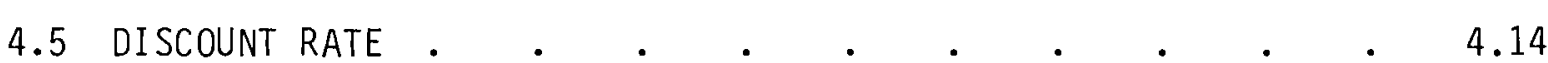

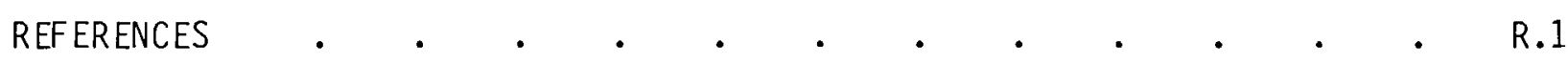

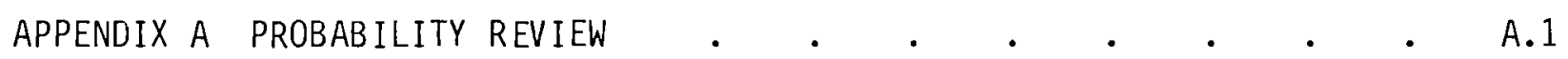

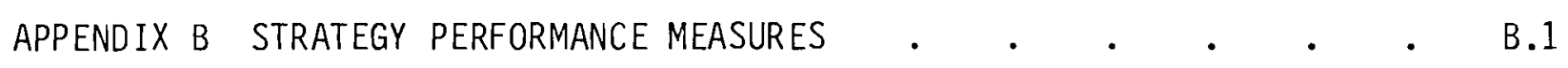

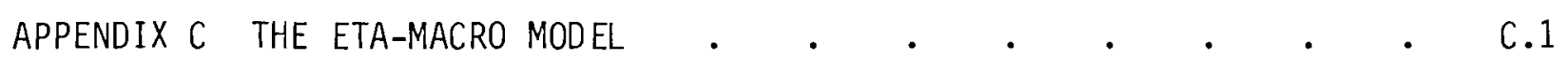

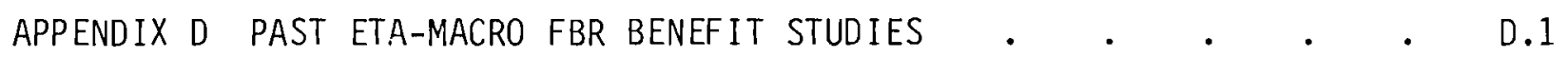

APPENDIX E ENERGY DEMAND ELASTICITIES $•$ • 
FIGURES

2.1 Completion Distribution for Sequential Strategy $\quad$ • • • • • 2.6

2.2 Development Cost Distribution for Sequential Strategy . • . 2.6

2.3 Competitive Date Distribution for 1457-MWe Commercial FBR . $\quad 2.8$

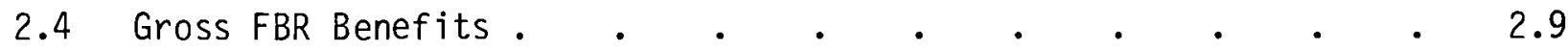

\begin{tabular}{l}
2.5 Comparison of Completion and Competitive Dates for \\
Sequential Strategy \\
\hline
\end{tabular}

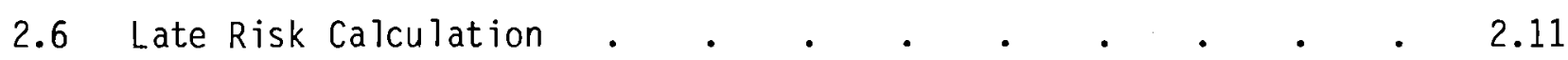

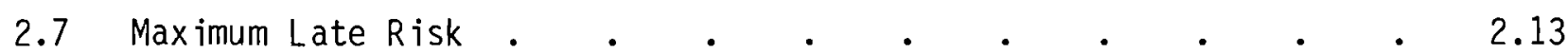

3.1 Probability as a Function of Time for Completion of Those
Strategies that Result in a 1457 -MWe FBR . . . 3.2

3.2 Probability as a Function of Time of Completion of Those
Strategies that Result in a 1000 -MWe FBR . . . . . . 3.3

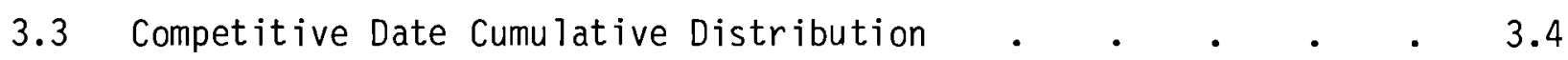

3.4 Calculated Growth of the Electrical Energy Sector for

3.5 Annual LWR Electrical Generation as a Function of Elasticity

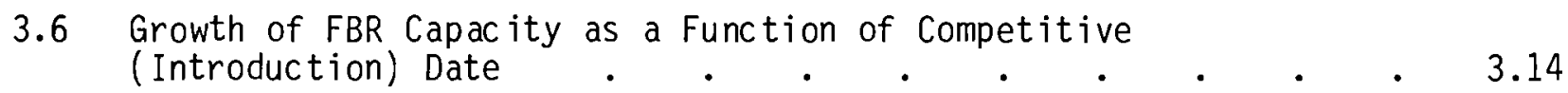

3.7 Total Electric Generation as a Function of Time . . . . $\quad 3.15$

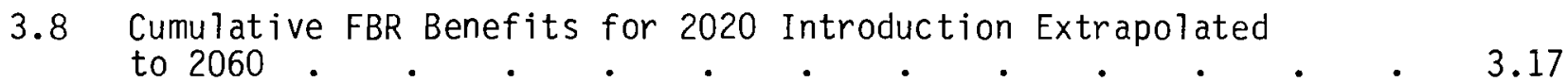

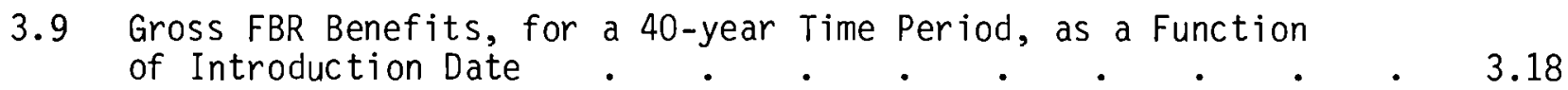

3.10 Benefits of Late FBR Introduction for Three Introduction

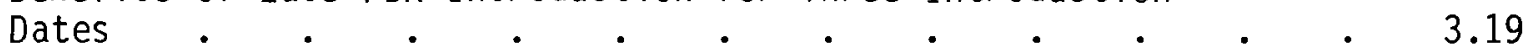

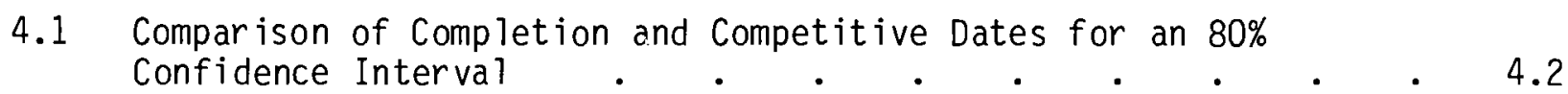

4.2 Strategy Net Benefits as a Function of Completion Date $\quad$ - 4.8 
4.3 Strategy Total Risk as a Function of Completion Date . . 4.9

4.4 Strategy Decision Tree . . . . . . . . . . . . . 4.11

4.5 Simplified Decision Tree . . . . . . . . . 4.12

4.6 The Decision on the CDS Plant . . . . . . . 4.13

A.1 Frequency Histograms of Activity Completion for 50 Trials . . A.2

A.2 Probability Density Function for Activity Completion . . . A.3

A.3 Cumulative Distribution Function for Completion Times . . . A.4

A.4 Skewed Distribution . . . . . . . . . . . A.5

A.5 Confidence Interval . . . . . . . . . A.6

A.6 "One-Sided" Confidence Interval . . . . . . . . A.6

B.1 Completion Probability for a Given Competitive Date $(t)$. . B.2

B.2 Example Benefit Function $B(t)$. . . . . . . B.3

B.3 Calculation of Expected Benefits . . . . . . . B.4

B.4 Late Benefits. . . . . . . . . . . B.5

B.5 Expected Strategy Benefits . . . . . . . . . B.6

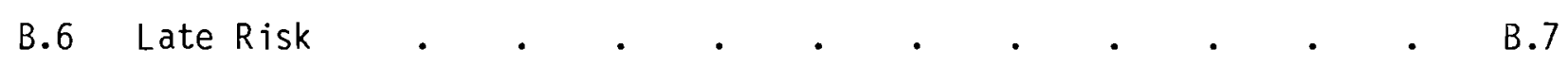

B.7 Maximum Late Risk Confidence Intervals . . . . . . . B.11

C.1 The Two Parts of ETA-MACRO . . . . . . . . . C.3

D.1 Benefit Sensitivities • • • • • • • • . 0.4

E.1 Facsimile of Elasticity Poll • • • • • • • • • E.3

E.2 Frequency Histogram of Poll Results . . . • . . E.5

E.3 Smoothed Distribution of Poll Results . . . . . . E.5 


\section{$\underline{\text { TABLES }}$}

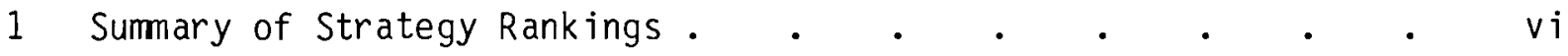

2.1 Measures for Analys is of Development Strategies . • • • • 2.5

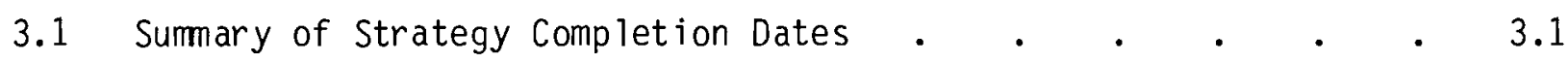

3.2 Summary of Competitive Dates .

3.3 Discounted Expected Strategy Costs and Their Ranges . . . $\quad 3.4$

3.4 Potential GNP .

3.5 Assumed Upper Bounds for Conventional (LWR) Nuclear Capacity $\quad 3.7$

3.6 Uranium Supply Functions (Cumulative Amount of Uranium in
Million Short Tons Available at Price Level) $\quad . \quad . \quad . \quad$. 3.8

3.7 Summary of Uranium Supply's Effect in 2030 . $\quad$. $\quad$. 3.9

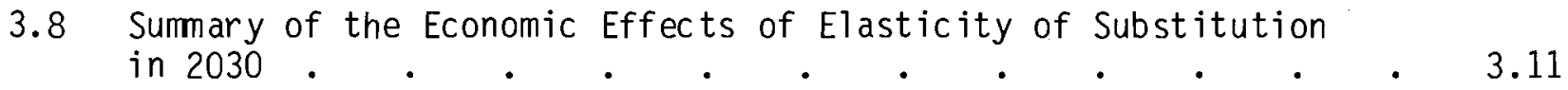

3.9 LWR Electrical Generation Capacity (GWe) in 2030 . . . . 3.12

3.10 Limits on Total FBR Capacity as a Function of Time After

3.11 Undiscounted Cumulative FBR Benefits to 2050 for Various
Introduction Dates.

4.1 Standard Deviation of Strategy Completion Dates and $80 \%$ Confidence Interval .

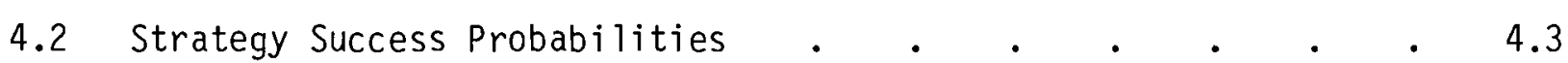

4.3 Expected Strategy Benefits (Discounted at $5 \%$ to 1980) . . . 4.4

4.4 Early and Late Risks (Discounted at 5\% to 1980) . $\quad$. $\quad$. 4.4

Sumary of Maximum Early and Late Risks (Discounted at 5\%
to 1980)

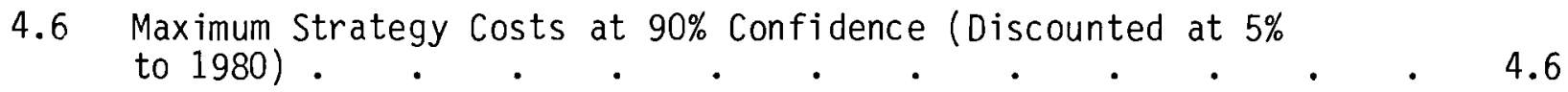

4.7 Strategy Net Benefits (Discounted at 5\% to 1980) . . . . 4.7

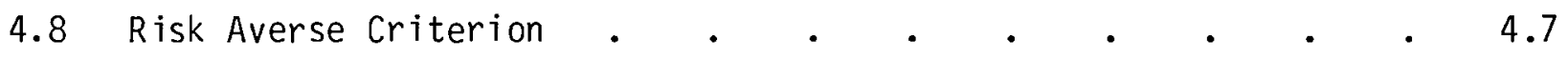


4.9 Summary of Strategy Rankings .

4.10 Expected Strategy Costs (Discounted to 1980) . $\quad$ • . . $\quad 4.16$

4.11 Net Strategy Benefits (Discounted to 1980) • . . . . . 4.16

C.1 Energy-Economic Data to Initialize the Model $. \quad . \quad$ • $\quad$ C.5

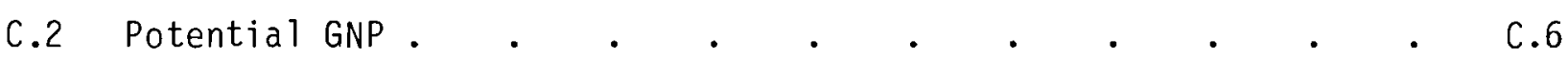

C.3 Synthetics and Nonelectric Backstops . . . . . . . . . C.9

C.4 Cost Assumptions for Economic Comparison of Base-Load Non-Nuc lear Electricity Plants . . . . . . . . . . ${ }$ C.11

D.1 Benefits of Introducing 6 GWe of FBR . . . . . . . . . D.1

D.2 ETA-MACRO Assumptions for Estimating FBR Benefits . • . D.2

D.3 Benefits of Introducing 6 GWE of FBR in 2010

(Billions \$ Discounted to 1975 @ $5 \% / y r$ ) . . . . . . . D.3

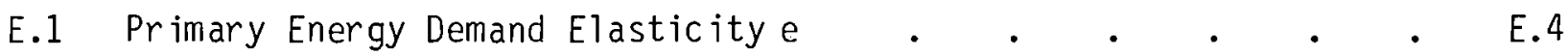




\subsection{INTRODUCTION}

The development of the commercial Fast Breeder Reactor (FBR) will require significant federal expenditures over several decades. There are several approaches the U.S. can adopt for developing this technology, and the selection of a single approach or strategy strongly depends on such factors as the duration and costs of the development program and the ultimate competitiveness of the technology. In order to select an approach or strategy, three basic issues must be addressed:

1. Timing--What is the relation of strategy completion dates to the FBR's commercially competitive dates?

2. Benefits--What are the benefits of timely introduction of a commercial FBR and how do these compare to development costs?

3. Risks-- What are the risks associated with completing the strategy before the technology should be introduced or not having the technology ready when it is an economic energy source?

\subsection{IMPORTANT FACTORS FOR THE DECISION}

Proponents of FBR development argue that uranium scarcity will result in higher electricity costs in the next century. The FBR will significantly expand the effective uranium resource base. If a mature FBR is available to the market at the proper time, considerable savings in national energy costs can be anticipated. Therefore, they argue, the FBR could play a large role in supplying our nation's energy needs and contributing to our energy independence.

Critics argue that the FBR is uneconomical and provides unnecessary inter im insurance before other, more desirable, energy technologies are available (Cochran, Speth, and Tamplin 1975). Other opponents insist that the FBR introduces unnecessary safety, environmental, and nuclear-proliferation risks to society.

This report does not address the decision to pursue the FBR as a longterm energy supply technology, but rather assumes FBR development will occur. 
The study limits its consideration to the problem of selecting a costeffective FBR development program timed to provide a commercial technology when it is economically attractive. Therefore, many oft-cited factors, such as public acceptance questions, environmental effects, or societal values of alternative energy sources, are not included in the analysis.

To address the issues of timing, risks, and benefits, the following major factors require resolution:

- costs and completion dates of alternative development strategies

- dates when the FBR becomes commercially competitive

- possible benefits of FBR deployment

- penalties associated with developing the FBR too early or too late.

The uncertainty associated with each of the major factors affecting a selection is explicitly treated in this analysis. The factors are characterized probabilistically to allow consideration of their uncertainties. The first two factors are assessed, respectively, in two associated studies (Boegel and $\mathrm{Cl}$ ausen 1981; White and Merri11 1981). The latter two factors, benefits from FBR introduction and penalties of time mismatches, are necessary to provide a social perspective on the strategy comparison and are a major part of the effort described in this report.

Each strategy considered represents one approach to gaining technological experience (U.S. ERDA 1975) that results in a commercial technology. The duration of the development's steps in each strategy is uncertain, which results in a range of possible completion dates. In addition to these timing uncertainties are development costs with their own ranges of uncertainty. Both the actual magnitude of these costs and the time stream of their accrual must be assessed in the analysis of total development costs.

The time at which the FBR will become economically competitive is also uncertain. Economic competitiveness of the FBR has been modeled by comparing its lifetime energy costs with those of light water reactors (LWRs). This comparison requires estimates of capital and fuel cycle costs for both technologies. LWR fuel cycle costs are dependent on uranium costs. These, in 
turn, are a function of uranium consumption, which is dictated by the growth of the LWR industry. Thus, uncertainties in capital costs, uranium resources, and electric energy demand a 11 add to the uncertainty surrounding the date of the FBR's commercial competitiveness.

The FBR's potential economic benefits are also dependent on the factors affecting its commercial introduction. Conversely, there may be significant lost benefits for introducing a commercial FBR either before or after it becomes economically competitive. The consideration of these factors adds perspective on the relative societal value of the costs and completion times resulting from each of the strategies.

\subsection{ORGANIZATION OF REPORT}

The report first describes the technical approach and measures developed for comparing strategies for developing the FBR (Chapter 2). Chapter 3 summarizes the information needed for comparing strategies. Much of the information used in this study is derived from companion reports (Boegel and Clausen 1981; Piepel et a1. 1981; White and Merri11 1981). Economic benefits from FBR introduction are developed here. Detailed results are reported and interpreted in Chapter 4. Appendices A through E describe in greater detai1 the computational methods that have been developed. 



\subsection{APPROACH}

The issues of timing, benefits, and risks of a development strategy are all interrelated and each issue has factors contributing to its uncertainty. This study is founded on a need to account for these key factors and uncertainties in selecting a sound strategy for FBR development. The first section of this chapter presents a background for the approach taken in this study.

\subsection{PAST FBR COST-BENEFIT ANALYSES}

The primary approach to assessing the principal issues of FBR development has been cost-benefit analysis. A cost-benefit analysis gives a dollar figure as net benefit (benefits less costs) or ratio figure of merit (benefits to costs) for successful FBR development. This approach requires the selection of specific circumstances from a range of uncertain futures.

A number of cost-benefit analyses have been published in the past decade. The principal government studies appear as a sequence of Atomic Energy Commission (AEC) studies (U.S. AEC 1970, 1972, 1974) culminating with the Energy Research and Development Administration's (ERDA) Final Environmental Impact Statement--Liquid Metal Fast Breeder Reactor Program (U.S. ERDA 1975a) in 1975. This latter study resulted in further comments and reviews by ERDA (U.S. ERDA 1975b,c) and the U.S. General Accounting Office (U.S. GAO 1975a,b).

Independent FBR benefit studies have been performed by A. S. Manne (1974a), Manne and Yu (1975), and Stauffer, Palmer, and Wyckoff (1975). Manne and Yu consider the relationship between uranium resources and economic benefits. Stauffer, Palmer, and Wyckoff first introduce the effect of a development's timing on gross benefits.

A report for the Joint Economic Committee of the U.S. Congress (Sharefkin 1976) recormended that: "Instead of casting the LMFBR problem as one of 'to have or not to have an LMFBR,' net benefit estimates can be used to evaluate alternative LMFBR development strategies, with the overall social evaluation 
of the program left to other, broader devices, including legislative dec ision." The report also summarized key FBR studies to date (1976) and finds a common criticism: "A problem with all of the breeder cost-benefit studies except that by Manne (1974b) involves their specification of the future alternatives. The other studies analyze only one future that assumes as certain, breeder commercialization by a certain date."

Manne's study considers two future scenarios, one allowing alternative introduction dates. R. G. Richels (1979) takes this concept further by considering several alternative development strategies that result in a commercial FBR at different dates. He considers these alternatives in the context of a "reference" set of assumptions about key uncertainties in electrical demand growth, uranium resources, and capital cost differentials. Sensitivity of the results to various reference assumptions is also analyzed.

This report describes a method to capture the various uncertainties inherent in selection of a strategy for FBR development. It represents an advance over past methodologies by explicitly accounting for a range of possible outcomes (uncertainties) rather than considering singular sets of assumptions.

\subsection{SUMMARY OF THE APPROACH}

The approach may be viewed as proceeding in a sequence of five steps which are described below.

Step 1. State the Objective

The goal is to select a strategy that will provide a mature FBR technology at the most economically opportune time. To select a strategy, three basic issues must be addressed:

1. Timing--What is the relation of strategy completion dates to possible commercially competitive dates for the FBR?

2. Benefits-- What are the benefits of timely introduction of a commercial FBR and how do these compare to development costs? 
3. Risks--What are the risks associated with not being on time (e.g., completing the strategy before the technology is competitive or not having the technology ready when it is an economic energy source)?

Step 2. Describe the Alternative Strategies

Seven FBR development strategies (Boegel and $\mathrm{Cl}$ ausen 1981) are considered. Each strategy is characterized as a succession of FBR plants leading to fullpower operation of the first comercial breeder reactor (CBR). The strategies represent different approaches to development and are designed to address the implications of timing, development costs, and their respective uncertainties.

Step 3. Identify Key Data

To address the study's objective, the following information is required:

- costs and completion dates of alternative development strategies

- dates when FBR technology becomes commercially competitive

- economic benefits from society's use of the technology

- penalties (risks) of mismatching FBR availability and its

competitiveness.

In defining the alternative strategies, Boegel and $\mathrm{Cl}$ ausen (1981) provide probabilistic descriptions of the strategies' completion times and development costs. White and Merrill (1981) give the range of FBR competitive dates and their probabilities. The benefits from the FBR's introduction are assessed in Chapter 3 of this study. The risks of each strategy are determined by combining the information on a strategy's timing with the strategy's benefits and costs.

Step 4. Design Measures for Characterizing Strategies

To capture the uncertainties in the key data, the information is described using probability distributions. The methods of probability and statistics provide several direct measures of a strategy's performance. Principal measures include expected values, cumulative probabilities, and confidence intervals. 
Several combined measures are also defined:

- The timing of a strategy is analyzed by comparing probable strategy completion dates with probable FBR competitive dates.

- The strategy's benefits are measured by combining the FBR's estimated benefits with the strategy's completion dates and the FBR's competitive dates.

- Strategy risks are separated into early and late risks. Early risk measures the premature expenditure of strategy development monies. Late risk measures the benefits lost due to completing FBR development after the technology is economically competitive.

Step 5. Model the Decision

Once the key information has been determined and the strategies' performance measured, the results are compared. Because a number of measures are provided, the approach suggests several criteria for comparing the strategies. The criteria include a measure of net benefits (benefits less costs and risks), maximum benefits, and minimum risks. The decision-maker can also specify his own criteria or test certain assumptions.

The elements of probability theory used in the approach are summarized in Appendix A. Appendix $B$ provides the mathematical description of each of the measures introduced below.

\subsection{MEASURES}

A number of measures have been developed for the purpose of analyzing the strategies' performance. These measures are listed in Table 2.1. The singular measures are input data which characterize the individual strategies. Combined measures are calculated by combining the strategy's characteristics with other data, such as the probable competitive dates and societal benefit of the FBR. Some of the measures listed in the table are used in this analys is (see chapter 4). Others such as success probability are available for potential use by dec ision-makers. 
TABLE 2.1. Measures for Analys is of Development Strategies

Singular Measures

1. Strategy Completion

2. Strategy Costs

Combined Measures

3. "Too Early" Risk

4. "Too Late" Risk

5. Success Probability

6. Worst case outcomes
Probability that a strategy is complete (first commercial FBR on-line) at a given date

Probable net costs of a development strategy

Probable social costs due to strategy completed before FBR is commercial

Probable social costs from late strategy completion

Probability that a strategy is complete before commercial, competitive date

Consideration of extreme outcomes

(e.g., minimum benefits or maximum risk)

\subsubsection{Singular Measures}

Most of the data used in the analysis are developed in the form of probability density functions. The completion date distribution gives, for each development strategy, the probability that development is complete (the first commercial FBR achieves full power and is on-line) at a given date. Figure 2.1 depicts the completion distribution for the Sequential Strategy--the first strategy assessed in the study. The earliest completion date is the year 2022, the latest date is 2031.5. For computational purposes dates are expressed in half-year intervals. The figure's shaded area represents the probability (approximate 1 y 20\%) that the strategy is complete before 2025 .

The development cost distribution represents the range of uncertainty of the total development costs for each strategy. The costs (in constant 1980 do 11 ars) are discounted at 5\% to 1980 . Figure 2.2 gives the development cost distribution for the Sequential Strategy, whose completion distribution was 


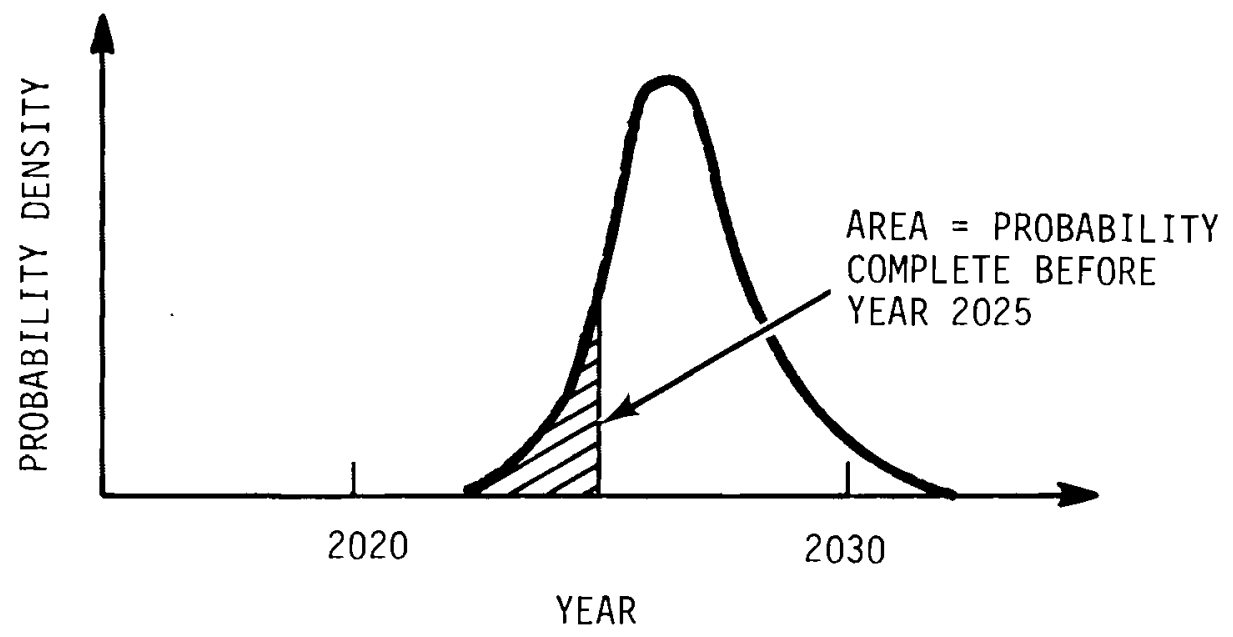

FIGURE 2.1. Completion Distribution for Sequential Strategy

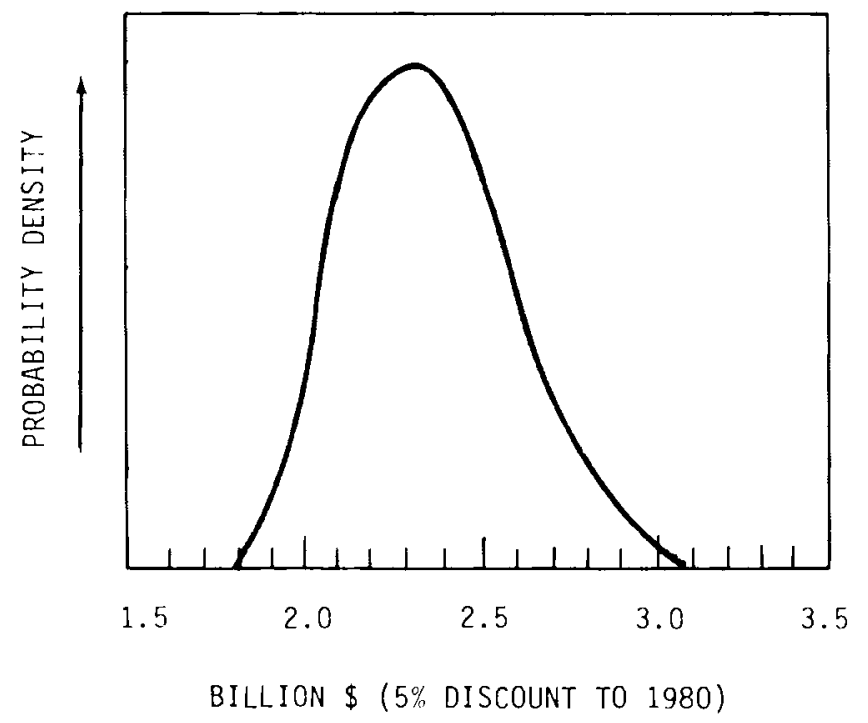

FIGURE 2.2. Development Cost Distribution for Sequential Strategy

shown in Figure 2.1. The expected discounted cost for the Sequential Strategy is $\$ 2.34$ billion. The effect of discounting on strategy cost is discussed in Chapter 4.

The statistical treatment of the probability data results in three principal direct measures of performance: 
- Expected Value

- Cumulative Probability

- Confidence Points
The "mean" or average completion date, competitive date, or development cost.

The probability that strategies are complete before a given date, the FBR is competitive before a given date, or the development costs are less than a given amount.

The date or cost for a given probability (e.g., the date at which there is a 0.9 probability (90\%) that the strategy is complete).

Confidence intervals are also useful in some applications. For example, some of the calculations described later chop off the tails of the distributions and look at the central portion. The $80 \%$ confidence interval for completion, for example, has truncated the earliest and latest $10 \%$ of the completion distribution.

\subsubsection{Combination Measures}

Strategies can be compared initially by sorting on the singular measures described above. It is also useful to develop combination measures; for example, a strategy's completion time combined with the time distribution of the FBR's competitive dates.

The competitive date distribution represents the probable dates when FBR technology could become commercially competitive. This is defined herein as the year that a mature (fifth of a kind) FBR achieves full-power operation. If its lifetime costs are equal to or less than an LWR coming on-line in the same year, it is deemed economically competitive. These dates are based on the assessment of a number of uncertain factors that include: uranium resources, capital costs of FBR technology compared to alternative nuclear technology, nuclear industry growth, and electrical energy demand. Figure 2.3 shows the competitive date probability density for the 1457-MWe commercial FBR plant. Here, the probability that the FBR is competitive before the year 2025 


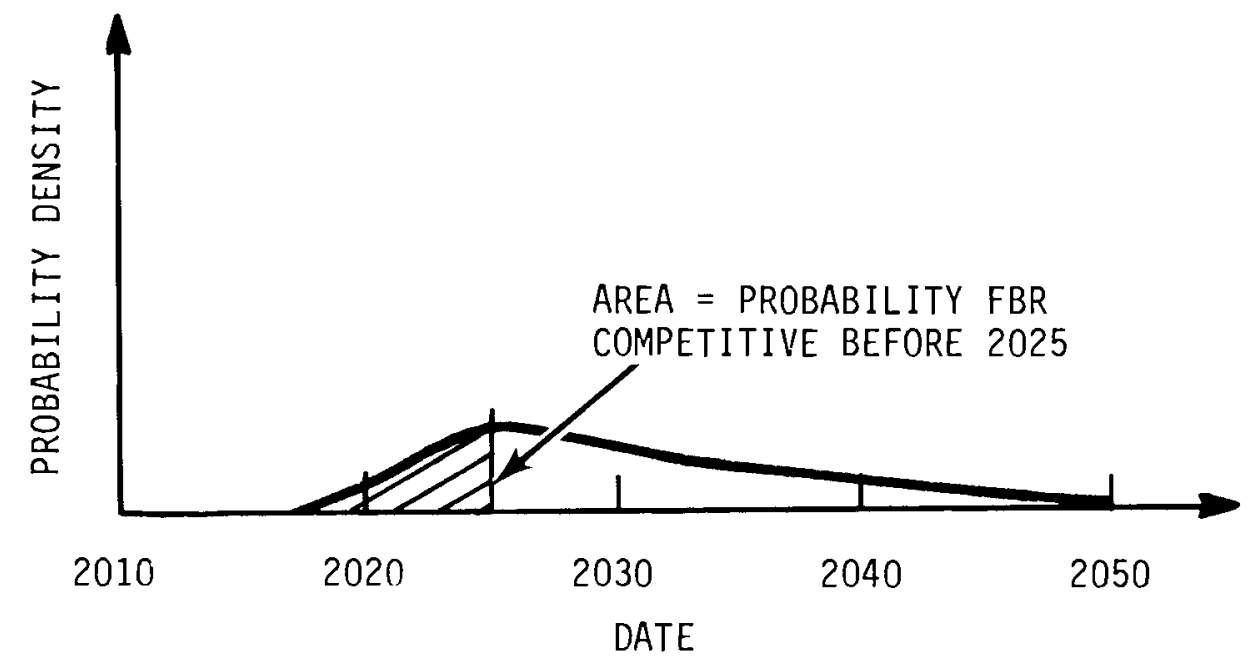

FIGURE 2.3. Competitive Date Distribution for 1457-MWe Commercial FBR

is 0.23 or $23 \%$. The expected competitive date is 2029.7 . Three of the strategies (Component Testing, Direct Prototype, and Direct Replicate) result in a 1000-MWe commercial breeder. Because of its higher capital cost, this FBR is expected to become competitive about 3 years later than the 1457-MWe design. Before these combined measures are described, it is necessary to introduce the subject of FBR benefits.

An important element in several combined measures is the benefits derived from the introduction of the FBR. If the FBR is available for commercial deployment at some date after it is commercially competitive, it will substitute for some more expensive energy form. Hence, societal benefits will accrue from the availability of the cheaper FBR energy. In the analysis, the gross benefits of the FBR are calculated with an econometric model (see section 3.2). Figure 2.4 shows the benefit function developed in this analysis. It represents the discounted social benefits of deploying the FBR over a range of years. A point on the gross benefit curve (Figure 2.4) represents the benefits of 40 years of commercial FBR deployment. These calculations are performed with economic conditions such that the FBR is competitive on or before the dates shown. Later, these gross benefits must be modified by the timedependent probability of strategy completion and the FBR's competitiveness. 


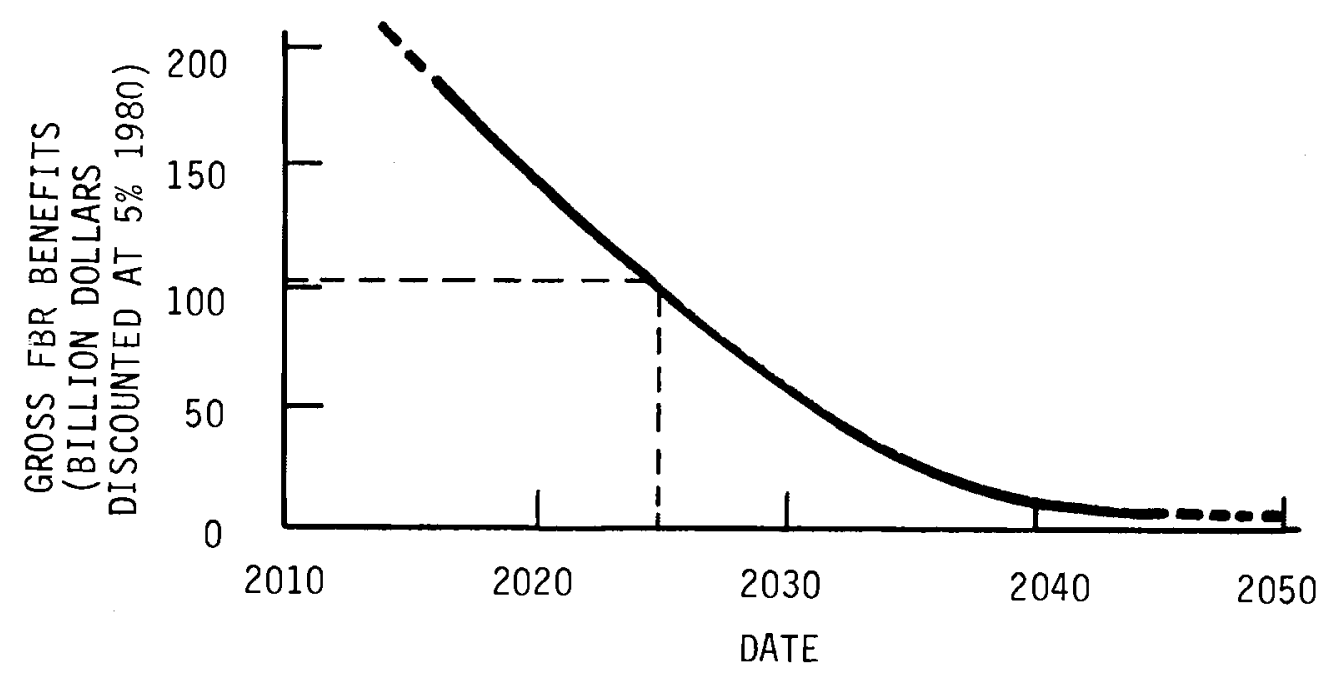

FIGURE 2.4. Gross FBR Benefits

The 40-year period was used only for calculational purposes, even though it was recognized that the FBR potentially represents a 1000 -year national energy supply. If, for example, the FBR were commercially deployed in the year 2025, it would provide $\$ 102$ billion of discounted benefits. Primarily because of discounting, the benefits decrease with later introduction dates.

Several additional measures are developed to help address the issues of a strategy's timing, benefits, and risks. Each of these measures is based on combinations of the information on a strategy's completion dates, development costs, FBR competitive dates, and FBR benefits.

"Success" probability is defined as the probability that a strategy is complete before it is economically competitive. Figure 2.5 displays examples of the completion date distribution for the Sequential Strategy and its associated competitive date distribution. Success probability is determined by calculating the completion probability for each possible competitive date, weighted by the competitive date's probability. For the Sequential Strategy shown in Figure 2.5, the success probability is 0.65 . Appendix B gives the mathematical expression of success probability. 


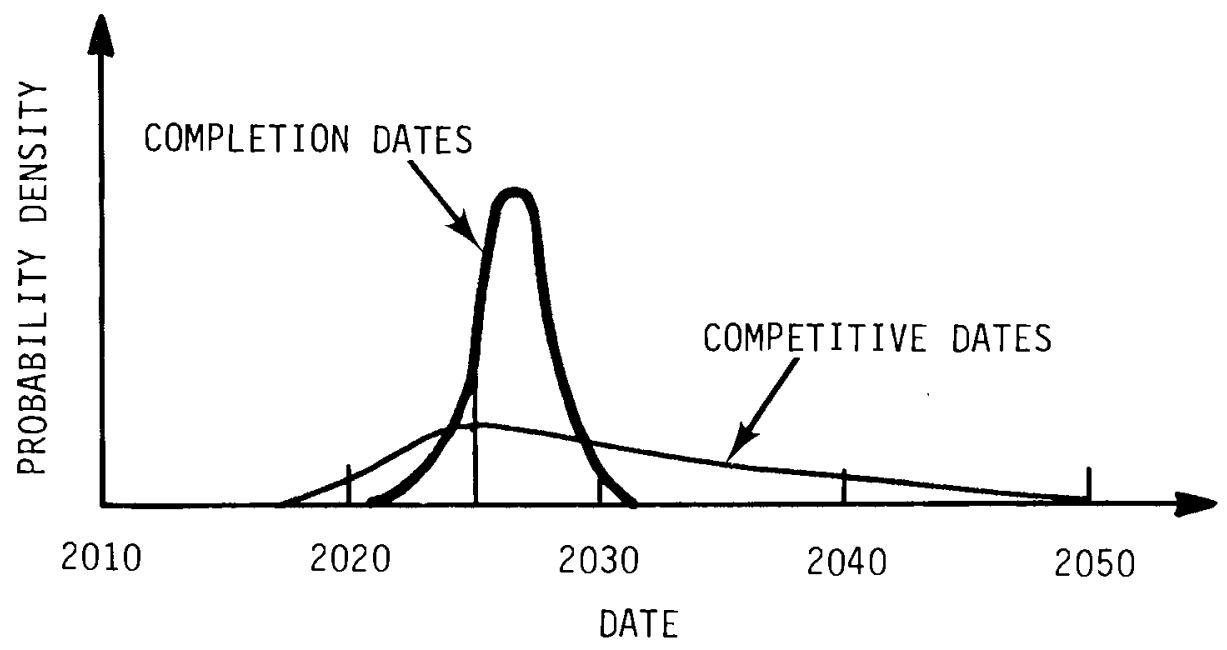

FIGURE 2.5. Comparison of Completion and Competitive Dates for Sequential Strategy.

Late Risk measures the benefits that are expected to be lost due to the likelihood that a particular strategy will be completed after the FBR is economically competitive. For a given competitive date, the probability of a strategy being complete (FBR availability) after that date and the associated benefits are combined. The lost benefits are the difference between benefits of timely introduction and late introduction for all possible late conditions.

Figure 2.6 shows the competitive date and completion date distributions for the Sequential Strategy. The figure displays the calculation of late risk of a given competitive date, $t$. The total late risk is this value summed over all competitive dates. The equations for this measure are also given in Appendix B. The late risk for the Sequential Strategy in the example is $\$ 8.3$ billion (discounted at $5 \%$ to 1980 ).

Early Risk represents the economic penalties associated with completing a technology development before it is commercially competitive. A number of factors contribute to the risk of being "too early." The first is the time value of money that is used in the calculation.

The second factor is more difficult to quantify. This factor is the "shelf life effect." This is the risk of losing the designers and fabricators who contributed to the development of the commercial FBR. In an extreme case 


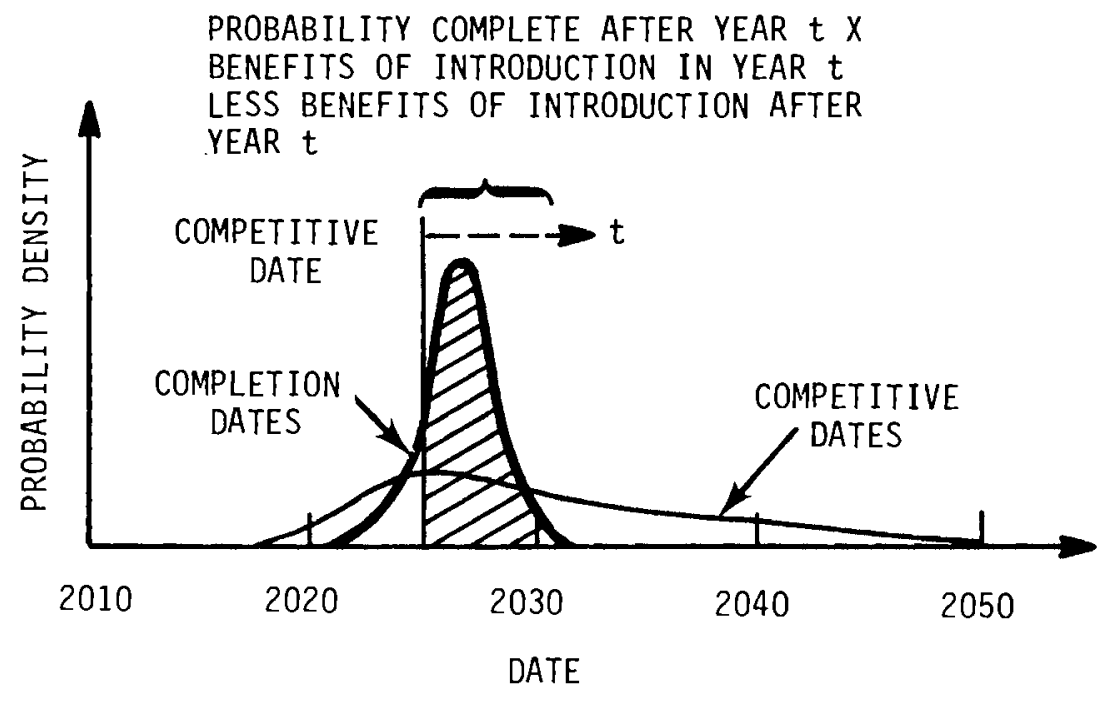

FIGURE 2.6. Late Risk Calculation

where the development is 25-30 years too early, much of the design and deve1opment would have to be repeated. The likelihood of any strategy being early by an entire technical generation is small.

Therefore, the early risk to society has been simplified in this analysis to the difference in discounted development costs between the strategy's expected completion dates and the development cost for completion at later probable competitive dates. To determine early risk, discounted development costs (at the expected completion date) are first calculated. Discounted development costs for competitive dates later than the expected completion date are then determined. These are weighted by the probability of each competitive date. Early risk is the difference between these costs. Early risk for the Sequential Strategy is $\$ 0.4$ billion (discounted at $5 \%$ to 1980 ).

\subsection{CRITERIA TO COMPARE STRATEGIES}

Three alternative criteria, based on the measures described above, that $c$ an be used to compare strategies are suggested. It is possible for the decision maker to design alternative criteria or incorporate other concerns in comparing strategies. The criteria suggested here are based on possible 
preferences of the decision-maker concerning the treatment of the data contained in the various measures. Three suggested criteria, and their philosophical basis, are:

- Net Benefit

- Risk Averse

- Mini-max
Select strategy with maximum net benefit

Select strategy with least total risk

Select strategy that minimizes the worst possible outcome.

The first criterion, net benefit, provides an expected value criterion where the average benefits, costs, and risks are considered. As an expression:

net benefit $=$ expected benefits - (expected costs) - (total risks)

where total risks are the sum of early and late risks. Expected benefits are the time-dependent benefits averaged over the FBR competitive date distribution. The net benefit for the Sequential Strategy is $\$ 57.4$ billion (discounted at $5 \%$ to 1980 ).

The objective of risk aversion is to select the strategy with the least total risk. The criterion is the average total risk where

$$
\text { total risk = "early" risk + "late" risk }
$$

For a completely risk-averse decision, the strategy with the minimum total risk, ignoring any expected benefits, would be selected. Risk aversion is based on the premise that people "value" their potential losses or outlays on a different scale than their potential gains or benefits.

In the mini-max criterion the decision-maker determines the worst that can happen for each alternative strategy and selects the strategy that minimizes the worst consequence. The objective is to select the strategy that makes probability of "worst case" consequences as small as possible; these include maximum late $r$ isk and maximum early $r$ isk. 
To determine these "worst cases" the decision-maker must specify desired confidence intervals. These measures are calculated in a procedure similar to that used for other measures. Here, the appropriate tails of the completion date, competitive date, and cost distributions are used instead of the entire probability distribution. The decision-maker first chooses a confidence (e.g., 10\%) that defines the interval he wishes to consider.

The maximum late risk quantifies the lost benefits of early FBR competitiveness (first 10\% of the probable competitive dates) and late strategy completion (last $10 \%$ of probable completion dates). The calculation is similar to late risk except that it is performed only over specified probability intervals. In Figure 2.7 an example depicts the time intervals of interest for $10 \%$ confidence on the earliest competitive dates (i.e., before 2022) and for $10 \%$ confidence on latest completion dates (i.e., from approximately 2028 to its latest completion date). The maximum late risk for the Sequential Strategy is $\$ 92.1$ billion (discounted at $5 \%$ to 1980 ).

Maximum early risk is similar to the early risk metric, again using a confidence interval for the cost distribution. First, a maximum cost interval is calculated, and the early risk calculation is made for this strategy cost. The maximum early risk for the Sequential Strategy is $\$ 1.1$ billion (discounted at $5 \%$ to 1980). As is to be expected, a strategy with a large late risk will demonstrate a small early risk and vice versa.

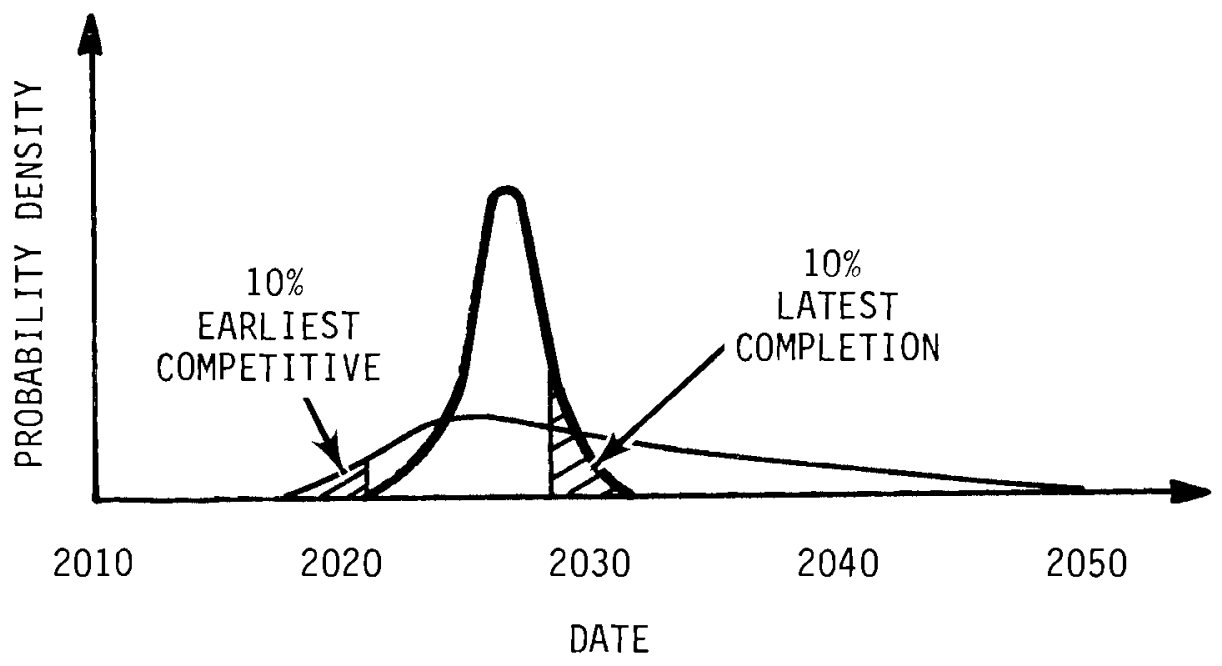

FIGURE 2.7. Maximum Late Risk 


\subsection{DATA FOR STRATEGY COMPARISON}

Four categories of information are necessary to compare the strategies: 1) the time necessary to complete technology development, 2) associated development costs, 3) probable dates of FBR commercial competitiveness, and 4) potential economic benefits of FBR introduction. Completion times and development costs for each strategy are developed by Boegel and Clausen (1981). The probable dates of the FBR's commercial competitiveness are addressed by White and Merri11 (1981). Their results are summarized in the first section of this chapter. Estimates of the potential economic benefits of FBR introduction are the subject of the remainder of the chapter. The benefits of commercial FBR introduction are estimated by a model of the U.S. economy (Manne 1977).

\subsection{COMPLETION DATES, COMPETITIVE DATES, AND COSTS}

The seven strategies addressed by Boegel and $\mathrm{Cl}$ ausen (1981) represent several alternative development sequences. The strategies result in two sizes of commercial FBR plants. The first four ( $A$ through $D$ in Table 3.1 ) result in

TABLE 3.1. Summary of Strategy Completion Dates

\begin{tabular}{lcccc}
\multicolumn{1}{c}{ Strategy } & $\begin{array}{c}\text { Earliest } \\
\text { Completion Dates }\end{array}$ & $\begin{array}{c}\text { Expected } \\
\text { Completion Dates (a) }\end{array}$ & $\begin{array}{c}\text { Latest } \\
\text { Completion Dates (a) }\end{array}$ \\
\cline { 1 - 1 } A--Sequential & 2022.0 & 2026.5 & 2031.5 \\
B--Delayed Sequential & 2027.0 & 2031.5 & 2036.5 \\
C--Compressed & 2010.5 & 2014.5 & 2018.5 \\
D--Delayed Compressed & 2015.5 & 2019.5 & 2023.5 \\
E--Component Testing & 2015.5 & 2019.5 & 2024.0 \\
F--Direct Prototype & 2005.0 & 2009.5 & 2013.0 \\
G--Direct Replicate & 2006.5 & 2011.0 & 2014.5
\end{tabular}

(a) To the nearest half year. 
a 1457-MWe commercial FBR and the remaining three ( $E$ through $G$ ) result in a 1000-MWe plant. Table 3.1 summarizes the completion dates for the seven development strategies. Figure 3.1 shows the completion date probability density functions for the four strategies (A-D) that result in a 1457-MWe FBR plant. Figure 3.2 shows the same information for the three strategies (E-G) resulting in a 1000 -MWe FBR plant.

The range of commercially competitive dates is different for the two plant sizes (Table 3.2). This report and the companion reports assumed that the FBR's competitive date is the date at which the first commercial FBR would reach full power. This date is determined based on a comparison of lifetime economics with an LWR completed in the same year. Determining economic competitiveness requires the prediction of such factors as nuclear power growth, uranium cost, implementation of technology improvements, and ultimate FBR cost. White and Merrill (1981) analyze the relationships among these factors and the commercial introduction date. Figure 3.3 shows the cumulative distribution functions for the 1000- and 1457-MWe FBR's commercially competitive dates.

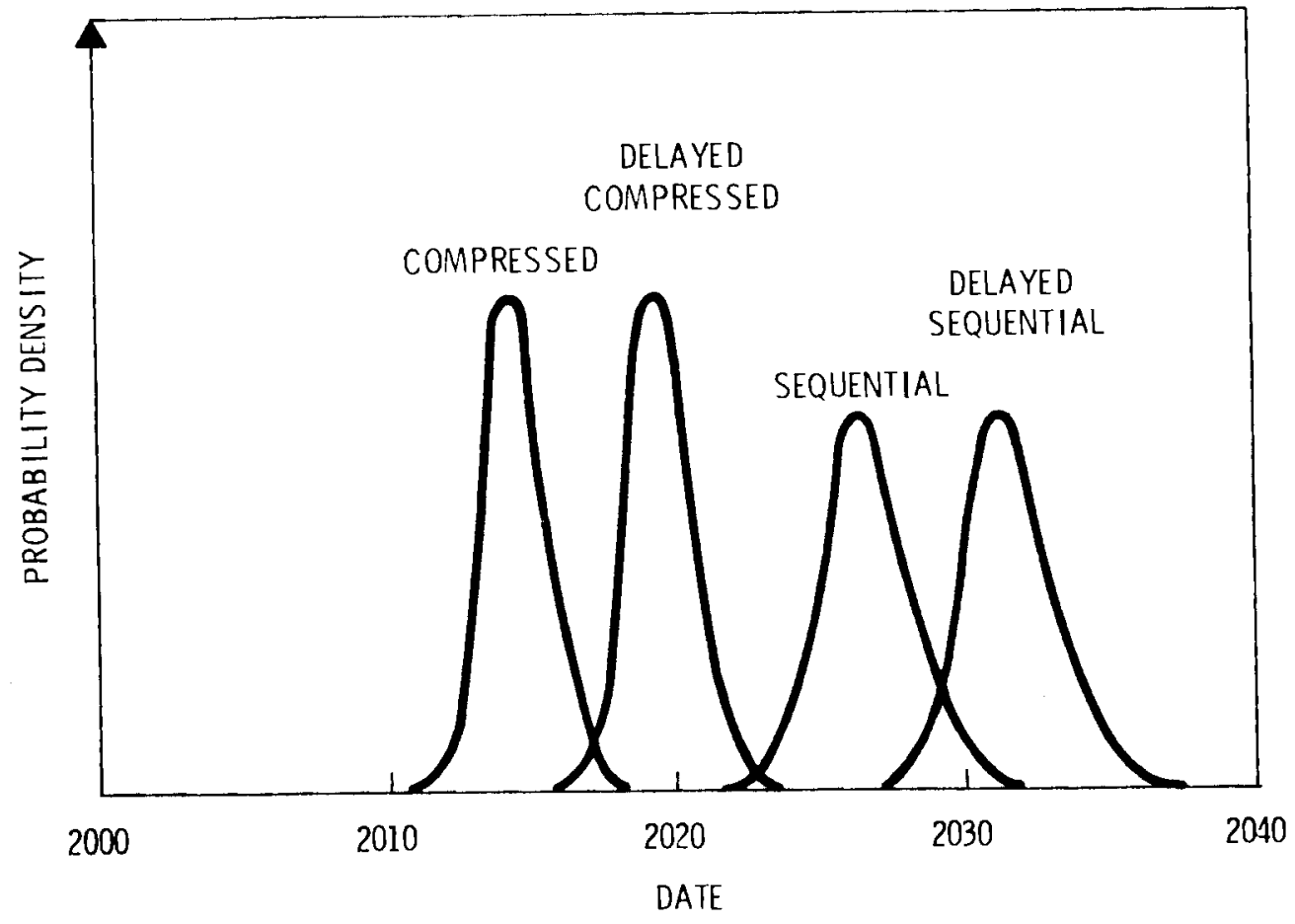

FIGURE 3.1. Probability as a Function of Time for Completion of Those Strategies That Result in a 1457-MWe FBR 


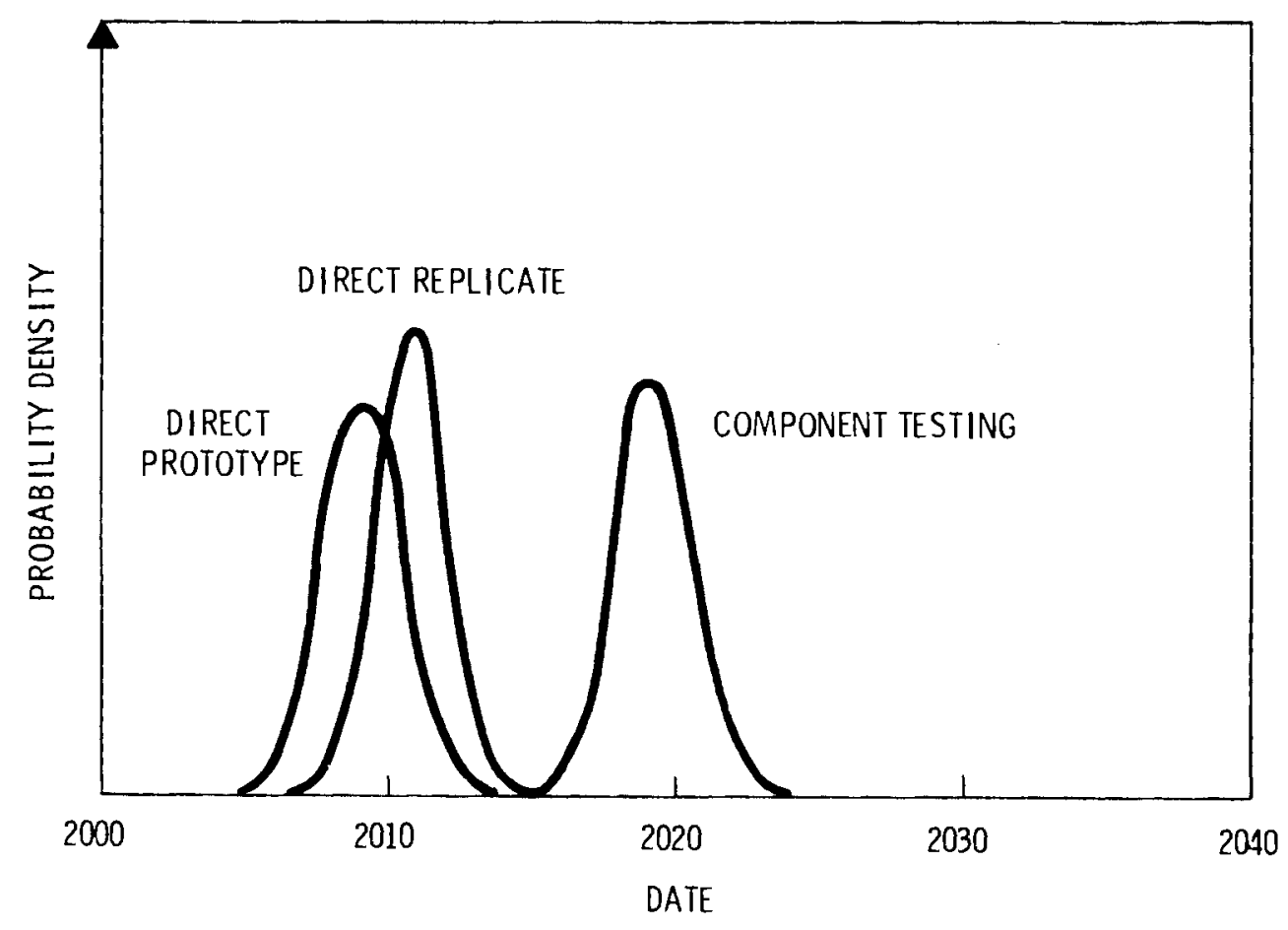

FIGURE 3.2. Probability as a Function of Time of Completion of Those Strategies That Result in a 1000-MWe FBR

TABLE 3.2. Summary of Competitive Dates

\begin{tabular}{|c|c|c|c|}
\hline & $\begin{array}{l}\text { First Compe- } \\
\text { titive Date }\end{array}$ & $\begin{array}{c}\text { Expected Compe- } \\
\text { titive Date } \\
\end{array}$ & $\begin{array}{l}\text { Last Compe- } \\
\text { titive Date } \\
\end{array}$ \\
\hline $\begin{array}{l}\text { 1457-MWe FBR } \\
\text { (Strategies A-D) }\end{array}$ & 2014 & 2029.5 & 2050 \\
\hline $\begin{array}{l}\text { 1000-MWe FBR } \\
\text { (Strategies E-G) }\end{array}$ & 2016 & 2033.5 & 2054 \\
\hline
\end{tabular}

Table 3.3 summarizes the range of development costs for each of the seven strategies. These costs are discounted at $5 \%$ to 1980 . The und iscounted costs of the strategies are negative (i.e., income exceeds expense); this is discussed in some detail by Boege 1 and Clausen (1981). 


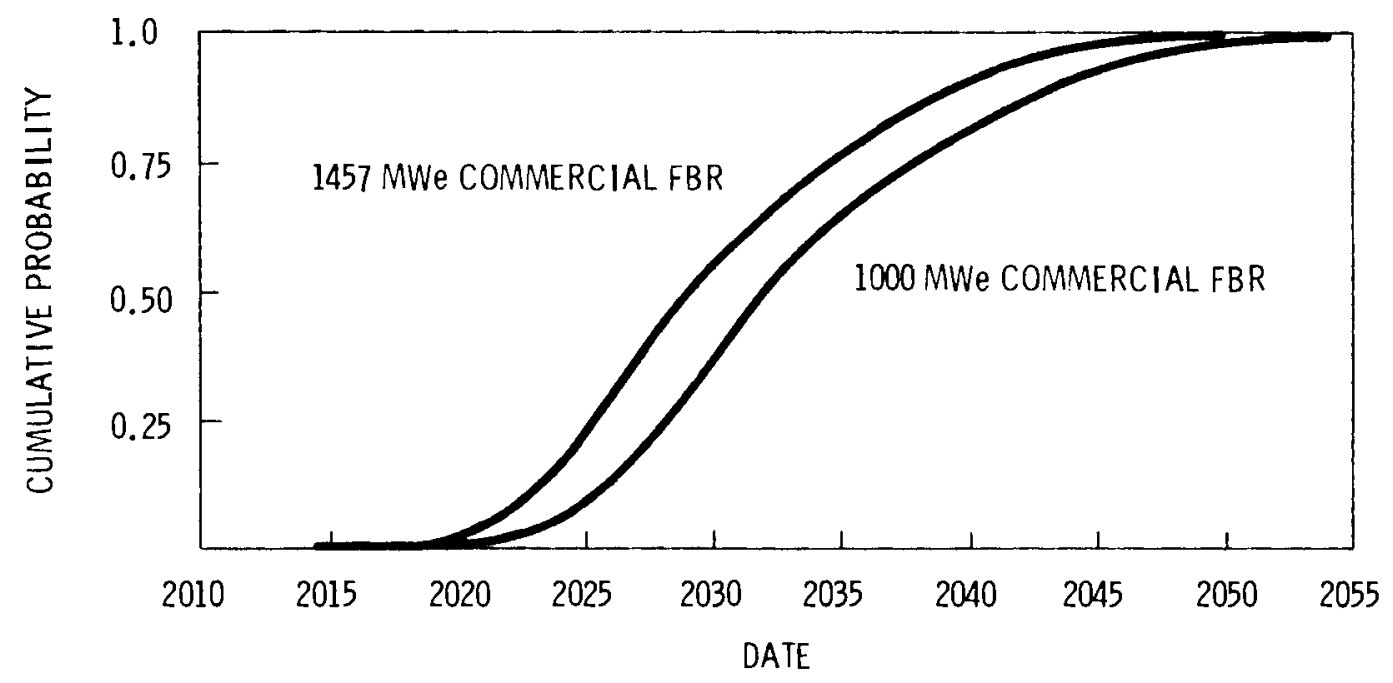

FIGURE 3.3. Competitive Date Cumulative Distribution

TABLE 3.3. Discounted Expected Strategy Costs and Their Ranges

\begin{tabular}{|c|c|c|c|}
\hline Strategy & $\begin{array}{c}\text { Billion } \\
\text { Lowest } \\
\text { Cost }\end{array}$ & $\begin{array}{l}\text { scounted } \\
\text { Expected } \\
\text { Cost } \\
\end{array}$ & $\begin{array}{c}5 \% \text { to } 1980 \\
\text { Highest } \\
\text { Cost }\end{array}$ \\
\hline A--Sequential & 1.83 & 2.34 & 3.24 \\
\hline B--Delayed Sequential & 2.00 & 2.39 & 3.12 \\
\hline C--Compressed & 2.10 & 2.78 & 3.96 \\
\hline D--Delayed Compressed & 2.25 & 2.79 & 3.76 \\
\hline E--Component Testing & 3.42 & 3.55 & 3.75 \\
\hline F--Direct Prototype & 4.01 & 4.19 & 4.58 \\
\hline G--Direct Replicate & 4.13 & 4.39 & 4.91 \\
\hline
\end{tabular}

\subsection{CALCULATION OF BENEFITS}

Calculation of benefits of commercial FBR introduction (which was introduced in Section 2.3.2) is necessary to analyze the economic risks of being either too early or too late in the development of the FBR. It also facilitates the comparison of the various strategies on the bas is of net benefit or maximum benefit. To capture the FBR's full impact on the U.S. economy, we 
used a large-scale energy-economic model of the U.S. economy, the ETA-MACRO model developed by Alan S. Manne (1977) of Stanford University.

In order to use a large econometric model such as ETA-MACRO to calculate benefits, it was important to understand how it responds to key variables. Of prime importance to this study are reactions of the econometric projections to:

- specified economic growth (GNP goals)

- elasticity of substitution

- interfuer switching

- growth of LWR nuc lear capacity

- U.S. uranium supplies

While relative LWR and FBR capital costs are important economic factors, their influence is so straightforward it was not necessary to test the model's reactions to this variable. The impact of these principal variables is discussed in the following section. Scenarios were constructed to test the most powerful variables (uranium supply and elasticity of substitution) singularly and in combination. Other non-nuclear variables such as oil and coal costs, the potential costs of synthetic fuels, the costs and deployment rate of solar and other advanced technologies are all reviewed in Appendix $C$.

\subsubsection{Principal Variables}

Several simulations of the U.S. economy were performed to estimate the benefits of FBR technology and the sensitivity to key variables. The simulations had two objectives: 1) to determine the relative magnitude of the economic benefits and 2) to test the effects of the "timing" of the FBR's introduction on benefits.

Unlike other key data in this study, which are described probabilistically, the estimated benefits are based on a set of selected scenarios. Like the factors leading to probable commercial FBR competitive dates, the possible circumstances influencing the U.S. economy's future are numerous. The scenarios were developed consistent with best economic estimates and reflecting current realities. To calculate FBR benefits, the ETA-MACRO model is rerun with the FBR unavailable during the planning horizon. Benefits are then defined as the difference in economy-wide consumption (GNP less capital investments) with and without the FBR. 
The economy's energy demand is strongly influenced by the potential GNP. Assuming that energy prices remain constant, ETA-MACRO uses estimates of potential GNP as inputs. Since energy prices do not remain constant, these assumptions do not uniquely determine overall growth rate. Generally, potential GNP growth is assumed to be a function of societal productivity as determined by industrial output, population trends, employment, and worker productivity. The trend for the past 15 years has been a general slowing of the growth rate (Economic Report of the President 1979). For potential GNP growth, the rates shown in Table 3.4 were adopted. These estimates allow for an expected long-term decline in population growth, shrinkage of the labor force, and a decrease in labor productivity. In the longer term (post-2000 period) there is general agreement that GNP growth will be lower than in the past (Manne 1979).

TABLE 3.4. Potential GNP

$\begin{array}{cc}\text { Years } & \text { Annual Growth }(\%) \\ 1980-2000 & 3.5 \\ 2000-2005 & 3.0 \\ 2005-2010 & 2.5 \\ 2010-2050 & 2.0\end{array}$

One more set of macroeconomic parameters strongly influences the energy growth projections obtained from this model. Within the energy sector and between the energy sector and the remainder of the economy, two econometric parameters are used to drive energy demands. Between the energy sector and the general economy there is the potential substitutability between energy and capital and labor. This substitutability is summarized through a parameter, "the elasticity of substitution."

Because the "elasticity of substitution" is a major factor in energyeconomic estimates and because of the lack of a consensus on its possible value, several alternative values were used in our analysis. First, to estimate the general range of elasticities we polled Energy Modeling Forum (EMF 1980) participants. This analysis is summarized in Appendix D. For 
simplicity of communication, respondents were asked to estimate the long-run elasticity of demand for primary energy. These estimates were then averaged and adjusted to account for benchmark economic factors used in this analysis. From the resulting distribution four elasticities of substitution of equal statistical probability were selected for use in the model.

In addition to elasticity between the energy sector and the remainder of the economy, it is possible to substitute between alternative energy sources, referred to as interfuel switching. In ETA-MACRO it is the switching within the energy sector between electric and nonelectric energy sources. This phenomenon is described as electricity's "value share."

Electricity's value share is much less the subject of debate than linkage between the energy sector and the economy. A number of ETA-MACRO experiments have tested the effects of this input parameter. The electricity value share used in the model was set at 0.33 .

In the U.S. economy, FBR competitiveness is clearly influenced by the cost of uranium resources and the rate at which they are consumed by LWRs. Given current lead times to build LWRs, nuc lear installed capacity through the early 1990s will be largely determined by plants already ordered. Therefore, LWR capacity is fixed at 145 GWe for the year 1990. After this time, industry growth will be determined by new orders starting now and limited by the industry's capability to fill those orders. In the analysis, the model estimates general nuclear capacity growth with upper bounds on total allowable growth. Table 3.5 sumarizes these upper bounds.

TABLE 3.5. Assumed Upper Bounds for Conventional

(LWR) Nuc lear Capacity

Year $\quad$ Capacity (GWe)


Estimates of U.S. uranium resources were developed by Piepel et al. (1981). These estimates provide a supply curve (cumulative resource available at a given price) that includes the uncertainty in the estimates. ETA-MACRO requires a supply curve for each scenario. For estimates of FBR benefits, three supply curves were used. They represent the expected uranium supply and uranium supplies at the $90 \%$ confidence points; that is, one we are $90 \%$ confident of exceeding and one we are $90 \%$ confident of not exceeding. These are referred to as the "low", "mid", and "high" supplies respectively. The three supply functions are listed in Table 3.6, and their use in the FBR benefit scenarios is discussed in the next section.

TABLE 3.6. Uranium Supply Functions (Cumulative Amount of Uranium in Million Short Tons Available at Price Level)

\begin{tabular}{|c|c|c|c|c|c|c|c|c|}
\hline \multirow{2}{*}{$\begin{array}{l}\text { Uranium } \\
\text { Supply }\end{array}$} & \multicolumn{8}{|c|}{ Price Level $\left(\$ / 1 \mathrm{~b} \mathrm{U}_{3} \mathrm{O}_{8}\right)$} \\
\hline & 50 & 70 & 100 & 150 & $\underline{200}$ & 250 & 350 & 500 \\
\hline Low (1) & 1.89 & 3.09 & 4.37 & 5.41 & 5.75 & 5.88 & 6.05 & 6.26 \\
\hline Mid (2) & 2.16 & 3.49 & 4.91 & 6.11 & 6.49 & 6.66 & 6.84 & 7.05 \\
\hline High (3) & 2.43 & 3.82 & 5.47 & 6.86 & 7.31 & 7.53 & 7.71 & 7.92 \\
\hline
\end{tabular}

Estimates of LWR unit costs (White and Merrill 1981) were also used as model inputs. Similarly, capital and operating cost estimates for a mature FBR were developed (Boegel and Clausen 1981). As with other data used in the analysis, these costs were characterized probabilistically. Certain improvements in LWR technology are anticipated (White and Merrill 1981). These potential improvements are also included in ETA-MACRO.

Appendix $C$ details the inputs used in the ETA-MACRO calculations. The reader is referred to ETA-MACRO: A User's Guide (Manne, Condap, and Preckel 1981) for more detailed information on the model, its structure, and its operation.

The first set of strategies considered the effect of the uranium supply. Three alternative uranium supply functions (see Table 3.6) are used. For this first set of scenarios, the real cost of oil imports increases at $4 \% / y r$ and the elasticity of substitution is constant at 0.32 . Table 3.7 shows the 
TABLE 3.7. Summary of Uranium Supply's Effect in 2030

\begin{tabular}{|c|c|c|c|c|c|}
\hline $\begin{array}{l}\text { Uranium } \\
\text { Supply } \\
\text { Scenario } \\
\end{array}$ & $\begin{array}{c}\text { GNP } \\
(\operatorname{tr} i 11 \text { ion } \\
\$ 1981) \\
\end{array}$ & $\begin{array}{l}\text { Total Energy } \\
\text { Con sumption } \\
\text { (quads) }\end{array}$ & $\begin{array}{c}\text { Electric }(a) \\
\text { Generation } \\
\text { (trillion kWh) } \\
\end{array}$ & $\begin{array}{c}\text { LWR } \\
\text { Generation } \\
\text { (trillion kWh) } \\
\end{array}$ & $\begin{array}{c}\text { Average } \\
\text { Electric } \\
\text { Prices } \\
\text { (mills/kWh) } \\
\end{array}$ \\
\hline Low (1) & 8.440 & 194.76 & 8.95 & 6.08 & 45.80 \\
\hline Mid (2) & 8.450 & 197.16 & 10.28 & 6.33 & 41.07 \\
\hline High (3) & 8.453 & 197.99 & 10.39 & 6.44 & 39.28 \\
\hline
\end{tabular}

(a) Based on $65 \%$ capacity factor and heat rate of $10,000 \mathrm{Btu} / \mathrm{kWh}$.

results for three uranium supplies in the year 2030. These results are used by White and Merrill (1981) to calculate the growth of LWR capacity.

Note that GNP and total energy consumption increase as the availability of uranium increases. As a reference, the 1979 GNP was at 2.4 trillion dollars. The 1979 energy consumption was 78.787 quads (see Appendix C). For each case shown in Table 3.7 the calculated growth rates are considerably lower than in other projections--2.8\% for GNP, $1.7 \%$ for primary energy consumption, and $3.2 \%$ for electrical generation to the year 2030 .

Figure 3.4 shows growth in the electrical sector for the "mid" uranium supply (Scenario 2, Table 3.7). Hydroelectric, geothermal, solar, etc. represent a limited but growing source throughout this time period. Beyond the year 2000, coal use essentially saturates and nuclear power gains a clear economic advantage--effectively supplying all the new base-load power.

A second set of example scenarios focuses on the effect of energy demands. The elasticity of substitution is a principal determinant of energy demand in the economy. Table 3.8 gives results for four alternative substitution elasticities. The table shows the sensitivity of the growth of general electrical and nuc lear generation to energy demand for the year 2030. Note that if the economy actually operates at a high elasticity of substitution, it is possible to expand the economy with only a modest increase in energy consumption. From the poll of experts (see Appendix E), the expected value of this elasticity 


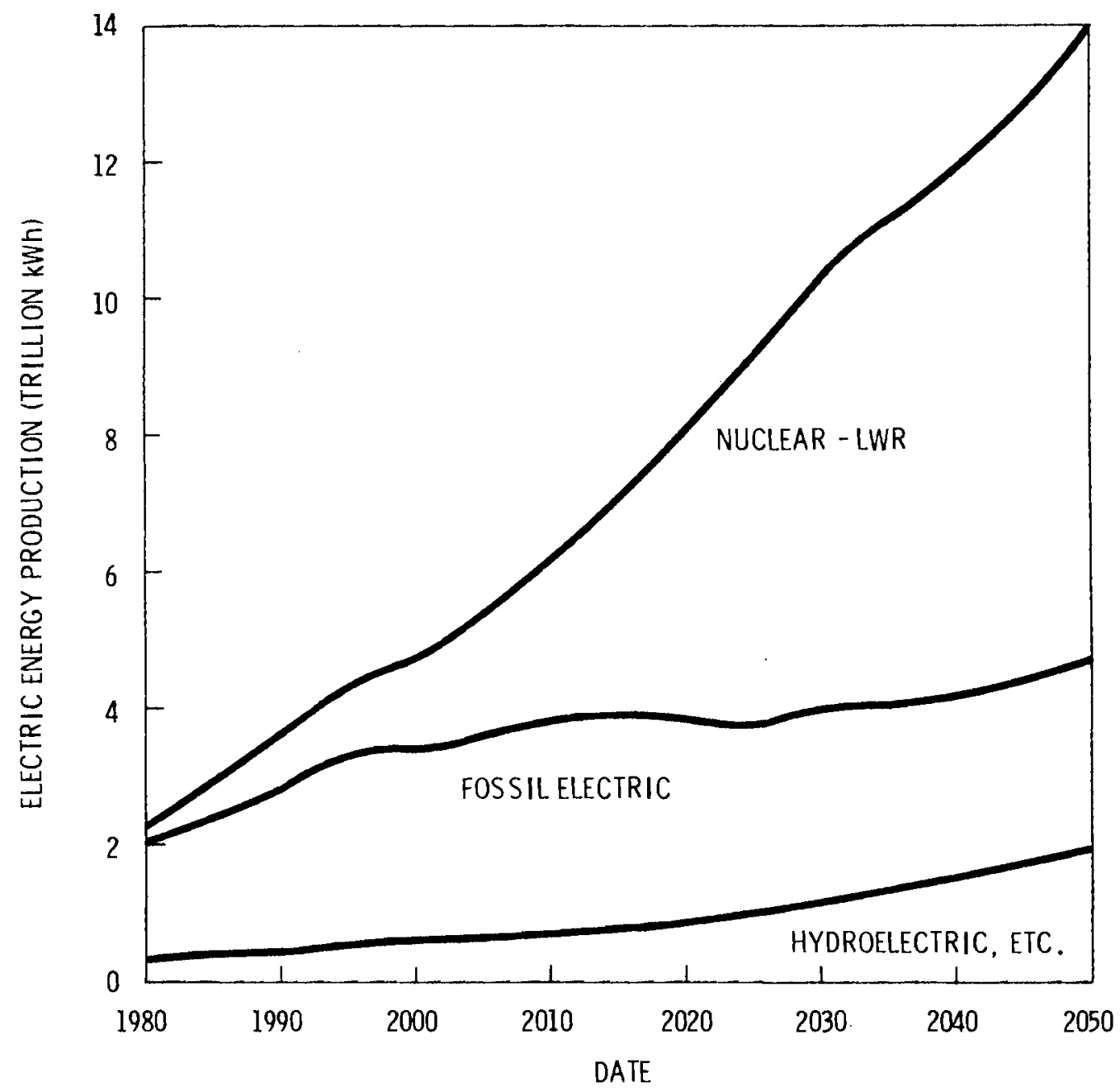

FIGURE 3.4. Calculated Growth of the Electrical Energy Sector for Mid-Uranium Supply

is around 0.4. A lower elasticity of substitution stimulates the development of such supply technologies as synthetic fuels and nuclear power. Figure 3.5 shows the growth of conventional nuclear (LWR) energy production for the four scenarios sumarized in Table 3.8 .

The combined effects of energy demand and uranium supply uncertainties were also tested in ETA-MACRO. Table 3.9 summarizes these combined effects on LWR capacity in the year 2030. Possible LWR capacities range from 710 to 1300 GWe. 
TABLE 3.8. Summary of the Economic Effects of Elasticity of Substitution in 2030

\begin{tabular}{|c|c|c|c|c|c|c|}
\hline $\begin{array}{l}\text { Elasticity of } \\
\text { Substitution } \\
\text { Scenario (a) }\end{array}$ & 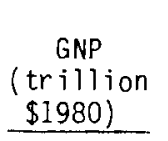 & $\begin{array}{l}\text { Total Energy } \\
\text { Consumption } \\
\text { (quads) }\end{array}$ & $\begin{array}{c}\text { Electric } \\
\text { Generation } \\
\text { (trillion kWh) } \\
\end{array}$ & $\begin{array}{l}\text { Installed LWR } \\
\text { Capacity (GWe) }\end{array}$ & $\begin{array}{l}\text { LWR } \\
\text { Generation (b) } \\
\text { (trillion kWh) }\end{array}$ & $\begin{array}{l}\text { Average } \\
\text { Electric } \\
\text { Prices } \\
\text { (mills/kwh) } \\
\end{array}$ \\
\hline 0.18 (1) & 7.932 & 220.21 & 11.57 & 1280 & 7.26 & 48.47 \\
\hline $0.32(2)$ & 8.450 & 197.16 & 10.28 & 1115 & 6.33 & 41.07 \\
\hline $0.45(3)$ & 8.707 & 173.06 & 8.83 & 925 & 5.26 & 42.99 \\
\hline $0.63(4)$ & 8.971 & 146.05 & 7.25 & 720 & 4.08 & 42.38 \\
\hline
\end{tabular}

(a) "Mid" uranium supply as given in Table 3.7

(b) Based on a $65 \%$ capac ity factor and a heat rate of $10,000 \mathrm{Btu} / \mathrm{kWh}$.

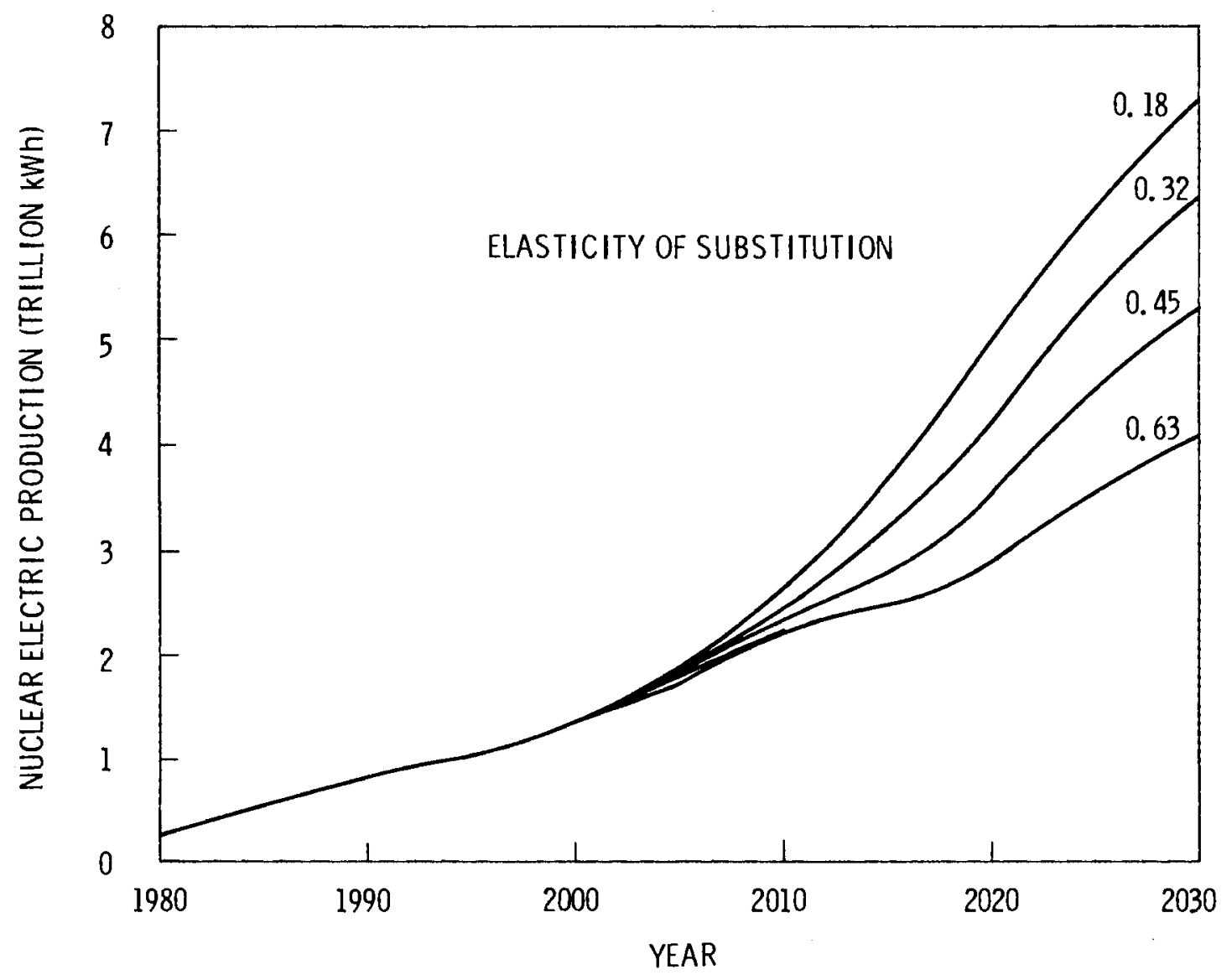

FIGURE 3.5. Annual LWR Electrical Generation as a Function of Elasticity of Substitution 
TABLE 3.9. LWR Electrical Generation Capacity (GWe) in 2030 (a)

Elasticity of

Substitution

0.18

0.32

0.45

0.63

$\frac{\text { Generation Capacity (GWe) }}{\text { Scenario 1 - Scenario? Scenario 3 }}$

1175

1070

1280

1115

1300

915

925

1130

710

720

930

725

(a) Results to nearest 5 GWe based on a $65 \%$ capacity factor.

\subsubsection{FBR Benefits}

With the model runs described above, we learned how to specify variables such that the econometric model would find the FBR competitive (and thus introduce it) at various desired dates. This was essential in the calculations of the time-dependent benefit functions described next. To analyze strategies in the context of their completion times, competitive dates and benefits, it is necessary to develop a time-dependent benefit function. The range of times must correspond to the probable range of dates (Table 3.2) over which the FBR will become commercially competitive. It is also necessary to assess the economic penalties to be expected from completing a strategy too late (introduction of the FBR after it is commercially competitive). This section describes how these benefit functions are derived.

The gross benefits of the FBR are determined by comparing ETA-MACRO scenarios with the FBR available to scenarios without the FBR available. Benefits are the difference in economy-wide consumption (GNP less capital investments) with and without the FBR. It was necessary to set up econometric scenarios such that the FBR would be competitive at a given date, and hence, ETA-MACRO would call for introduction (startup) at that date. Three econometric variables were used to construct these scenarios: 1) energy demand (elasticity of substitution), 2) uranium supply, and 3) capital cost differential between FBRs and LWRs. 
Within the range of likely values of high energy demand, low uranium supply and favorable FBR capital cost ratios were used to set up the early competitive scenarios. The inverse of these conditions set scenarios such that the FBR was competitive at later dates. A number of trial calculations and past ETA-MACRO results (see Appendix D) were used to develop scenarios in which ETA-MACRO "decided" the FBR should be introduced at various dates over the period of interest.

As is usually the case with econometric models, it was necessary to constrain the FBR construction to a rate realistically achievable by industry. Table 3.10 shows the limits which were established. Without this constraint, the model, in almost every case, wanted to build FBR capacity more quickly than the limit would allow. Figure 3.6 shows FBR capacity as a function of three different introduction dates. The figure illustrates that the model is building close to its allowable rate (see Table 3.10 ).

TABLE 3.10. Limits on Total FBR Capacity as a Function
of Time After Introduction
\begin{tabular}{cc} 
Years After Introduction & Capacity (GWe) \\
\hline 0 & 6 \\
5 & 25 \\
10 & 125 \\
15 & 300 \\
20 & 500 \\
25 & 700 \\
30 & 900 \\
35 & 1100 \\
40 & 1300
\end{tabular}

As is to be expected, when a cheaper energy form is available, the model calls for its construction. With cheaper energy the GNP is stimulated and more energy is consumed. This is illustrated in Figure 3.7, where total electric generation as a function of time is illustrated for a scenario in which the FBR is competitive in 2025. The increased electric generation noted before the 2025 startup of the FBR illustrates the synergism between the LWR and FBR. This apparently anomalous result is due to the model's preview of decreased 


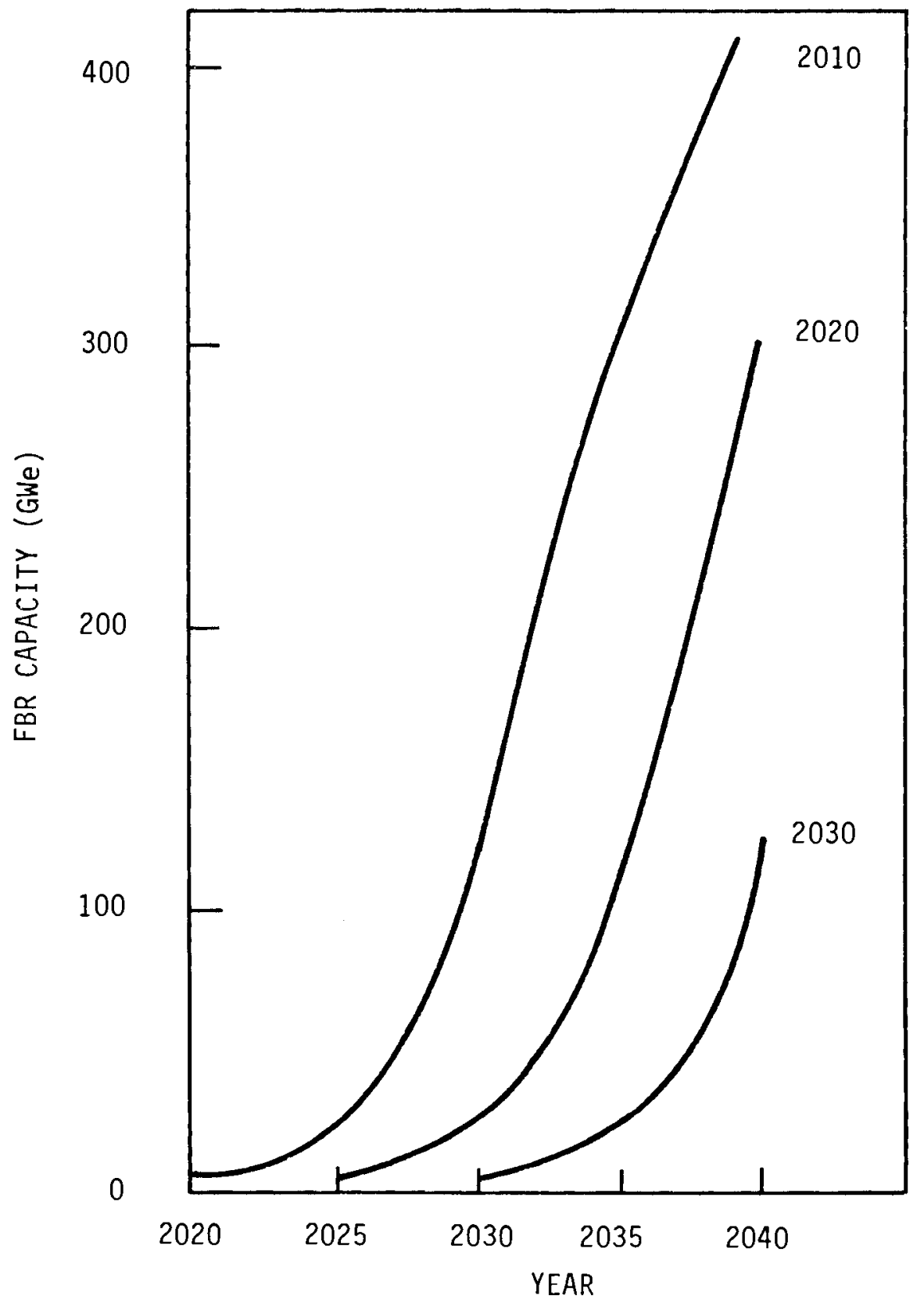

FIGURE 3.6. Growth of FBR Capacity as a Function of Competitive (Introduction) Date 


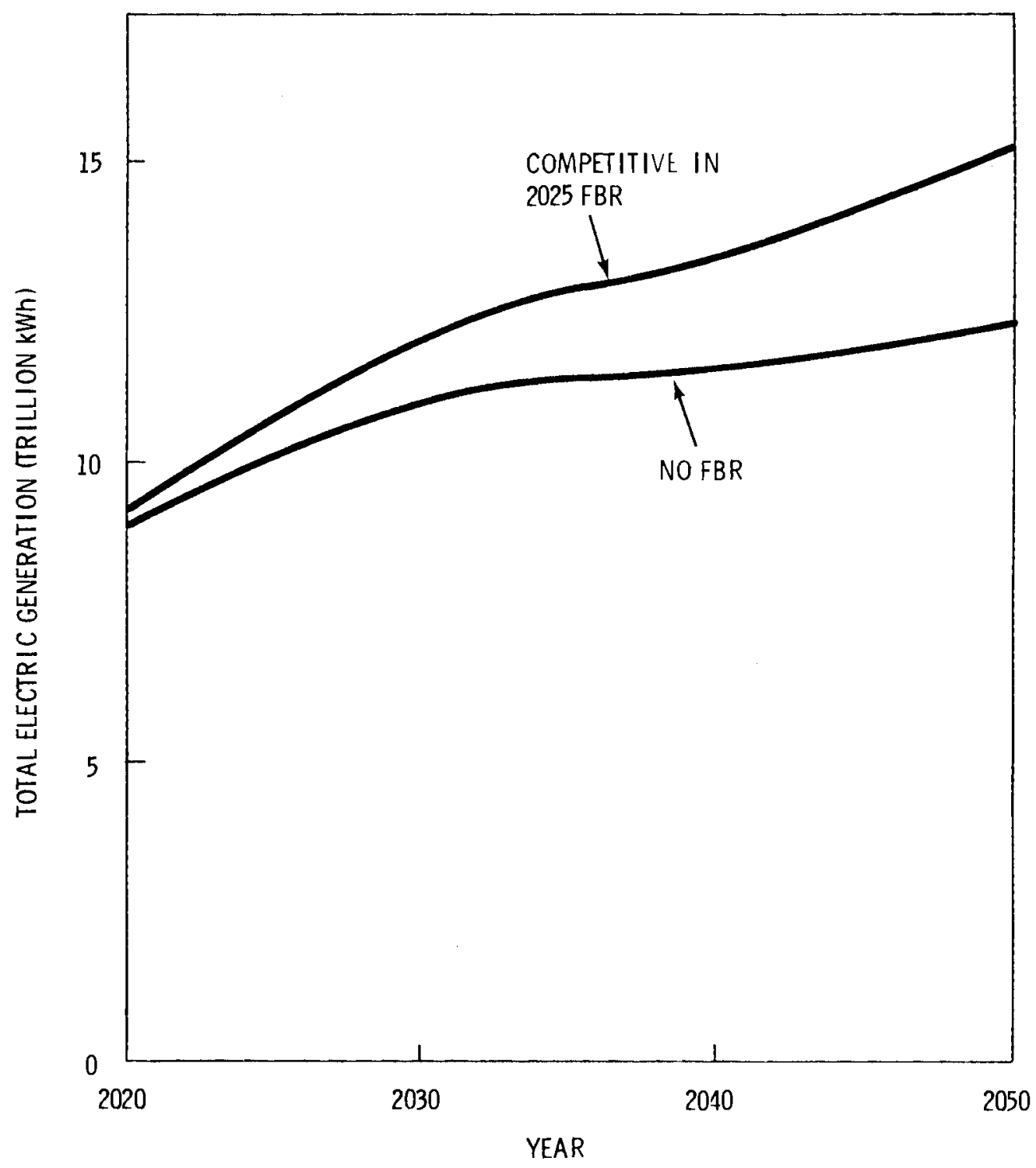

FIGURE 3.7. Total Electric Generation as a Function of Time

pressure on future uranium supplies. With this information it decides that more LWRs should be built than would be the case without the FBR.

Since the FBR is potentialiy a 1000-year energy source for the country, it would be desirable to analyze its performance over a comparable time period. Unfortunately, most econometric models cover a 50-100 time period. ETA-MACRO is no exception-- it covers the period from 1975 to 2050. This means that when the FBR is introduced in, say 2035, its economics are considered for only a 15-year time period. This "end effect" problem is illustrated in Table 3.11. 
TABLE 3.11. Undiscounted Cumulative FBR Benefits to 2050 for Various Introduction Dates

\begin{tabular}{cc} 
Availability & (Billion \$) \\
\hline 2020 & 2105 \\
2025 & 1940 \\
2025 & 1670 \\
2030 & 543 \\
2035 & 165 \\
2035 & 70
\end{tabular}

Note in the table that the undiscounted cumulative benefits from FBR introduction in 2035 are about 5\% those resulting from introduction in 2020. Also notice two scenarios for 2025 and two for 2035 introduction. Since there are various sets of econometric variables which will result in conditions favoring FBR introduction at a given date, several combinations were used to ensure that no systematic bias was introduced in the calculation of benefits.

We decided it was necessary to study all FBR strategies over some reasonable time period long enough to allow them significant development, but short enough to avoid serious extrapolation difficulties. For comparability all strategies must, obviously, operate over the same length of time. Forty years after FBR introduction was selected as an appropriate time span for study. Figure 3.8 illustrates the manner in which each scenario was extrapolated to a 40-year period. The discounted benefits for each 5-year period are plotted. Note that these benefits do not start showing up until 2025 even though the FBR was introduced in 2020. These data are fitted by linear regression, illustrated by the dashed line in the figure and extrapolated to 2060. The derived benefit for a 40-year economy with the FBR starting in 2020 is about $\$ 130$ billion (discounted at $5 \%$ to 1980). This same procedure was used for all the scenarios. The resulting points and their fitted curve are shown in Figure 3.9. This curve is used in the analysis to represent the benefit of introducing the FBR on time. Note that the duplicate calculations for 2025 and 2035 (see Table 3.11) were incorporated into the regression. 




FIGURE 3.8. Cumulative FBR Benefits for 2020 Introduction Extrapolated to 2060

A number of additional cases were run for the purpose of estimating late benefits. For the analysis, a singular function was developed. These late benefits were based on not allowing the FBR to be available until a number of years after its first commercial, competitive date. For example, an FBR competitive in 2020 was not made available until 2025 and 2030 . The results from these cases were then discounted and fitted in the manner described above. Figure 3.10 shows the "late" benefits of introducing the FBR after the commercially competitive dates of 2020, 2025, and 2030. Because there are a large number of such curves, i.e., one for each possible commercially competitive date, a functional representation was derived for dates not calculated directly (Appendix B). This "late" benefit function is used to calculate the lost benefits, or late risk, from introducing the FBR after its competitive dates. 


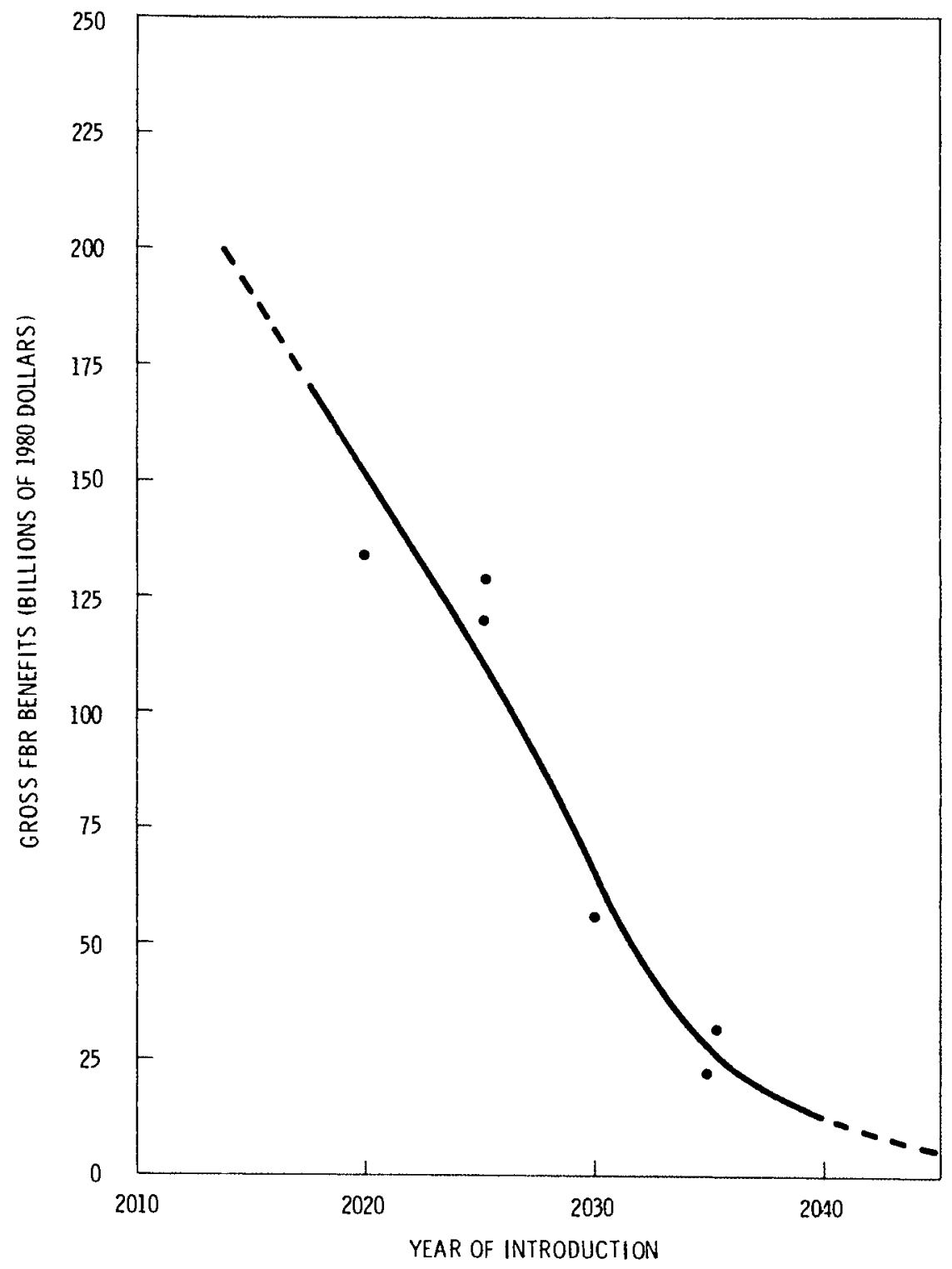

FIGURE 3.9. Gross FBR Benefits, for a 40-year Time Period, as a Function of Introduction Date 


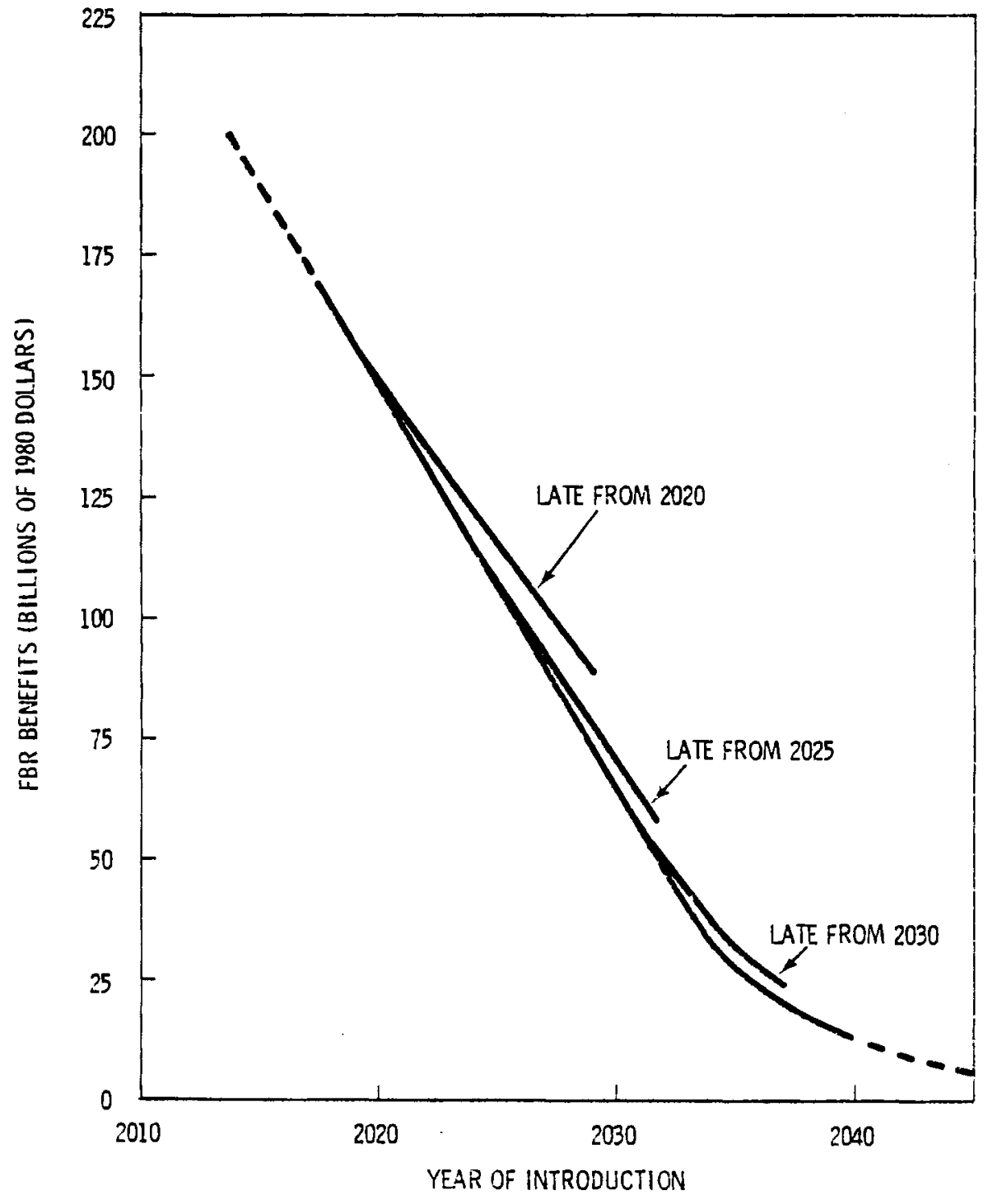

FIGURE 3.10. Benefits of Late FBR Introduction for Three Introduction Dates 



\subsection{STRATEGY COMPARISON}

This chapter compares strategies' performances based on the methodology presented in Chapter 2 and the data discussed in Chapter 3 . First, results based on direct measures are reviewed. Next, this information is combined to give probabilities of early strategy completion, expected benefits, and risks of being early or late. These results are used to rank strategies.

To help define a preferred strategy, two additional factors are considered. First, the selection process takes place now, in 1981. This means that the strategies must be considered in the context of currently available information. Second, the magnitude of the economic costs, risks, and benefits of the alternative strategies is sensitive to the assumptions about the discount rates. Hence, it is important to ensure that the choice of discount rates does not change the ranking of strategies.

\subsection{STRATEGY COMPLETION DATES, FBR COMPETITIVE DATES, AND COSTS}

The derivation of data on strategy completion dates, costs, and FBR competitive dates was discussed in the preceding chapter. A first level comparison of strategies is possible with this basic data. Table 4.1 shows the statistical analys is of completion dates. Note that the earliest expected completion date (2009) can be realized with the Direct Prototype Strategy; but

TABLE 4.1. Standard Deviation of Strategy Completion Dates and $80 \%$ Confidence Interval

\begin{tabular}{|c|c|c|c|c|}
\hline \multirow[b]{2}{*}{ Strategy } & \multirow[b]{2}{*}{$\begin{array}{l}\text { Expected } \\
\text { Date } \\
\end{array}$} & \multirow[b]{2}{*}{$\begin{array}{l}\text { Standard } \\
\text { Deviation }\end{array}$} & \multicolumn{2}{|c|}{$80 \%$ Confidence Interval } \\
\hline & & & $\begin{array}{c}\text { Early } \\
\text { Completion }\end{array}$ & $\begin{array}{c}\text { Late } \\
\text { Completion }\end{array}$ \\
\hline A--Sequential & 2026.5 & 1.59 & 2024.5 & 2028.5 \\
\hline B--Delayed Sequential & 2031.5 & 1.59 & 2029.5 & 2033.5 \\
\hline C--Compressed & 2014.5 & 1.12 & 2013.0 & 2015.5 \\
\hline D--De layed Compressed & 2019.5 & 1.13 & 2018.0 & 2020.5 \\
\hline E--Component Testing & 2019.0 & 1.37 & 2017.5 & 202.0 \\
\hline F--Direct Prototype & 2009.0 & 1.37 & 2007.5 & 2010.5 \\
\hline G--Direct Replicate & 2011.0 & 1.26 & 2009.0 & 2012.0 \\
\hline
\end{tabular}


this must be compared with the expected competitive dates associated with the 1000-MWe FBR resulting from this strategy. The relationship between expected completion dates and competitive dates is shown in Figure 4.1. In this figure the $80 \%$ confidence intervals are used for both the completion and competitive data. This amounts to "chopping off" the bottom 10\% and top 10\% distribution tails.

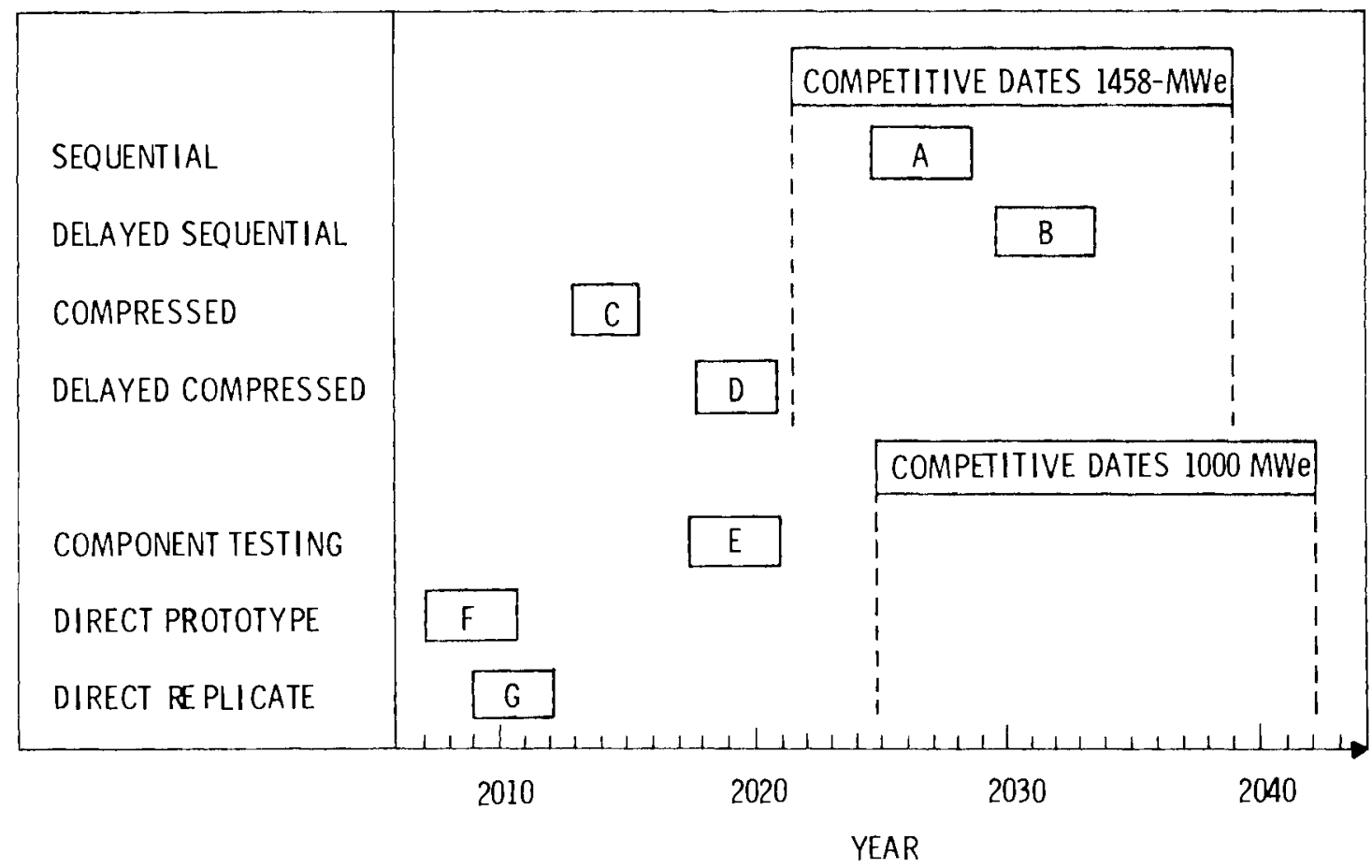

FIGURE 4.1. Comparison of Completion and Competitive Dates for an $80 \%$ Confidence Interval

Based on estimated strategy costs and their associated uncertainty, distributions of discounted strategy costs were also developed. These expected strategy costs and their ranges were listed in Table 3.2. The effect of discounting on strategy evaluation is discussed later in this chapter. 


\subsection{STRATEGY TIMING, BENEFITS, AND RISKS}

The "success probability" (see Section 2.3.2) can also be used to compare the timing of the alternative strategies. The "success probability" measures the probability of a strategy being complete before it is commercially competitive. Table 4.2 gives the success probabilities of the seven strategies. A high success probability indicates that a strategy is likely to be complete before it is competitive. For example, Strategies C, E, F, and $G$ all have a probability of 1.0 of being complete before the FBR is commercially competitive. The Delayed Sequential Strategy has a particularly low success probability.

\section{TABLE 4.2. Strategy Success Probabilities}

\begin{tabular}{lc}
\multicolumn{1}{c}{ Strategy } & Success Probability \\
A--Sequential & 0.65 \\
B--Delayed Sequential & 0.36 \\
C--Compressed & 1.0 \\
D--Delayed Compressed & 0.98 \\
E--Component Testing & 1.0 \\
F--Direct Prototype & 1.0 \\
G--Direct Replicate & 1.0
\end{tabular}

The "expected strategy benefits" relate the strategy's completion dates to the FBR's expected competitive dates. This measure accounts for the possibility that a strategy is not completed before a given competitive date, thus resulting in lost benefits. The "expected strategy benefit" is the gross strategy benefit (discussed in Section 2.3.2) less the "late risk" term discussed below. Table 4.3 lists the expected strategy benefits for each strategy.

The risks associated with a strategy's being late outweigh those related to being too early. Simply stated, the "late" $r$ isk is the economic measure of benefits lost from introducing the FBR after it is economically competitive. 
TABLE 4.3. Expected Strategy Benefits

(Discounted at $5 \%$ to 1980 )

\begin{tabular}{lll}
\multicolumn{1}{c}{ Strategy } & & Billion $\$$ \\
\cline { 1 - 1 } A--Sequential & & 60.11 \\
B--Delayed Sequential & & 40.11 \\
C--Compressed & & 68.38 \\
D--Delayed Compressed & & 68.18 \\
E--Component Testing & & 50.32 \\
F--Direct Prototype & 50.35 \\
G--Direct Replicate & & 50.35
\end{tabular}

The "early risk" measures the effect of spending monies to develop the FBR before it is economical. Table 4.4 gives the early and late risks for each strategy.

TABLE 4.4. Early and Late Risks (Discounted at $5 \%$ to 1980 )

\begin{tabular}{|c|c|c|}
\hline Strategy & $\begin{array}{l}\text { Early Risks } \\
(\text { Billion } \$)\end{array}$ & $\begin{array}{l}\text { Late Risks } \\
\text { (Billion } \$)\end{array}$ \\
\hline A--Sequential & 0.34 & 8.28 \\
\hline B--Delayed Sequential & 0.18 & 28.27 \\
\hline C--Compressed & 1.40 & 0.00 \\
\hline D--Delayed Compressed & 1.02 & 0.21 \\
\hline E--Component Testing & 1.60 & 0.03 \\
\hline F--Direct Prototype & 2.79 & 0.00 \\
\hline G--Direct Replicate & 2.80 & 0.00 \\
\hline
\end{tabular}

Note that the early risks increase for strategies that are expected to be complete before their expected competitive date. Estimates of early and late risks indicate the timing mismatch between a strategy's completion date and its probable competitive date. As can be seen in Table 4.4, a high late risk is generally associated with a low early risk and vice versa. 
Strategy performance can also be considered in the context of "worst-case" outcomes (see Section 2.4). It is possible to assign a confidence that a strategy will be completed early or late and be competitive early or 1 ate. These calculations can be made for any desired confidence level. A worst-case early risk assumes a strategy is complete in its earliest time period (the first $10 \%$ probability interval on the completion date distribution) and competitive late (the last $10 \%$ probability interval on the competitive date distribution). For example, the Sequential Strategy $(A)$ has a $10 \%$ probability of completion by the date 2024.5 (see Table 4.1); there is a $10 \%$ probability that it will not be competitive until after 2039 (Figure 4.1).

Worst-case late risks represent outcomes opposite to those considered for maximum early risk. The earliest competitive dates and latest completion dates are compared. Again, considering the $10 \%$ tails of the distributions, the late completion date for the Sequential Strategy is 2028.5. The strategy is assumed to be complete after this date and assumed to be competitive before the year 2022. Table 4.5 sumarizes maximum early and late risks for each strategy.

TABLE 4.5. Summary of Maximum Early and Late Risks (Discounted at $5 \%$ to 1980 )

\begin{tabular}{|c|c|c|}
\hline Strategy & $\begin{array}{l}\text { Maximum } \\
\text { Early Risks } \\
\text { (Billion } \$) \\
\end{array}$ & $\begin{array}{l}\text { Maximum } \\
\text { Late Risks } \\
\text { (Billion \$) }\end{array}$ \\
\hline A--Sequential & 1.1 & 92.1 \\
\hline B--Delayed Sequential & 0.8 & 158.5 \\
\hline C--Compressed & 2.0 & 0.0 \\
\hline D--Delayed Compressed & 1.8 & 26.4 \\
\hline E--Component Testing & 2.4 & 0.0 \\
\hline F--Direct Prototype & 3.4 & 0.0 \\
\hline G--Direct Replicate & 3.5 & 0.0 \\
\hline
\end{tabular}

(a) Based on a $90 \%$ confidence on early completion and late competitive dates.

(b) Based on a $90 \%$ confidence on late completion and early competitive dates. 
Note that four of the strategies shown in Tables 4.4 and 4.5 have no 1 ate $r$ isk. This is an important measure when the high costs of being late are considered. Another "worst-case" outcome includes strategy's development costs. Table 4.6 lists a strategy's maximum costs at the $90 \%$ confidence point. For the Sequential Strategy, for example, one is $90 \%$ confident that development costs will not exceed $\$ 2.73$ billion, discounted at $5 \%$ to 1980 . For a "worstcase" outcome, development costs are assumed to equal or exceed this value.

TABLE 4.6. Maximum Strategy Costs at $90 \%$ Confidence (Discounted at $5 \%$ to 1980 )

\begin{tabular}{lr}
\multicolumn{1}{c}{ Strategy } & Billion \$ \\
A--Sequential & 2.73 \\
B--Delayed Sequential & 2.71 \\
C--Compressed & 3.33 \\
D--Delayed Compressed & 3.23 \\
E--Component Testing & 3.66 \\
F--Direct Prototype & 4.38 \\
G--Direct Replicate & 4.65
\end{tabular}

\subsection{STRATEGY RANKINGS}

Three alternative criteria have been suggested for comparing strategies' performances. The first was a net benefit criterion, based on the equation:

net benefit $=$ expected gross benefits $-($ expected costs $)-($ total risks)

where total risks are the sum of early and late risks. Table 4.7 gives net benefits and strategy rankings for this criterion. Strategies $C$ and $D$ are considered equivalent in performance, with net benefits of $\$ 64.2$ to $\$ 64.4$ billion respectively. 
TABLE 4.7. Strategy Net Benefits (Discounted at $5 \%$ to 1980)

\begin{tabular}{lcc}
\multicolumn{1}{c}{ Strategy } & $\begin{array}{c}\text { Net Benefits } \\
\text { (Billion \$) }\end{array}$ & $\begin{array}{c}\text { Strategy } \\
\text { Ranking }\end{array}$ \\
& 56.4 & 3 \\
A--Sequential & 37.5 & 7 \\
B--Delayed Sequential & 64.2 & 1 \\
C--Compressed & 64.4 & 1 \\
D--Delayed Compressed & 45.2 & 4 \\
E--Component Testing & 43.4 & 4 \\
F--Direct Prototype & 43.2 & 4 \\
G--Direct Replicate & &
\end{tabular}

(a) A rank of (1) denotes best performance.

The second criterion, risk aversion, focuses only on the total risks of each strategy. The total risks (early plus late risk) are given with the strategy ranking in Table 4.8. Three strategies ( $C, D$, and $E$ ) are considered approximately equal in performance based on this criterion.

\section{TABLE 4.8. Risk Averse Criterion}

\begin{tabular}{lcc}
\multicolumn{1}{c}{ Strategy } & $\begin{array}{c}\text { Total Strategy } \\
\text { Risk (Bilion \$) }\end{array}$ & $\begin{array}{c}\text { Strategy } \\
\text { Ranking }\end{array}$ \\
\cline { 1 - 1 } A--Sequential & 8.7 & 6 \\
B--Delayed Sequential & 28.5 & 7 \\
C--Compressed & 1.4 & 1 \\
D--Delayed Compressed & 1.2 & 1 \\
E--Component Testing & 1.6 & 1 \\
F--Direct Prototype & 2.8 & 4 \\
G--Direct Replicate & 2.8 & 4
\end{tabular}

(a) Discounted at 5\% to 1980 . 
These criteria are illustrated in Figures 4.2 and 4.3 where strategy net benefits and total risks are plotted as a function of expected completion dates. Figure 4.2 shows that, for the strategies resulting in a 1457-MWe plant ( $A$ through D), net benefits decrease for later completion dates. The net benefits for strategies resulting in the 1000-MWe plant (E, F, and $G$ ) are smaller and show less variation. Figure 4.3 shows that total risks are minimized for strategies completed from 2014 to 2020. Later completion dates, after 2020, increase the strategy's total risk.

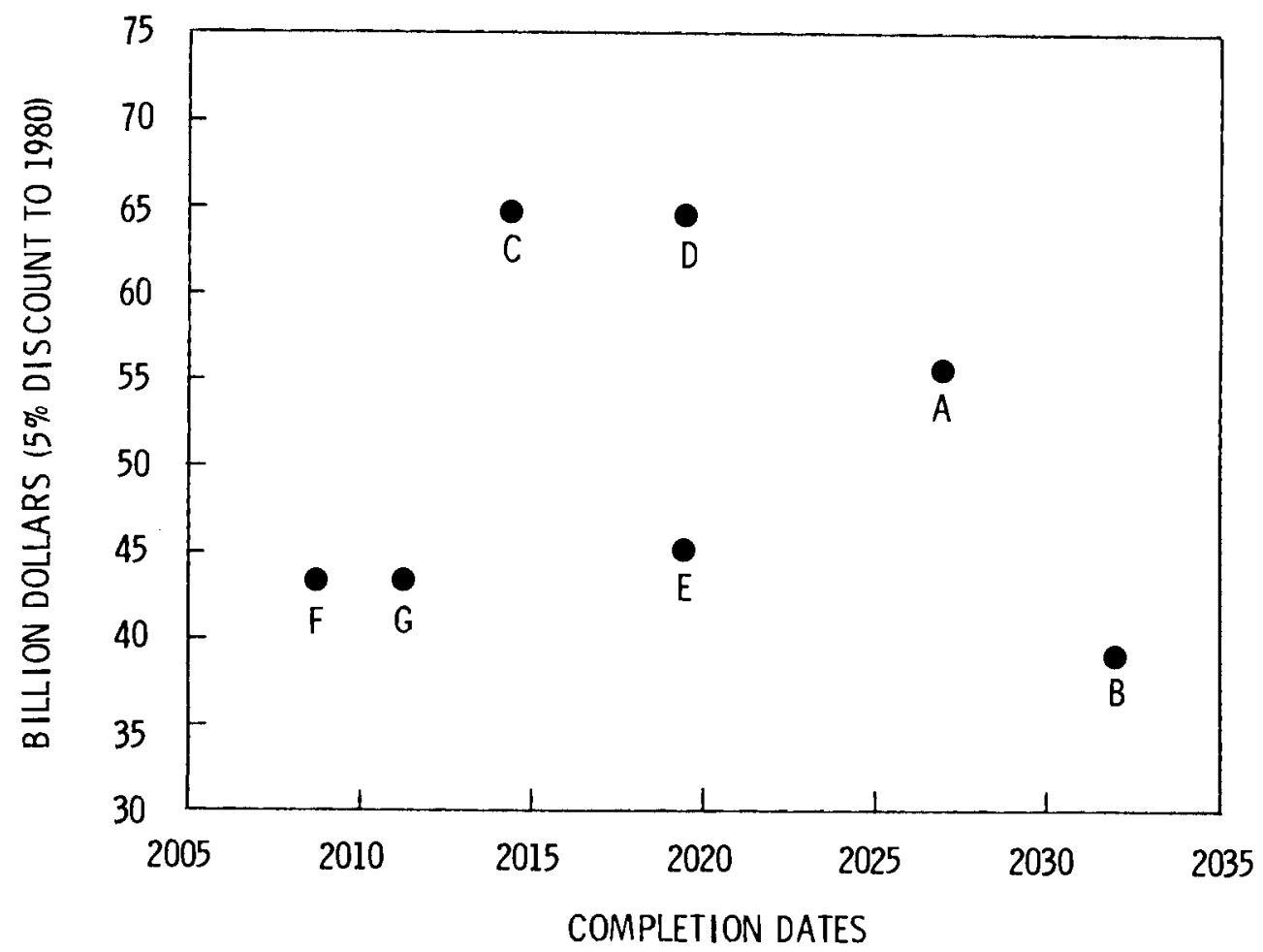

FIGURE 4.2. Strategy Net Benefits as a Function of Completion Date

The strategies may also be ranked on the basis of "worst-case" outcomes. In assessing these outcomes, a 90\% confidence interval has been used in all of the results presented. Results for maximum early and late risks were shown in Table 4.5. As one would expect, the strategies with a high risk of being late show little risk of being early. In the analysis several other confidences 


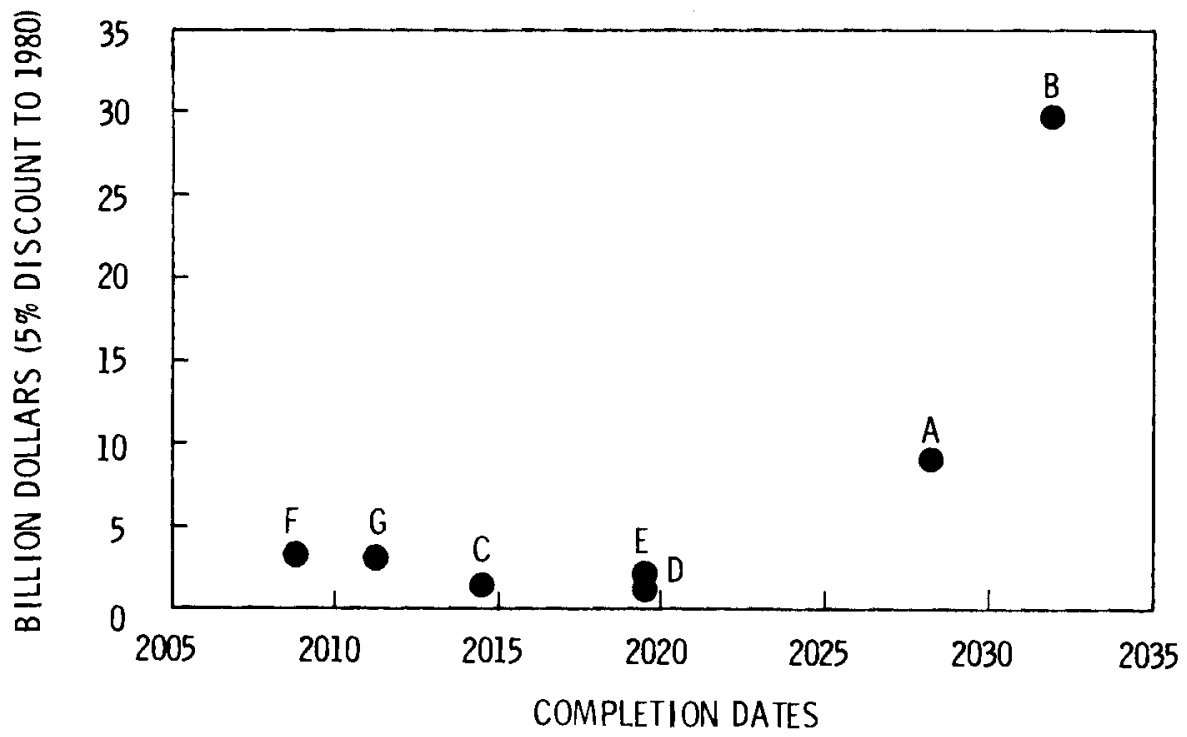

FIGURE 4.3. Strategy Total Risk as a Function of Completion Date

were also tested, including 80 and 95\%. Although the magnitudes of outcomes vary, the relative strategy ranking remains the same. Both maximum early risk and maximum late risk rankings are shown in Table 4.9. It must be remembered, though, that the risks associated with being late are two orders of magnitude greater than risks associated with being early and hence should be given considerably more weight. Likewise, maximum strategy costs differ by a relatively small amount and are not a major factor.

\section{TABLE 4.9. Summary of Strategy Rankings}

\begin{tabular}{|c|c|c|c|c|c|c|}
\hline Strategy & $\begin{array}{l}\text { Expected } \\
\text { Strategy } \\
\text { Benefit }\end{array}$ & $\begin{array}{c}\text { Net } \\
\text { Benefits } \\
\end{array}$ & $\begin{array}{c}\text { Risk } \\
\text { Averse } \\
\end{array}$ & $\begin{array}{l}\text { Maximum } \\
\text { Early } \\
\text { Risk } \\
\end{array}$ & $\begin{array}{c}\text { Maximum } \\
\text { Late } \\
\text { Risk } \\
\end{array}$ & $\begin{array}{l}\text { Maximum } \\
\text { Strategy } \\
\text { Cost }\end{array}$ \\
\hline A--Sequential & 3 & 3 & 6 & 2 & 6 & 1 \\
\hline B--Delayed Sequential & 7 & 7 & 7 & 1 & 7 & 1 \\
\hline C--Compressed & 1 & 1 & 1 & 4 & 1 & 3 \\
\hline D--Del ayed Compressed & 2 & 1 & 1 & 3 & 5 & 3 \\
\hline E--Component Testing & 4 & 4 & 1 & 5 & 1 & 5 \\
\hline F--Direct Prototype & 4 & 4 & 4 & 6 & 1 & 6 \\
\hline G--Direct Replicate & 4 & 4 & 4 & 6 & 1 & 7 \\
\hline
\end{tabular}


Strategy rankings are made for many of the measures and criteria as summarized in Table 4.9. As shown, each of the strategies result in a first place ranking on at least one criterion. To select a preferred strategy, one criterion may be used or relative performances may be weighted for selected criteria.

The criterion of net strategy benefits is the most closely ak in to the traditional cost-benefit measure. Since late risks exceed early risks, a strategy that is complete before its competitive date is preferred to one that is more likely to be late.

\subsection{THE 1981 DECISION}

In the preceding section, strategies were compared and ranked. The 1457 MWe plants show the greatest benefits; accelerated schedules result in lower late risks; hence the Compressed and Delayed Compressed Strategies rank highest. It is also useful to recast the development strategies as a sequence of development steps as shown in Figure 4.4. As shown, the Direct Replicate, Sequential, Compressed, and Direct Prototype Strategies all start with the Conceptual Design Study (CDS) Plant in 1981. Given that the CDS Plant is to be constructed, it is necessary to decide fairly early in the program whether to license the CDS Plant. If the Direct Prototype Strategy were chosen, the CDS Plant would be licensed. A decision on the 1457-MWe prototype plant is shown for 1985. The Compressed Strategy stems from a decision to build a prototype plant at this time. As an alternative, the prototype can be delayed until after the CDS Plant is completed or anytime in between. The Direct Replicate and Sequential Strategies evolve from this delayed decision. In 1981, either the CDS Plant can also be delayed or, alternatively, a component testing program pursued. The Delayed Sequential and Delayed Compressed Strategies both evolve from a delayed decision on the CDS Plant.

As shown in Figure 4.4, each strategy evolves from a sequence of decisions. There is considerable flexibility, though, in the decision process. A simplified diagram, Figure 4.5, illustrates the licensing of the COS required if the Direct Prototype Strategy is selected. While this is shown 


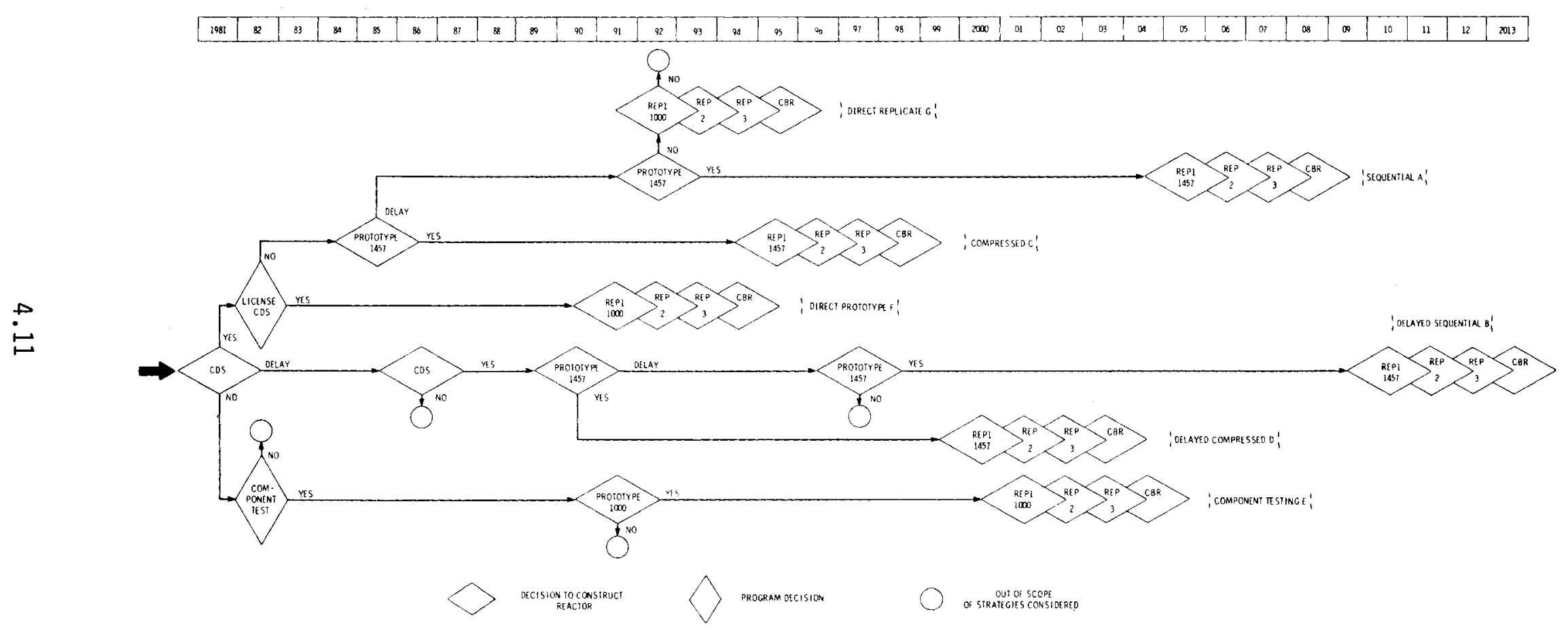

FIGURE 4.4. Strategy Decision Tree 


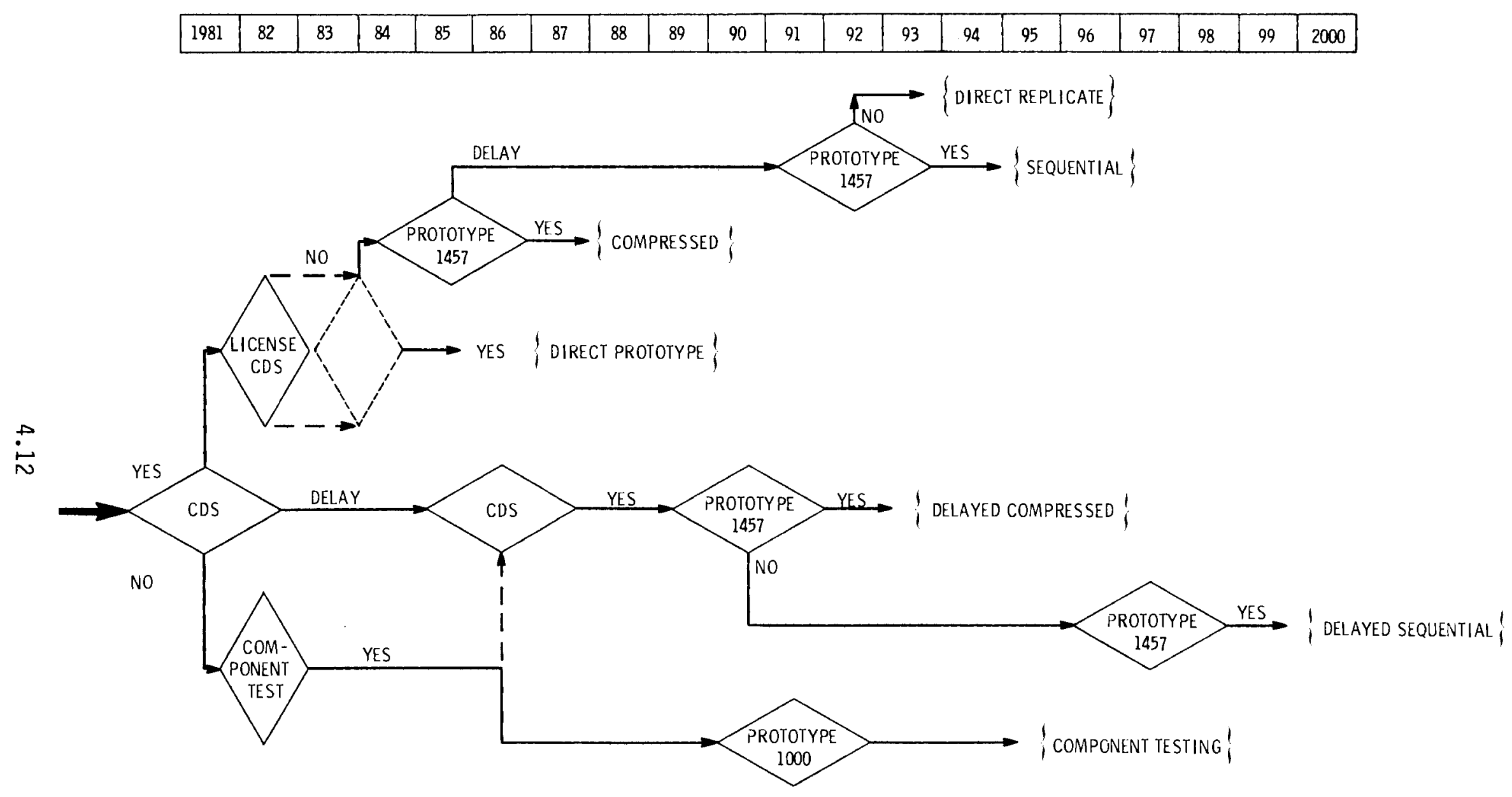

FIGURE 4.5. Simplified Decision Tree 
as a 1981 decision point, it is possible to delay this decision several years without ruling out any of the options on this branch of the decision tree.

The implications of the 1981 yes-no decision on the CDS Plant are shown in Figure 4.6. A "yes" decision leads to any one of the four strategies that $c$ an be selected at a later time. A "delay" decision leads to a later choice between two strategies. A "no" decision leads to a component testing strategy. As shown by the dashed line in Figure 4.5, the strategies associated with the decision to delay the CDS could still be pursued at a later date.

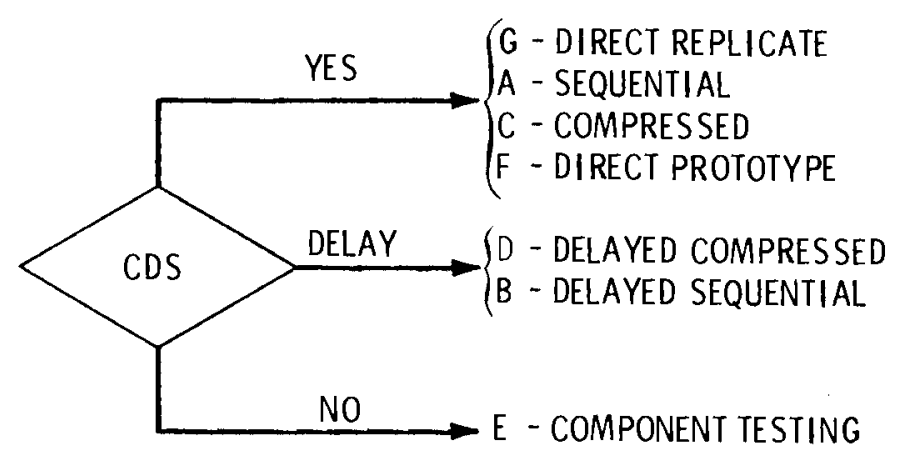

FIGURE 4.6. The Decision on the CDS Plant

In effect, the 1981 decision is a choice among three alternative groups of strategies: 1) construct the CDS, 2) delay and then construct CDS, and 3) proceed with a component testing program. To make the decision now, it is important to consider what the strategy's most probable results will be in the next century. For this reason, the retention of alternative courses of action (e.g., selecting a decision that offers the most flexibility) is an important factor. In the future, the critical uncertainties should be reduced as the forecasting horizon improves.

Similarly, the conclusion of a successful development strategy is represented not by a government decision but by a decision in the commercial sector. The utility's decision will not be made without information necessary to 
assess the FBR's economic competitiveness. For this reason, today's decision must consider a strategy's ability to demonstrate reliability and efficient performance.

It can be assumed that better information about the key factors affecting the FBR's competitiveness will become available. This better information will reduce the critical uncertainties in electrical energy demand, uranium resources, FBR capital costs, and the growth of nuclear generated electrical production, thus giving more confidence in the estimates. From this point of view, the choice to construct the CDS Plant leaves the most options open.

\subsection{DISCOUNT RATE}

For long-term programs with high developmental costs and deferred benefits, the selection of high discount rates may discourage the early expenditure of development monies. The long time periods associated with the FBR's development strategies make this consideration particularly important.

It is also difficult to assess the ultimate importance of the availability of the FBR technology to the nation. A recent FBR analys is advocated the value of its development as "energy insurance" (Droutman 1980). For the results presented thus far, all of the economic benefits have been made in 1980 do 11 ars discounted at $5 \%$ to that base year. The quantification of these benefits (and associated risks) in constant discounted dollars is always an issue in the assessment of long-term technology development.

The choice of a discount rate can affect the outcome of an economic analysis that compares investments over time to possible future benefits. The problem of selecting a discount rate is even more difficult for government decisions in which public investments are required. On one hand, the government may be viewed as responsible for investments in the public interest that would not be undertaken by the private sector because of long payback periods. If the expenditures are solely for the benefit of future generations, welfare economics theory says that discount rates should approach zero to reflect the intertemporal nature of the development. On the other hand, some argue that the public discount rate should be the same as that used for investment decisions in the private sector. 
The FBR development program is perhaps the best example of this dilemma. At higher discount rates (10 or 15\%), potential FBR benefits are overshadowed by development costs. Use of lower discount rates (2\%) or basing the decision on undiscounted dollars (0\%) results in benefits and risks dominating the decision. (This comment holds not only for the FBR but also for fusion, solarelectric, and virtually any other technology of the 21 st century).

Much study has focused on determining the appropriate numerical value of the public investment discount rate. For long-term energy projects, the discount rate is critically important for decisions being made today. For the current decision, the timing of investments to avoid mismatches with future "need" for FBR technology is the critical issue. The higher the discount rate, the more advantageous it is to delay the development decision. Opponents of the FBR have argued that if we can delay some of the costs of development and still develop the FBR (if it is needed), the present value costs would be lower.

In this study we have followed the practice of the CONAES Modeling Resource Group (1978) and assumed an after-tax rate of return to discount the streams of consumption benefits that accrue from adopting alternative energy technologies. In real terms, this public discount rate is taken to be $5 \%$.

A book edited by Robert $C$. Lind (1981) argues that a social discount rate of $2 \%$ should be used in cases where a 11 costs are borne by the government in increased expenditures or decreased tax revenues and where all benefits accrue to the government in the form of reduced costs or increased revenues from appropriate user charges. Where development is financed by taxation, assuming that individuals respond to taxes that diminish retained earnings, then a multiplier of 1.2 on development costs is suggested.

Development costs and benefits have been expressed in terms of dollars discounted at $5 \%$ to 1980 . These costs are discounted in Table 4.10 at both $2 \%$ and $5 \%$. It is interesting to note that for the strategies resulting in the larger, 1457-MWe commercial FBR, strategy revenues exceed development costs for the $2 \%$ discount rate. Recall that strategy development costs include a credit for the sale of electrical energy. It is interesting to note 
TABLE 4.10. Expected Strategy Costs (Discounted to 1980)

\begin{tabular}{llll}
\multicolumn{1}{c}{ Strategy } & & \multicolumn{2}{c}{ Billion $\$$} \\
A--Sequential & & $\frac{2 \%}{2.34}$ & 2.07 \\
B--Delayed Sequential & & 2.39 & -1.54 \\
C--Compressed & & 2.78 & -2.53 \\
D--Delayed Compressed & & 2.79 & -2.47 \\
E--Component Testing & & 3.55 & 2.79 \\
F--Direct Prototype & & 4.19 & 2.48 \\
G--Direct Replicate & 4.39 & 3.09
\end{tabular}

that for the optimal strategies the government is realizing an internal rate of return of about $3 \%$ solely on energy sales without any consideration of future societal benefits from the FBR.

A strategy's expected benefits and associated late risks increase significantly when using a $2 \%$ discount rate instead of $5 \%$. Table 4.11 shows net strategy benefits calculated at both discount rates. The magnitude of the net benefits is considerably higher at the lower discount rate, but the ranking of the strategies is unaffected. Table 4.11 compares the net strategy

TABLE 4.11. Net Strategy Benefits (Discounted to 1980)

\begin{tabular}{llll}
\multicolumn{1}{c}{ Strategy } & & \multicolumn{2}{c}{ Billion $\$$} \\
\cline { 1 - 1 } A--Sequential & & 437.7 & 57.4 \\
B--Delayed Sequential & & 148.0 & 37.5 \\
C--Compressed & & 475.2 & 64.2 \\
D--Delayed Compressed & 473.5 & 64.4 \\
E--Component Testing & 325.0 & 45.2 \\
F--Direct Prototype & 325.2 & 43.4 \\
G--Direct Replicate & 324.5 & 43.2
\end{tabular}


benefits discounted at both $2 \%$ and $5 \%$. As can be seen from the table the magnitude of the net benefits increases markedly.

In summary, on the basis of net benefits those strategies that develop a large commercial breeder are superior to those developing a smaller one. Consideration of the risk of being late makes the Sequential and Delayed Sequential Strategies less attractive than the Compressed and Delayed Compressed Strategies. A prudent development strategy appears to be one in which an early decision is made to proceed with a large development plant. 



\section{REFERENCES}

Boege1, A. J. and M. J. Clausen. 1981. Characterization of Alternative FBR Development Strategies. PNL-3596, Pacific Northwest Laboratoy, RichTand, Washington.

Cochran, T. B., Speth J. G. and Tamplin, A. R. 1975. "Bypassing the Breeder: A Report on Misplaced Federal Energy Priorities. National Resources Defense Counc i1, Inc.

Droutman, L. 1980. "Breeders: Energy Insurance for an Uncertain Future." Presented at the American Society of Mechanical Engineers Nuclear Engineering Conference, San Francisco, California.

Economic Report of the President. 1979. U.S. Government Printing Office, Washington, D.C.

Energy Modeling Forum. 1980. "Aggregate Elasticity of Energy Demand." EMF Report 4, Vol. 1. Stanford University, Stanford, California.

Lind, R. C., ed. 1981. The Rate of Discount and the Application of Social Benefit-Cost Analys is in the Context of Energy Policy Decisions. Scheduled for publication in 1981 .

Modeling Resource Group, Committee on Nuclear and Alternative Energy Systems (CONAES). 1978. "Energy Modeling for an Uncertain Future," National Research Council, Washington, D.C.

Manne, A. S. 1974a. "Electricity Investment Under Uncertainty: Waiting for the Breeder." Energy. Macrakis, M. S., ed. The MIT Press, Cambridge, Mass achu setts.

Manne, A. S. 1974b. "Waiting for the Breeder." Review of Economic Studies Symposium on the Economics of Exhaustible Resources.

Manne, A. S. 1977. ETA-MACRO: A Model of Energy - Economy Interactions. EPRI-EA-592, Electric Power Research Institute, Palo Alto, California.

Manne, A. S. 1979. "Long-Term Energy Projections for the U.S.A." Presented at the International Conference on Energy Systems Analysis, Dublin, Ireland.

Manne, A. S. and 0. S. Yu. 1975. "Breeder Benefits and Uranium Availability," Nuc lear News, 18, January 1975.

Manne, A. S., R. J. Condap, and P. V. Preckel. 1981. ETA-MACR0: A User's Guide. EA-1724, Electric Power Research Institute, PaTo ATto, California.

Manne, A. S. and R. G. Richels. 1980. "A Dec ision Analysis of Alternative Nuclear Fuel Cycles," Energy Policy 8(1). 
Piepel, G. F. et al. 1981. Probabilistic Estimates of U.S. Uranium Supply. PNL-3595, Pac ific Northwest Laboratory, Richland, Washington.

Richels, R. G. 1979. R \& D Under Uncertainty: A Study of the U.S. Breeder Reactor Program, Gar land Publishing Co., New York \& London.

Sharefkin, M. 1976. The Fast Breeder Reactor Decision: An Analysis of Limits and the Limits of Analysis. A Study prepared for the use of the Joint Economic Committee, U.S. Congress (by Resources for the Future Inc.), U.S. Government Printing Office, Washington D.C.

Stauffer, T. R., R. S. Palmer, and H. L. Wyckoff. 1975. "Assessment of the Economic Incentives for the Fast Breeder Reactor." Conference on Frontiers of Power Technology, Oklahoma State University, Stillwater, OkTahoma.

U.S. Atomic Energy Commission (AEC). updated. 1970. Liquid Metal Fast Breeder Reactor Prozian Plan. Vols 1-10, WASH-1101-1110 (1968). U.S. Government Printing Office, Washington D.C.

U.S. Atomic Energy Commission (AEC). 1972. Cost-Benefit Analys is of the U.S. Breeder Reactor Program. WASH-1184. U.S. Government Printing Office, Washington, D.C.

U.S. Atomic Energy Commission (AEC). 1974. Proposed Final Environmental Statment - Liquid Metal Fast Breeder Reactor Program. WASH-1535. U.S. Government Printing Office, Washington, D.C.

U.S. Energy Research Development Administration. 1975a. Report of the Liquid Metal Fast Breeder Reactor Program Review Group. ERDA-1. Washington, D.C.

U.S. Energy Research Development Administration. 1975b. Final Environmental Impact Statement - Liquid Metal Fast Breeder Reactor Program. ERDA-1535. Washington, D.C.

U.S. Energy Research Development Administration. 1975c. The LMFBR - Its Need and Timing. ERDA-38. Washington, D.C.

U.S. Energy Research Development Administration. 1975. Alternative LMFBR Program Plans - A Preliminary Examination of the Scope and Timing of LMFBR Plants and Test Facility Projects. Washington, D.C.

U.S. GA0. 1975a. The Liquid Metal Fast Breeder Reactor Program - Past, Present, and Future. 0SP-76-1. Washington D.C.

U.S. GAO. 1975b. The Liquid Metal Fast Breeder Reactor: Promises and Uncertainties. OSP-76-1. Washington, D.C.

White, M. K. and E. T. Merri11. 1981. Evaluation of the Commercial FBR Introduction Date. PNL-3597, Pac if ic Northwest Laboratory, Richland, Washington. 
APPENDIX A

PROBABILITY REVIEW 
APPENDIX A

\section{PROBABILITY REVIEW}

The uncertainties associated with the FBR development decision have been described probabilistically. This appendix reviews the definition and assignment of probabilities. These uncertainties are described by a probability density function. From this function, several parameters that characterize the range of possible outcomes can then be defined.

To illustrate, consider the activity completion over time. The actual completion time is uncertain and may fall anywhere within a continuous range of time. A quantitative measure is desired for the completion time of a representative case, where each time the activity is performed, the actual completion time may vary.

Let $t$ be the activity completion time in minutes. To establish a measure of $t$, an experiment is performed in which the activity is repeated a number of times and each completion time $t$ is recorded. The results of such an experiment are shown in Figure A.1. Each time the activity is completed within a two minute interval is represented by one square above that interval. Figure A.1 illustrates such a plot for 50 trial activities. The total number of trials that were completed before 41 minutes, for example, is given by the number of squares to the left of $t=41 \mathrm{~min}, i . e ., 30$.

This number can be used to predict the probability that a typical activity will be complete before 41 minutes by taking the ratio of the total number of trials to the total completed before this time i.e., 30/50, or, using compact notation:

$$
\operatorname{Prob}(t \leq 41)=30 / 50=0.6
$$

If, instead of the number of squares in Figure A.1, the area represented by the squares is considered, then the same result will be obtained by taking the 
area of the squares to the left of $t=41$ and dividing it by the total area of the squares. The area of each square can be adjusted so that the total area of all squares will be unity.

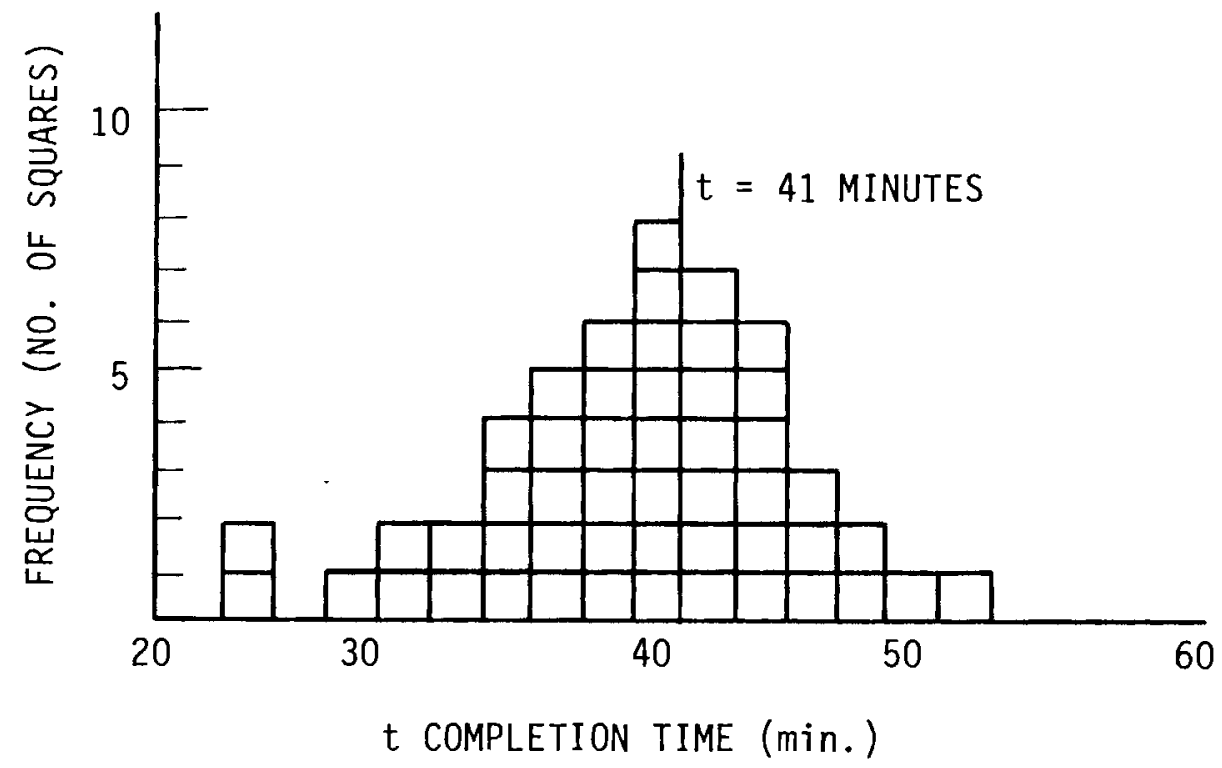

FIGURE A.1. Frequency Histograms of Activity Completion for 50 Trials

Extending the experiment to a large number $N$ of trial activities and making the time intervals vanishingly small, the plot of Figure A.1 will approach a continuous curve (Figure $\left.A: Z^{\prime}\right)$. Again, the total area under the curve can be normalized to unity so that Prob $(t \leq b)$ will be equal to the area under the curve $f(t)$ to the left of time (b). In Figure A.2, the completion time $t$ is a random variable. The function that expresses the relationship between the value of the random variable and the probability of its occurrence (expressed as a fraction of 1.0 ) is a probability density function (PDF).

Because possible completion times fall over a continuous range, the probability of an event is defined over an interval, for example the interval from time (a) to time (b) as shown. The probability that completion occurs in the time inverval from (a) to (b) is expressed by

$$
\operatorname{Prob}(a<t \leq b)=\int_{a}^{b} f(t) d t
$$




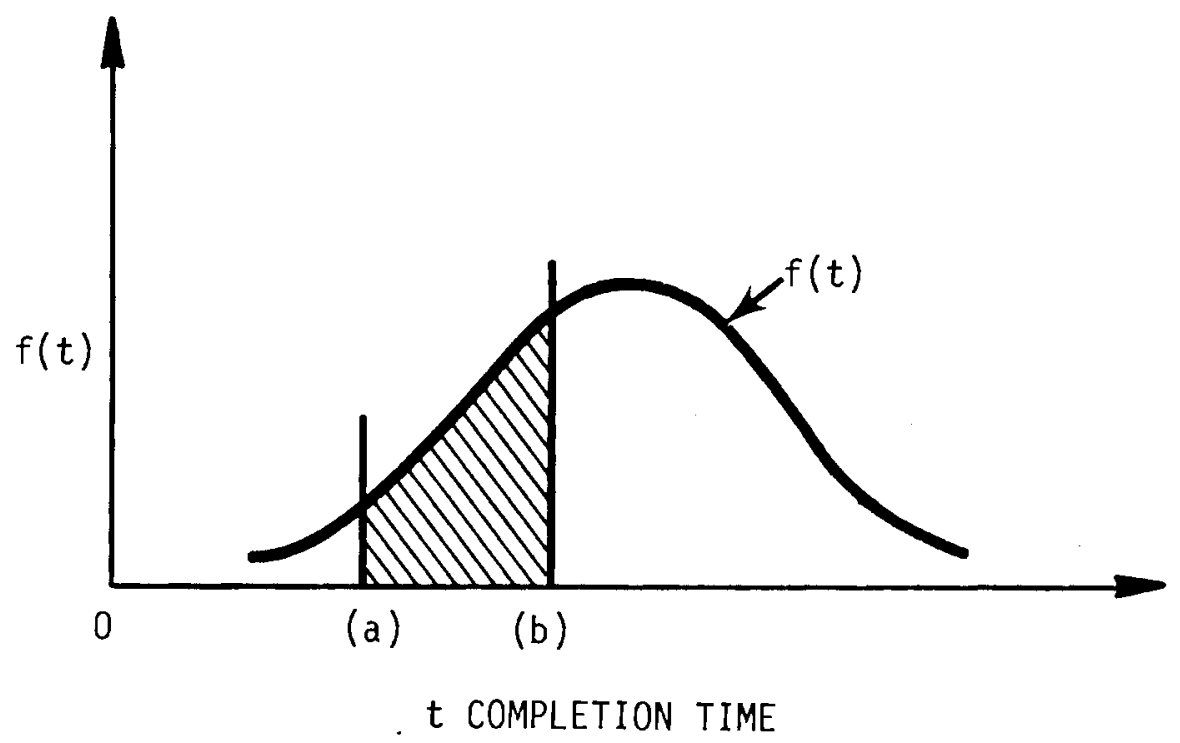

FIGURE A.2. Probability Density Function for Activity Completion

where the integral of the density function over the interval yields the area in that interval or, the probability of completion in that time period.

Uncertainty may also be expressed displaying the same information as a cumulative distribution function (CDF). The cumulative distribution function is the integral of the probability density function. It gives the probability that the value of the random variable is less than or equal to a specific event. This is defined by the same integral expression as above with the lower bound being the minimum of the range of possible outcomes:

$$
\operatorname{Prob}(t \leq b)=\int_{0}^{b} f(t) d t
$$

Figure A.3 shows the CDF for the density function given in Figure A.2. Note that its value at the latest possible time of completion is 1.0 .

It is useful to describe the information in the probability density function by a few characteristic numbers that specify its position and shape. Common parameters include the mean and variance or standard deviation. 


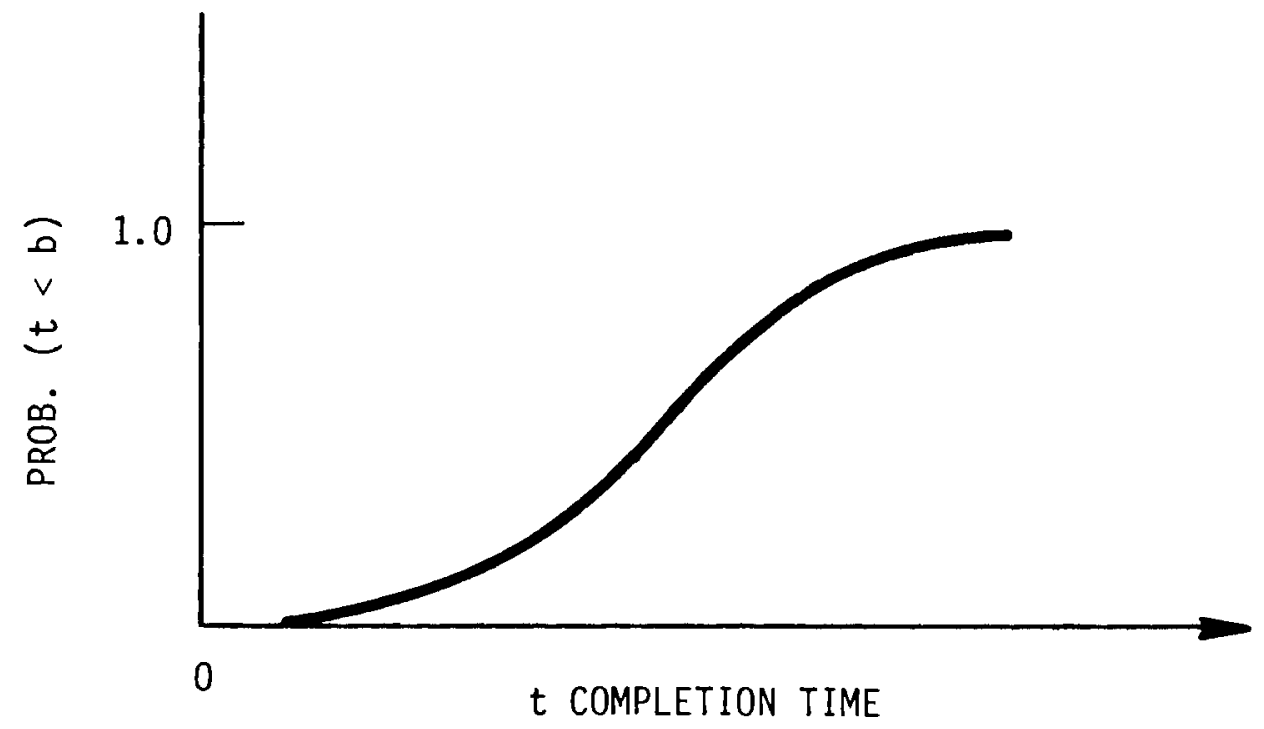

FIGURE A.3. Cumulative Distribution Function for Completion Times

The mean or expected value is a weighted integral of all possible outcomes with their probability of occurrence. It is taken over all possible outcomes as given by the expression:

$$
E(t)=\bar{t}=\int_{0}^{\infty} t f(t) d t
$$

The variance of a distribution is an indication of its spread over the range of possible outcomes:

$$
\text { Variance } t=\sigma_{t}{ }^{2}=\int_{0}^{\infty}(t-E(t))^{2} f(t) d t
$$

The square root of the variance, known as the standard deviation, is an alternative characterization of the spread or range of possible outcomes.

Other measures useful for decision making are also available. For example, several types of averages or measures of central tendency can be defined in addition to the mean. These include the median and the mode for continuous probability distributions. The median is the middle vaue of the range of 
possible outcomes. It is represented by the point where the cumulative probability is equal to 0.5 . The mode is the event or point having the highest probability. Figure A.4 shows the relative positions of the mean, median, and mode for a probability density function which is skewed to the right. For symmetrical curves the mean, median, and often the mode, all coincide.

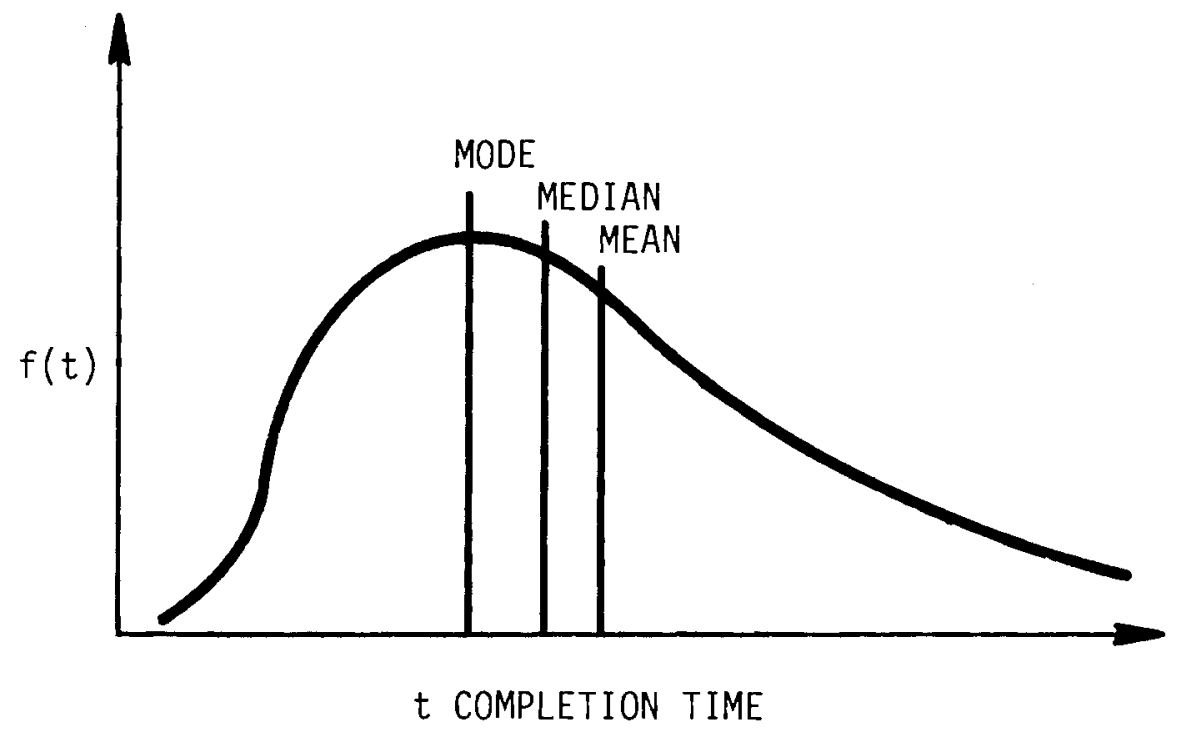

FIGURE A.4. Skewed Distribution

In assessing uncertainties, the decision maker may wish to incorporate his confidence of some outcomes and consider the errors that may be associated with his assumptions. A confidence interval is an interval specified over the range of probability density function. Confidence is expressed as a probability determined from the density function. Errors are probabilities of outcomes that occur outside of the confidence interval. Figure A. 5 gives an example of a confidence interval. If for example, the decision maker wishes to focus on those outcomes that occur $90 \%$ of the time, points (a) and (b) represent the minimum and maximum values of the range. The probability of outcomes in the interval from (a) to (b) is then 0.9. The "tails" or events outside the intervals have a total probability of 0.1 .

Figure A.5 shows a "two-sided" confidence interval. It is also possible to define a "one-sided" confidence interval. This is shown in Figure A.6. 
Here, a point is determined for a given confidence for outcomes which are "less than" or "greater than" the point. The confidence shown in Figure A.6 is for "greater than" confidence. This can be interpreted, for example, on a distribution over time, as the point in time after which $90 \%$ of the events are likely to occur.
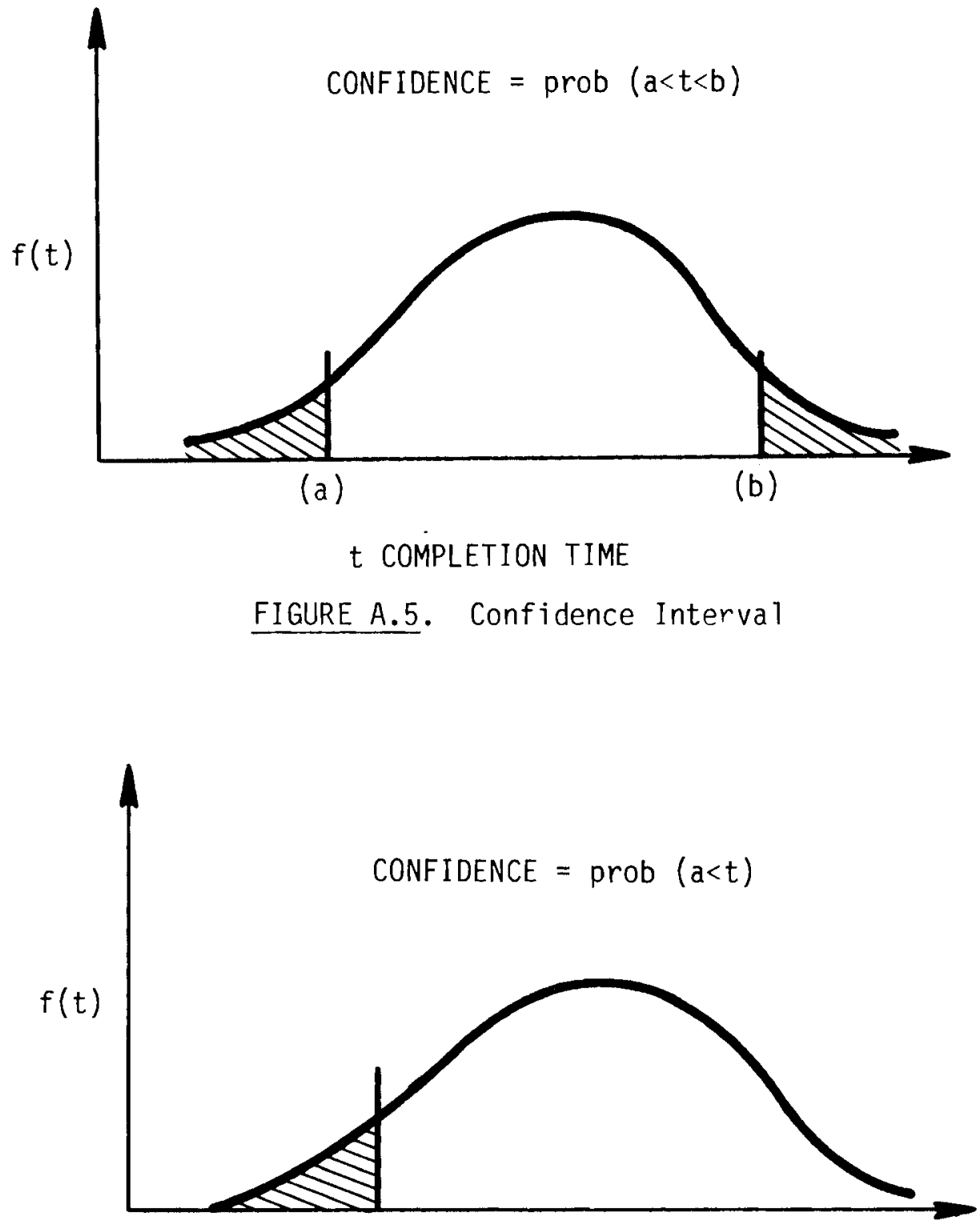

(a)

t COMPLETION TIME

FIGURE A,6. "One-Sided" Confidence Interval 
APPENDIX B

STRATEGY PERFORMANCE MEASURES 
APPENDIX B

\section{STRATEGY PERFORMANCE MEASURES}

In the approach, the uncertainties asociated with the FBR development decision are described probabilistically. This appendix gives the mathematical basis for the decision metrics and parallels the presentation in Chapter 3.

The method uses information about the magnitude of costs, the time of development completion and the date when the FBR is economically competitive expressed as random variables. Each random variable has a range of possible outcomes and each outcome is assigned a probability of occurrence. This relationship is expressed as a probability density function (PDF).

A computer model was developed to facilitate the analys is and to allow rapid calculation of the strategy measures. The model has the probabilistic descriptions and the analyst's desired confidences as inputs. The model provides all the salient information sumarized below as output. The following gives the mathematical equations for the various measures as calculated in the model.

Each alternative development strategy has an associated completion and cost distribution. Initial strategy comparison can be made by considering the mean cost or completion time of each, the variance of each distribution, or by selecting specific costs or dates and assessing probabilities of outcomes less than or greater than the selected value. Additionally, confidence intervals $c$ an be selected and the range of costs or times for each interval can be determined.

Associated with the completion and cost distributions for each strategy is the competitive date distribution. Because the completion and competitive date distributions are both defined over time, it is possible to compare the "overlap" of the two distributions. This comparison provides an additional metric. This measure is the "success" probability. "Success" as defined here 
is the probability that a strategy is complete before the FBR is competitive. It is defined by a completion distribution and a competitive date distribution taken together.

To exhibit this metric, consider Figure B.1 in which a completion time and competitive date distribution are displayed simultaneously. Here we will denote the completion PDF as $f_{c}(t)$ and the competitive date PDF as $f_{d}(t)$. Success probability is then defined as:

"Success Probability" = Probability the strategy is complete before it is competitive.

Mathematically, the expression is the probability that the random variable of completion (c) is less than the random variable (d) of introduction:

"Success probability" = Prob $(c \leq d)$

$$
=\int_{0}^{\infty} f_{d}(t) \int_{0}^{t} f_{c}\left(t^{\prime}\right) d t^{\prime} d t
$$

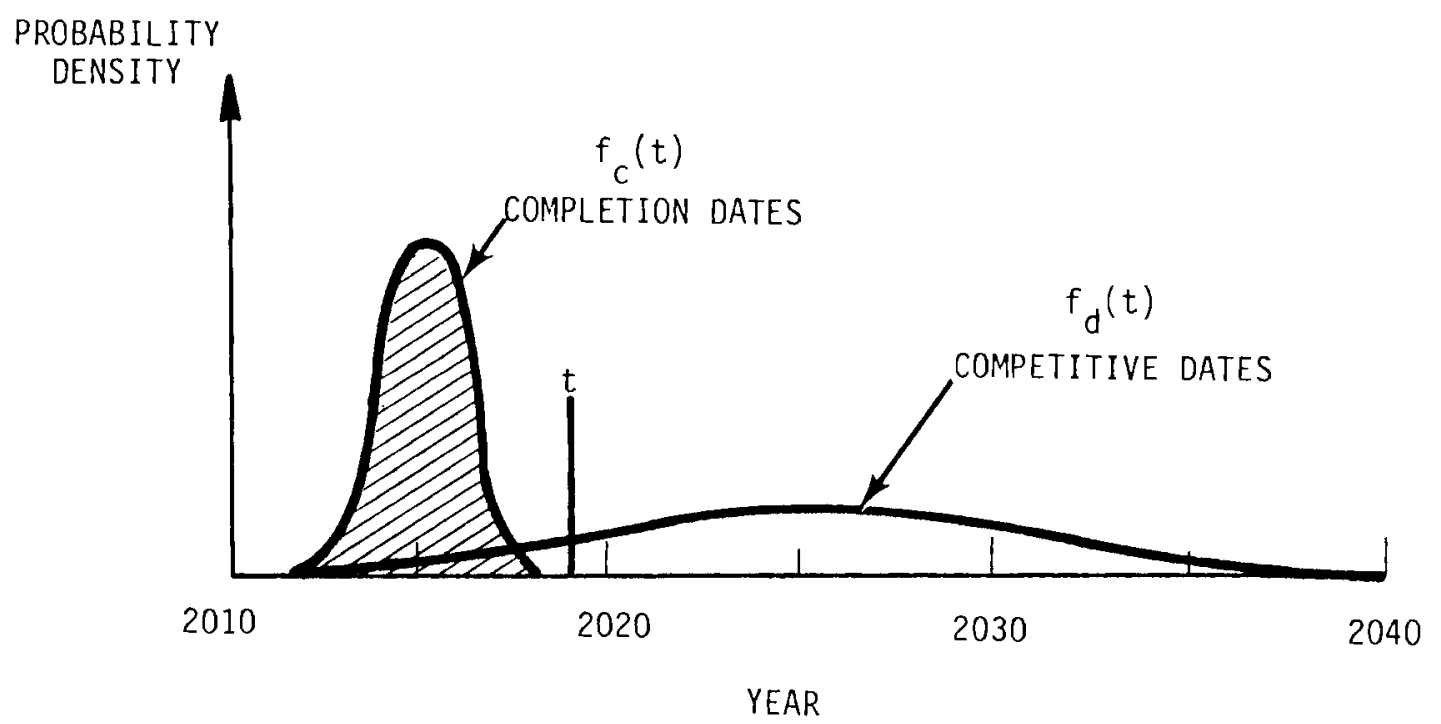

FIGURE B.1. Completion Probability for a Given Competitive Date ( $t)$ 
The expression of Equation (1) is equivalent to the probability that a new random variable $y$ is greater than 0 where

$$
y=d-c
$$

or probability $(y>0)$.

Figure B.2 shows example benefits of "on-time" introduction of the FBR for future dates. Benefits are measured as a function of the time of technology introduction, given that the FBR is economically competitive at that time.

The first measure, expected gross benefits, is determined by averaging the gross benefits over the FBR competitive date probability distribution. Figure B.3 depicts the probability weighting of the benefit function by the probability of introduction.

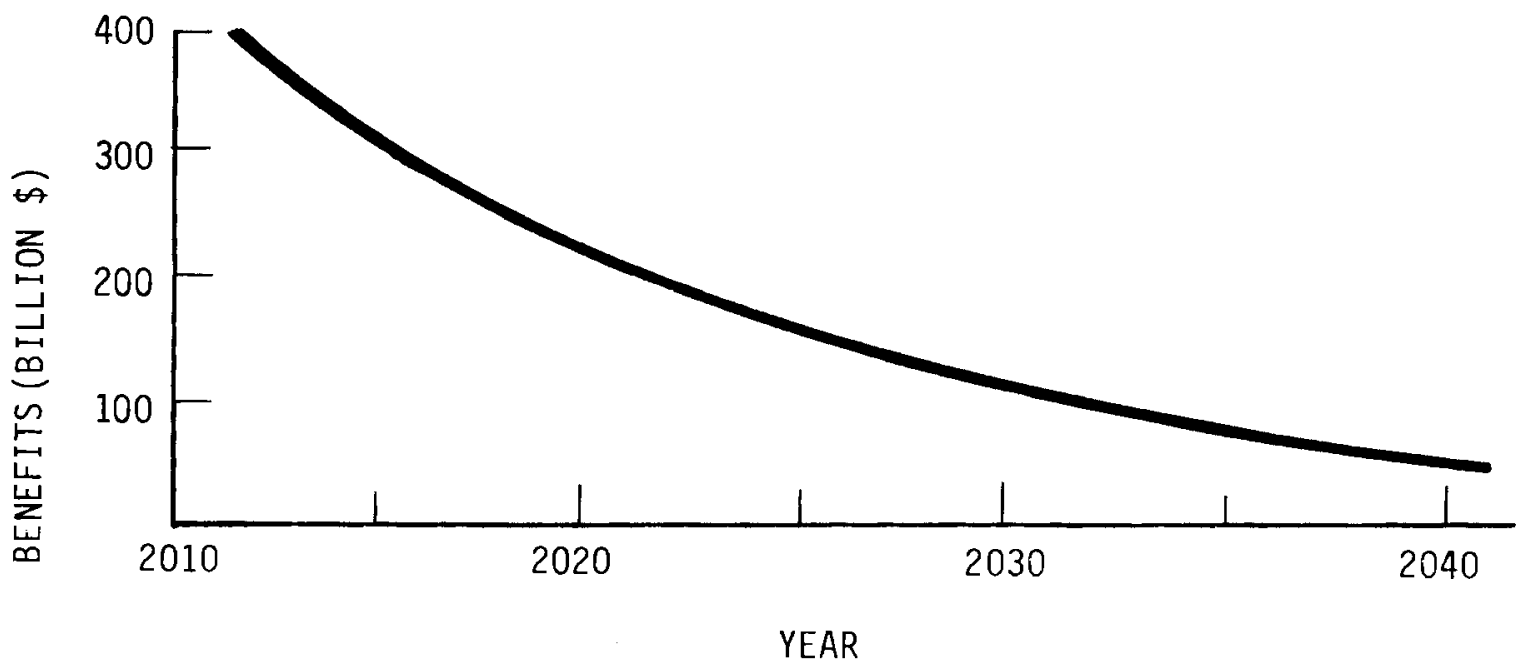

FIGURE B.2. Example Benefit Function $B(t)$ 


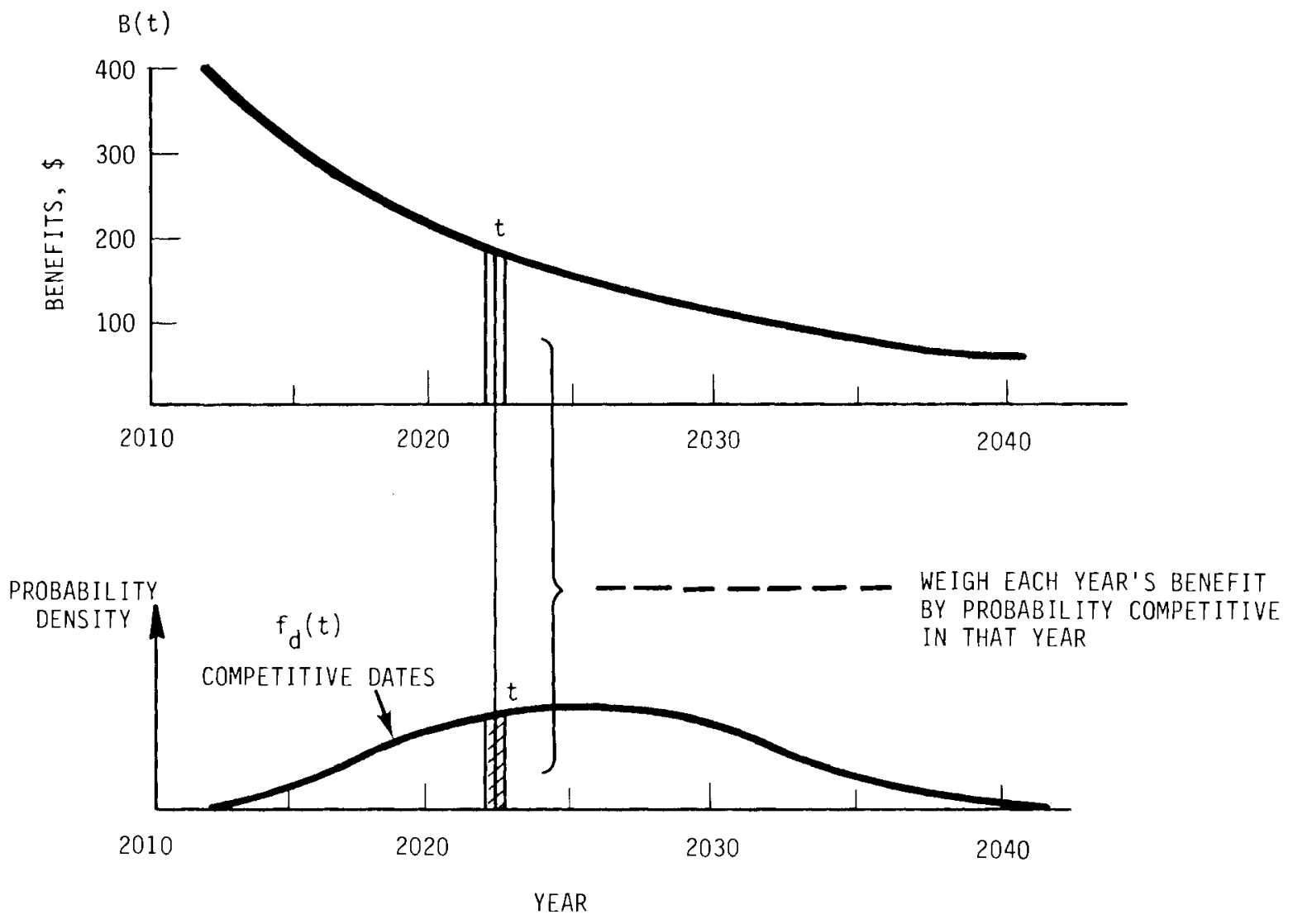

FIGURE B.3. Calculation of Expected Benefits

If we let

$$
B(t)=\text { gross benefits of FBR introduction at time } t \text {. }
$$

Then the function,

$$
\bar{B}=\int_{0}^{\infty} B(t) f_{d}(t) d t
$$

is a measure of the expected benefits over all possible introduction dates. Note that $\bar{B}$ is independent of strategy. It takes into account only the uncertainty in the competitiveness of the FBR in the US economy and represents the benefits that we would expect to recognize from "on time" introduction of the FBR. 
A "late benefit" curve, $B_{L}\left(t^{\prime}, t\right)$, can be developed for each date of introduction. This benefit function represents the benefits accrued to society as a result of introducing the FBR 1 ate, at time $t$ ' when $t$ represents the time when the FBR is first economically competitive. As was discussed in Chapter 3 of the text, it is necessary to derive the benefits of introduction after the FBR is commercially competitive. Figure B.4 is a reproduction of Figure 3.10 from the text. The illustration shows a few discrete points calculated with ETA-MACRO. The following expression was derived to approximate these results:

$B_{L}\left(t^{\prime} t\right)=B(t) \times e^{0.013\left(t^{\prime}-t\right)}$

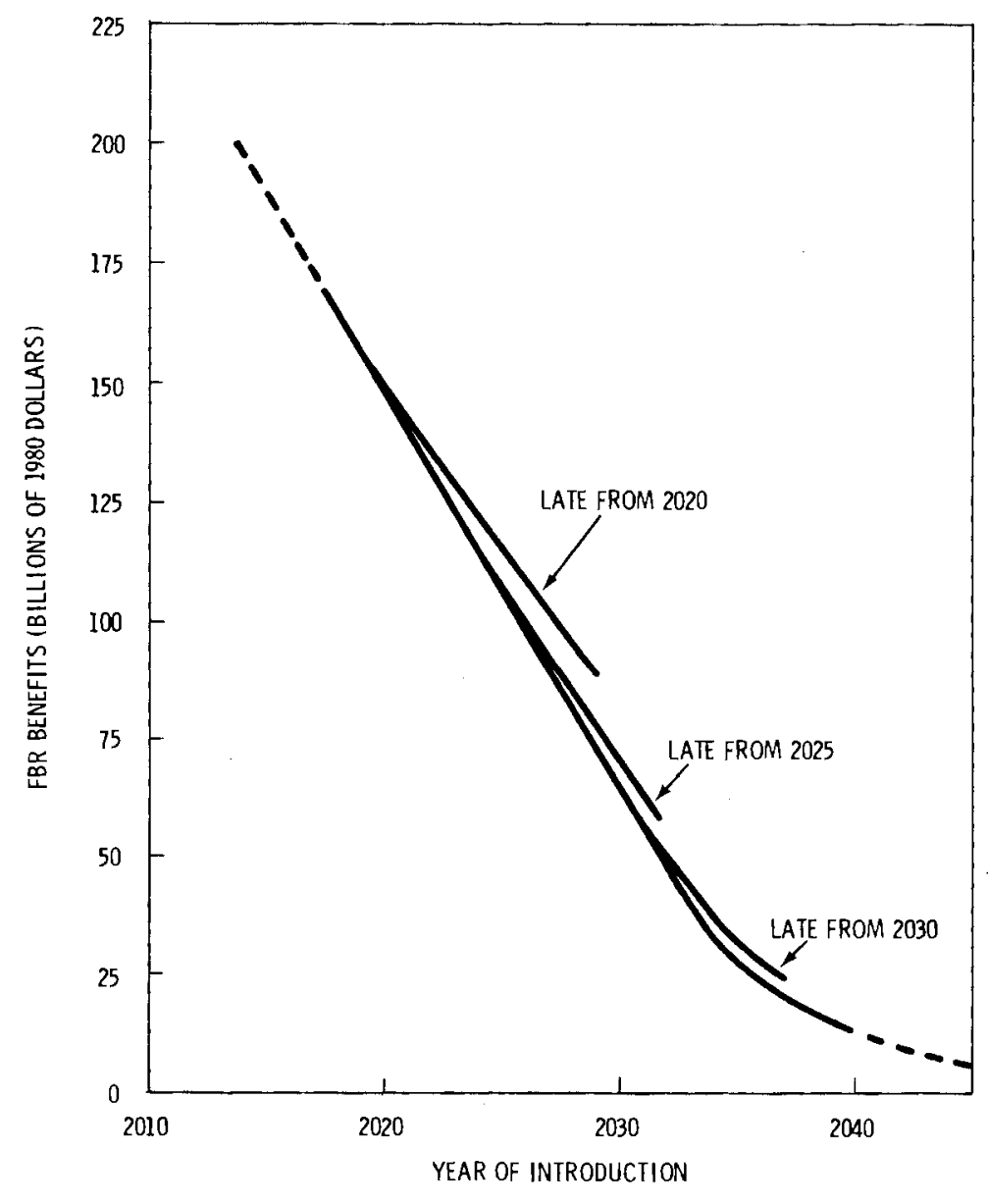

FIGURE B.4. Late Benefits 
The expected strategy benefit provides one indicator of how breeder benefits are dependent on both its availability and when it is introduced. To exhibit the determination of this measure, consider a given time $t$. At this time, the completion distribution yields the probability that development is complete. This probability is shown by the shaded area in Figure B.5. For outcomes that have the development complete before this date $(t)$, it is assumed that the FBR is introduced at this date. Outcomes that have the development complete after date $(t)$ are "late." The strategy benefits for this single commercial date are as follows:

$$
\begin{array}{cc}
\begin{array}{c}
\text { "Benefits for } \\
\text { complete before time } t "
\end{array} & \begin{array}{c}
\text { "Benefits for } \\
\text { complete after time } t^{\prime \prime}
\end{array} \\
{\left[\int_{0}^{t}{ }^{t}{ }_{C}(t) d t\right] \times B(t)+} & +\int_{t}^{\infty} f_{C}\left(t^{\prime}\right) B_{L}\left(t^{\prime}, t\right) d t^{\prime}
\end{array}
$$
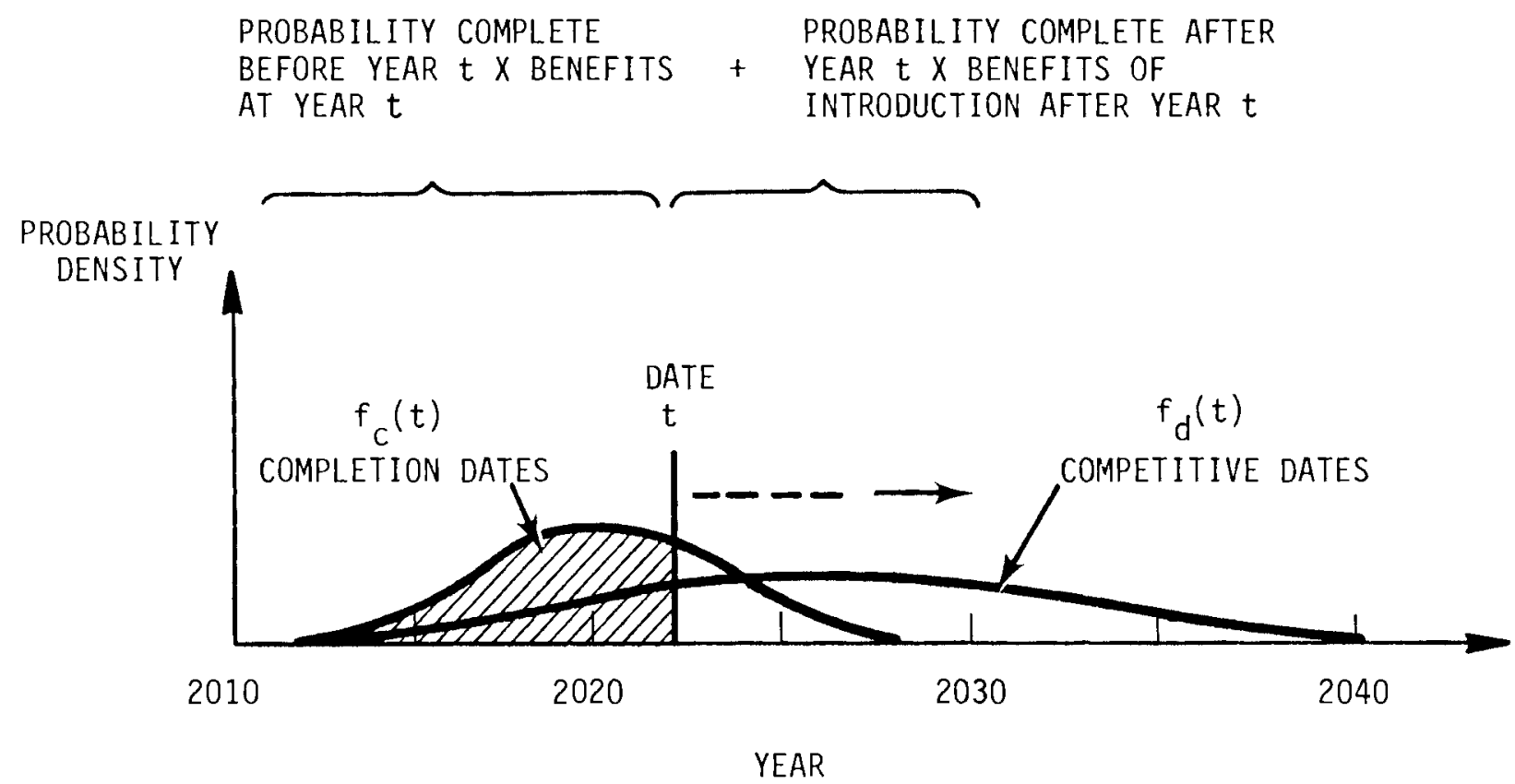

FIGURE B.5. Expected Strategy Benefits 
Now, because the competitive dates are also uncertain, all possible competitive dates must be considered. Thus, the expected strategy benefit is based on the above expression taken over all possible competitive dates; each being weighted by its probability of occurrence. To calculate the expected strategy benefit, $\bar{B}_{S}$, then, Equation (4) is evaluated as an integral:

$$
\bar{B}_{s}=\int_{0}^{\infty}\left[B(t) \int_{0}^{t} f_{c}(t) d t+\int_{t}^{\infty} f_{c}\left(t^{\prime}\right) B_{L}\left(t^{\prime}, c\right) d t^{\prime}\right] f_{d}(t) d t
$$

The expected strategy benefit measure represents the total expected benefits to society of persuing a given strategy.

Late risk is a measure of benefits lost when the technology is not available at the time it is first competitive. Matehmatically, the late risk can be calculated in the following manner. A given completion time will have:

$$
\text { (probability of complete after time) } \quad x \quad \text { (lost benefit of being late) }
$$

which is a measure of the difference in benefits at time $t$ and those at each time thereafter, weighted by the probability of being complete at those later times. Figure B.6 depicts this "late risk" calculation for a single completion time $(t)$ as shown.

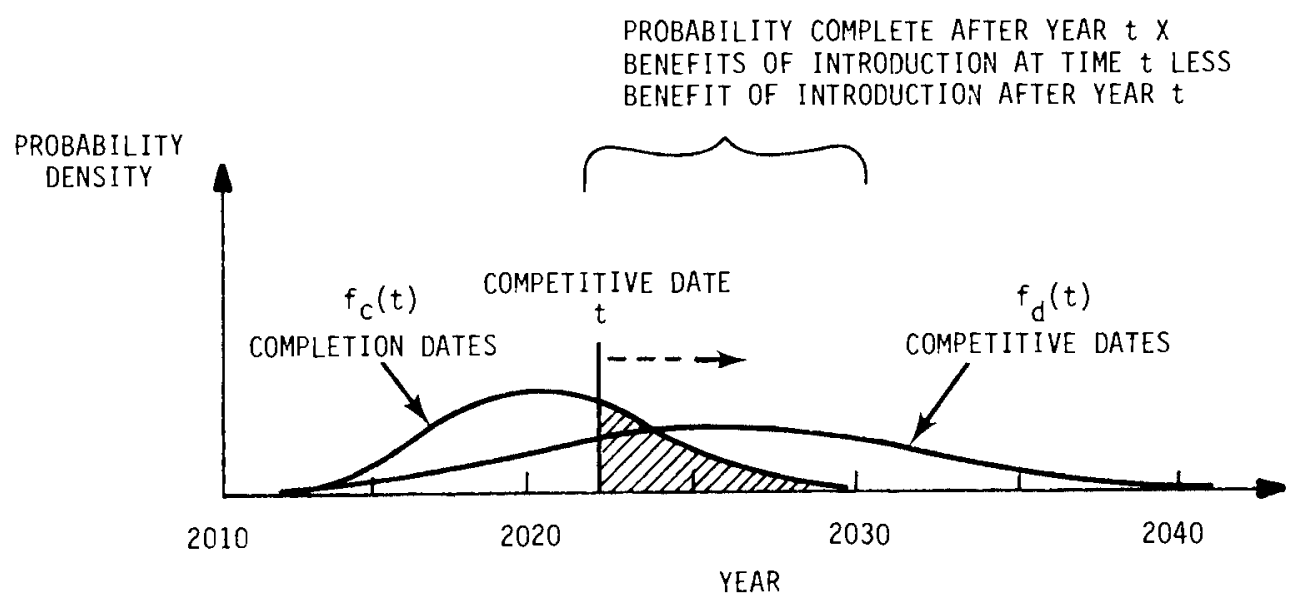

FIGURE B.6. Late Risk 
For a given competitive date $t$, the lost benefits of being late from that date are:

$$
\int_{t}^{\infty} f_{c}\left(t^{\prime}\right) B(t)-B_{L}\left(t^{\prime}, t\right) d t^{\prime}
$$

Here, the lost benefits of being late from year $t$ are $\left[B(t)-B_{L}\left(t^{\prime}, t\right)\right]$ for each late year t'. These are weighted by the probaility of being complete in year t'. To determine late risks, the expression of Equation (7) is integrated (weighted) over all possible competitive dates.

$$
\text { late risk } \left.=\int_{0}^{\infty} \int_{t}^{\infty}\left[f_{c}\left(t^{\prime}\right) B(t)-B_{L}\left(t^{\prime}, t\right)\right] d t^{\prime}\right\} f_{d}(t) d t
$$

Mathematically, "late risk" is the difference between expected gross benefits and expected strategy benefits:

$$
\text { late risk }=B-B_{s}
$$

or equivalently

$$
\bar{B}=\bar{B}_{S}+1 \text { ate risk }
$$

Combining Equations (8) and (11)

$$
\begin{gathered}
\int_{0}^{\infty}\left\{B(t) \int_{0}^{t} f_{C}(t) d t+\int_{t}^{\infty} f_{C}\left(t^{\prime}\right) B_{L}\left(t^{\prime}, t\right) d t^{\prime}\right\} f_{d}(t) d t \\
+\int_{0}^{\infty}\left\{\int_{t}^{\infty} f_{c}\left(t^{\prime}\right)\left[B(t)-B_{L}\left(t^{\prime}, t\right)\right] d t^{\prime}\right\} f_{d}(t) d t
\end{gathered}
$$




$$
\begin{aligned}
& =\int_{0}^{\infty}\left\{B(t) \int_{0}^{t} f_{C}(t) d t+\int_{t}^{\infty} f_{C}\left(t^{\prime}\right) B_{L}\left(t^{\prime}, t\right) d t^{\prime}\right. \\
& \left.+B(t) \int_{t}^{\infty} f_{C}\left(t^{\prime}\right) d t^{\prime}-\int_{t}^{\infty} f_{C}\left(t^{\prime}\right) B_{L}\left(t^{\prime}, t\right) d t^{\prime}\right\} f_{d}(t) d t \\
& =\int_{0}^{\infty}\left\{B(t) \int_{0}^{t} f_{C}(t) d t+B(t) \int_{t}^{\infty} f_{c}\left(t^{\prime}\right) d t^{\prime}\right\} f_{d}(t) d t \\
& =\int_{0}^{\infty}\left\{B(t) \int_{0}^{\infty} f_{C}(t) d t\right\} f_{d}(t) d t \\
& =\int_{0}^{\infty} B(t) f_{d}(t) d t \\
& =\bar{B}
\end{aligned}
$$

which is equivalent to Equation (2).

Early risk is based on the probability that development costs will be incurred early resulting in a technology that is not economic until later times. The development cost distribution, as estimated, does not explicitly incorporate the uncertainty in completion times for a strategy. The magnitude and variance of this distribution reflects assumptions about the actual time of completion whether it is early, expected, or late. This means that there are many different cost distributions, one for each point in time over the interval of possible completion times defines by the completion PDF. A lack of detailed information concerning the nature of this time dependency has lead to the simplifying assumption that one probability density function, that defined for the "on time" strategy development, will be used in the analysis.

The majority of cost risk to society then is the difference in the discounted development costs between completion at the fist competitive date and the early completion. The discounted expected strategy costs are first calculated. These are then compared to the discounted expected cost at each competitive date. This $c$ an be restated for a given competitive date as 
Early Risk = (discounted expected completion cost)

- (discounted expected completion cost at competitive date $t$ )

$x$ (probability competitive at date $t$ )

Mathematically, the expected strategy costs are:

$$
E(s)=\int_{0}^{\infty} s f(s) d s
$$

where

$s=$ the cost of the strategy.

Then, the above expression is given as

$$
E(S)-\frac{E(S)}{(1+\text { rate })} \Delta t f_{d}(t)
$$

where

$$
\begin{aligned}
t & =\text { the competitive date } \\
\Delta t & =t-E_{c}(t) \\
E_{c}(t) & =\text { expected completion date } \\
\text { rate } & =\text { discount rate. }
\end{aligned}
$$

Thus, the early risk is

$$
\text { early risk }=E(S)-\int_{0}^{\infty} \frac{E(s)}{(1+\text { rate })^{\Delta t}} f_{d}(t) d t
$$

There are four additional measures that quantify either maximum or minimum possible outcomes that are of interest to the decision maker. These measures represent "worst case" outcomes that one might expect. For each, the decision maker must specify $h$ is desired confidence in determining these outcomes. The calculation of these measures involves similar operation on the expectation measures above (e.g., expected cost, strategy benefit, late risk, 
and early risk). Here, the appropriate tails of the completion, introduction, and cost distribution were used in lieu of the entire original respective distribution.

The decision maker first chooses a confidence level "alpha" that defines the size or extent of the tail of the PDF that is used in the calculation. The general confidence interval chosen is usually 5 or $10 \%$.

The maximum late risk quantifies the expected cost where the FBR is economical early (e.g., in the first alpha percent time period as defined by the introduction PDF) and is complete late (e.g., in the last alpha percent time period as defined by the completion PDF). Figure B.7 depicts the time intervals of interest for $10 \%$ confidence on example distributions.

The calculation is similar to the late risk except that the integration is performed only over the specified confidence interval. As shown in Figure B.7 the competitive date PDF is integrated from its earliest time to time $t_{1}$. These times are determined from the specified confidence interval. The probability value defined from the confidence interval is used to appropriately scale the results. This is shown in Equation (11).

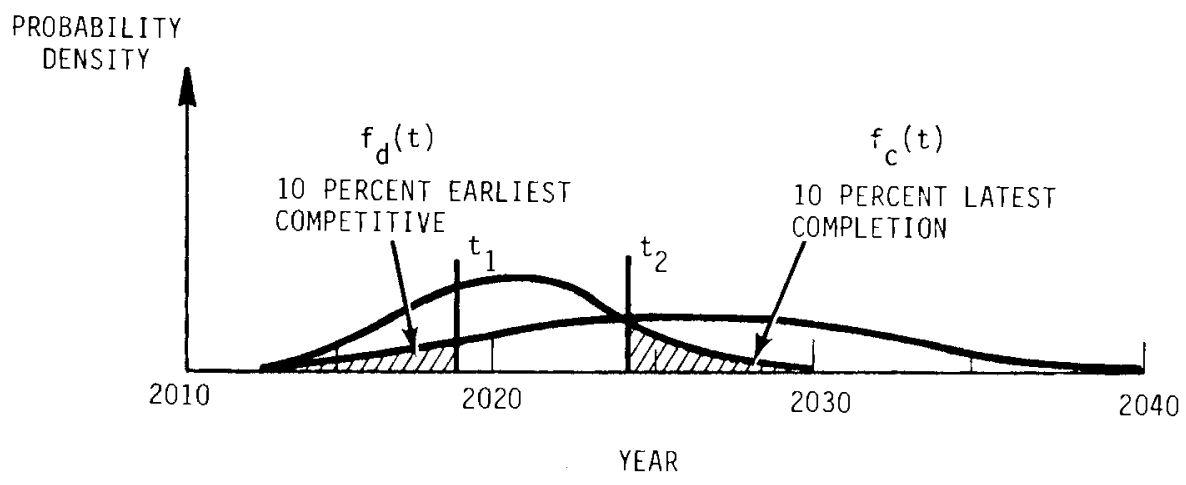

FIGURE B.7. Maximum Late Risk Confidence Intervals

$$
\underset{\text { risk }}{\operatorname{maximum}}=\int_{0}^{t_{1}}\left\{\int_{t_{2}}^{\infty} \frac{f_{c}\left(t^{\prime}\right)}{\alpha_{c}}\left[B(t)-B_{L}\left(t^{\prime}, t\right)\right] d t^{\prime}\right\} \frac{f_{d}(t)}{\alpha_{d}} d t
$$


where

$\alpha_{c}=$ confidence level on late completion (e.g., .1 for $10 \%$ confidence)

$\alpha_{d}=$ confidence level on early competitive dates.

Maximum early risk is defined similarly to the early risk metric in Equation 10, using a confidence on the latest competitive dates.

$$
\underset{\text { early risk }}{\operatorname{maximum}}=E(S)-\int_{t_{1}}^{\infty} \frac{E(S)}{(1+\text { rate })^{\Delta t}} \frac{f_{d}(t)}{\alpha_{d}} d t
$$

Minimum benefit determines the benefits for the FBR Introduction at the competitive dates having the lowest benefits. Since the benefit function $B(t)$ is monotonically decreasing in time, the minimum benefits occur for introduction at the latest competitive dates. Thus, for a confidence interval $\alpha_{d}$ on the competitive date distribution representing the latest competitive dates, the minimum benefit is:

$$
\underset{\text { Benefit }}{\operatorname{Min} \text { imum }}=\int_{t}^{\infty} B(t) \frac{f_{d}(t)}{\alpha_{d}} d t
$$

Maximum cost is the highest costs of the cost PDF for a confidence $\alpha_{s}$.

$$
\underset{\text { Cost }}{\operatorname{Maximum}}=\int_{s_{1}}^{\infty} \frac{s f(s)^{d s}}{\alpha_{s}}
$$

Note that Equations (11),(12), and (13) parallel Equations (8), (9), and (2). Here, however, a confidence $\alpha_{d}$ is specified and the limits of integration are based on this specified confidence. 
APPENDIX C

THE ETA-MACRO MODEL 


\section{APPENDIX C}

\section{THE ETA-MACRO MODEL}

To assess the FBR's role in the U.S. economy it was necessary to select an energy-economic model. We drew upon the Energy Modeling Forum's comparison of energy models (EMF 1977) and a review prepared for the Department of Energy (U.S. DOE 1979). Available models can be categorized as energy sector, energy system, and energy-economic models (Hoffmann and Wood 1976). Of these, energyeconomic models explicitly represent the interaction of the energy sector with the rest of the economy and best capture the long-term effects of FBR introduction. Their structure includes the energy sector, the U.S. economy, and a macroeconomic specification of interactions.

We considered the following models: 1) the Hudson-Jorgenson Model (Hudson and Jorgensen 1974), 2) The Wharton Annual Energy Model (Wharton 1978), 3) PILOT (Dantzig, Connolly, and Parikh 1978), and 4) ETA-MACRO. These were considered for use on several bases including: accessibility, documentation, time-finance capabilities, level of aggregation of the energy sector, representation of energy substitution, and energy supply and demand dynamics. Of the four, the Hudson-Jorgenson and the ETA-MACRO models were the best documented and most frequently exercised. The other two models are being revised and were considered difficult to use while in that status.

of these models, ETA-MACRO has been used to investigate the effect of technology introduction in the U.S. economy and has particularly focused on FBR technology (Richels 1979; Manne and Richels 1978; Manne 1974). ETA-MACRO compares available technology options in a context that captures interactions between energy supply and demand. For assessing potential FBR benefits, ETAMACRO has several unique capabilities:

- The model considers the entire energy sector. Other models have focused on either the electric or nonelectric sectors of the economy. Here, energy resources such as coal, which can be used as 
either an electric or nonelectric fuel, and new supply technologies, such as synfuels, solar, and advanced nuclear can be accounted for.

- The model considers both interfuel substitution and price induced energy conservation. Changing prices may induce consumers to substitute between alternate energy sources. Likewise, rising prices may also reduce energy demand.

- The effects of energy cost on the economy are included in ETAMACRO. Both higher energy costs and limited supplies will reduce the economy's potential growth.

- ETA-MACRO has a 75-year time horizon. The FBR will likely be a viable energy technology in the post-2000 time period. Therefore, a long time horizon is a requisite for the analysis. The model employs 5-year intervals to the year 2050 .

On the bas is of these characteristics ETA-MACRO was chosen for the calculation of benefits. The U.S. market economy is simulated in ETA-MACRO by price trajectories that balance supplies and demands in each time period. To focus on the long-term energy-economic issues, such as resource exhaustion and the introduction of new technologies, the model comprises two parts:

1. ETA - a process analysis for energy technology assessment. ETA represents the energy sector of the economy. Energy outputs are of two types: electric and nonelectric. Up to 30 technologies can be considered, including new technologies, availability dates, deployment rates, and initial and mature costs.

2. MACRO - a macroeconomic growth model of the remainder of the economy. It provides for substitution between capital, labor, and energy inputs to the economy.

As a whole, the model simulates the linkage between these two parts: the energy sector and the balance of the U.S. economy. In the model, electric and nonelectric energy are factors of production (i.e., intermediate goods); hence, they affect gross economic output. The prices of electric and nonelectric energy affect other factor prices (return on capital and wage 
rates), and ultimately they affect capital accumulation and growth. Figure C.1 depicts the static interaction of the two parts of the ETA-MACRO model.

The model simulates the market economy through a dynamic, nonlinear optimization process. Supplies, demands, and prices are matched in each time period, and "look-ahead" features allow for interactions between periods. This assumes that producers and consumers anticipate future scarcities.

The key linkage between the energy and economic sectors is through the elasticity of substitution--how easily energy may be substituted for other inputs to the economy. This is defined as the percent reduction in total energy demand associated with a $1 \%$ increase in the price of energy relative to capital and labor. The lower the value of the elasticity, the closer the linkage between energy consumption and economic growth. This in turn means higher U.S. demands for energy, more demand for oil imports, and higher economic benefits from nuclear power or other domestic energy sources.

Economic growth is measured in terms of gross national product (GNP). Two GNP concepts are distinguished, both measured in dollars of constant purchasing power: potential GNP growth at constant energy prices, and realized GNP growth under rising energy prices. Potential GNP growth is specified as an input; realized GNP growth is provided as a model output.

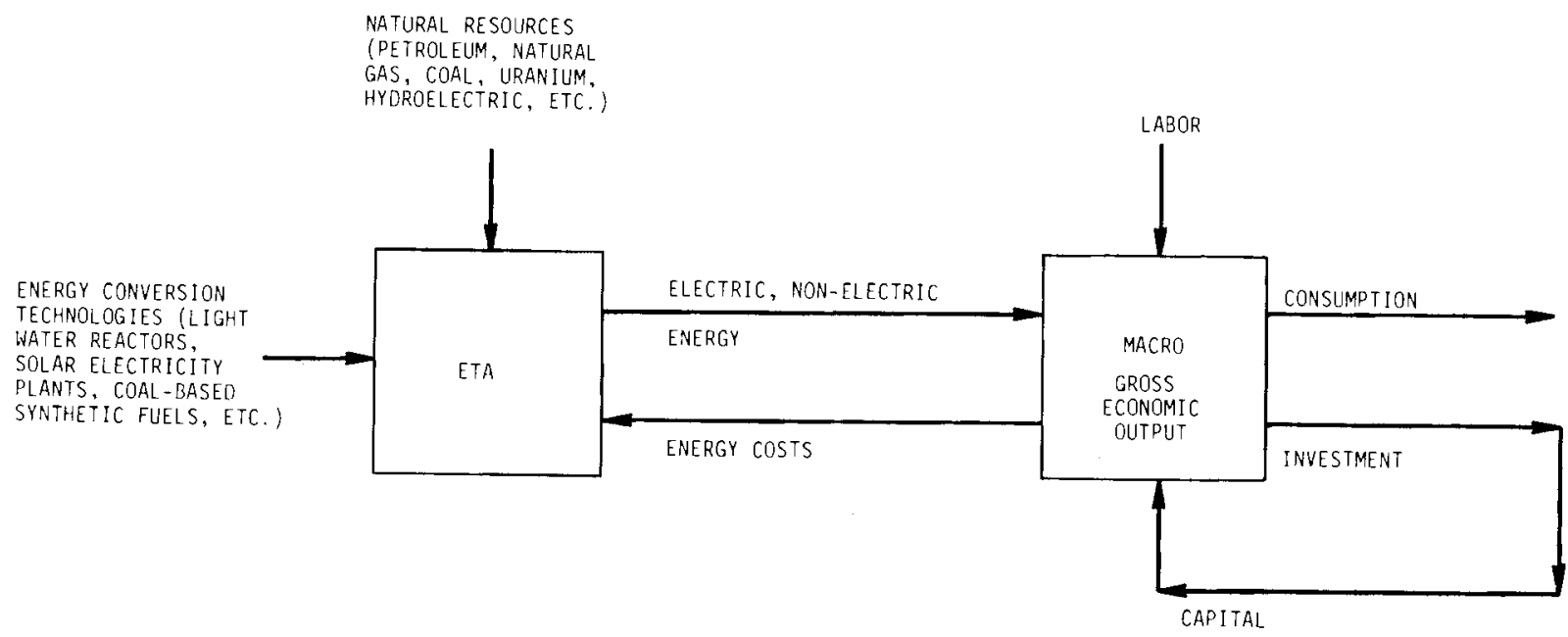

FIGURE C.1. The Two Parts of ETA-MACRO 
ETA-MACRO also addresses energy and energy-policy questions such as energy supply, demand, prices, and economic growth. Spec ific issues include the impact of higher coal and imported oil prices, production constraints, domestic oil and gas depletion, and the introduction of new technologies.

For our study, ETA-MACRO was used primarily to calculate the economic benefits arising from FBR introduction at various times, and only a few key inputs were treated as variables. These variables are discussed below.

\section{C.1 Input Specification}

ETA-MACRO assesses long-term energy issues in the U.S. economy, including:

- energy-economy interactions

- price-induced conservation

- interfuel substitution

- effects of new technologies.

The user must first specify the initial status of the U.S. economy, the degree of interaction between the energy and nonenergy sectors, and potential GNP growth. Parameters specifying the ease of conservation and substitution also describe the model economy's general behavior. Lastly, estimates of supplies, costs, and timing of the technologies within the energy sector must be specified. For this analys is key inputs include potential nuclear growth rates, uranium supplies, and LWR and FBR unit costs. Also important are the costs and quantities of available oil and coal and the cost and possible deployment rates of advanced technologies such as synfuels or solar electric generation.

The ETA-MACRO model can test a variety of energy sector policies. This study focused on measuring the macroeconomic effects of introducing FBR technology into the U.S. economy. These effects are characterized by the model as the gross benefits to society as measured by macroeconomic consumption.

To calculate FBR benefits, the model is run for two identical cases--one with the FBR technology available and one without. Benefits are then defined as the difference in economy-wide discounted consumption with and without the 
FBR. Benefits were estimated for a set of alternative introduction dates. These dates were in the range of the estimated competitive dates.

A range of input assumptions were incorporated and exercised in the model to test the sensitivity of FBR benefits. The remainder of this appendix discusses key input variables necessary to exercise the model.

The U.S. Economy - GNP

The model includes 16 individual 5-year time periods centered around a "representative" year: 1975, 1980,..,,2050. The actual 1975 status of the economy is specified and the model is checked for consistency with preliminary estimates for 1980. Table C.1 (U.S. DOE 1980) summarizes energy and economic indicators used to initialize the model. Model calculations and results are based on constant (1980) dollars.

Beyond 1980, the economy's energy demand is determined by the potential GNP. Assuming that energy prices remain constant, ETA-MACRO uses estimates of potential GNP as inputs. Since energy prices do not remain constant, these assumptions do not uniquely determine overall growth rate. Generally, potential GNP growth is assumed to be a function of societal productivity as determined by industrial output, population trends, employment, and worker productivity. The trend for the past 15 years has been a general slowing of the growth rate (Economic Report of the President 1979). For potential GNP growth, the rates shown in Table C.2 were adopted. These estimates allow for

\section{TABLE C.1. Energy-Economic Data to Initialize the Model}

\begin{tabular}{|c|c|c|c|}
\hline \multirow[b]{2}{*}{ Year } & \multicolumn{2}{|c|}{ Quadrillion $\left(10^{15}\right)$ Btu } & \multirow[b]{2}{*}{$\begin{array}{c}\text { Annual GNP } \\
\text { (Trillion } \$ 1980) \\
\end{array}$} \\
\hline & $\begin{array}{c}\text { Energy } \\
\text { Production }\end{array}$ & $\begin{array}{c}\text { Energy } \\
\text { Consumption }\end{array}$ & \\
\hline 1975 & 60.059 & 70.707 & 1.529 \\
\hline 1976 & 60.090 & 74.509 & 1.702 \\
\hline 1977 & 60.297 & 76.390 & 1.900 \\
\hline 1978 & 61.208 & 78.154 & 2.128 \\
\hline 1979 & 63.537 & 78.787 & 2.369 \\
\hline
\end{tabular}


TABLE C.2. Potential GNP

$\begin{array}{cc}\text { Years } & \begin{array}{c}\text { Percent } \\ \text { Annual Growth }\end{array} \\ 1980-2000 & 3.5 \\ 2000-2005 & 3.0 \\ 2005-2010 & 2.5 \\ 2010-2050 & 2.0\end{array}$

an expected long-term decline in population growth, labor force, and labor productivity. There is general agreement that GNP growth will be lower in the post-2000 period than in the past (Manne 1979).

Energy-Economy Interactions

Within the energy sector and between the energy sector and the remainder of the economy, two model parameters are used to drive energy demands. In the general economy there is the potential substitutability between energy and capital and labor. With in the energy sector, consumers may also be influenced by price to switch to alternative fuels.

The potential substitution of capital and labor for energy is characterized in ETA-MACRO through a single parameter termed the "elasticity of substitution." This parameter reflects the possibility of such tradeoffs as the use of insulation to replace heating fuels. These tradeoffs may result from behavior changes (e.g., turn down thermostats) or purchase (substitution) of capital stock (e.g., purchase insulation). Such tradeoffs become costeffective with a sufficient increase in energy prices.

Economists use the concept of "elasticity of substitution" to describe the tradeoff potential. Each $1 \%$ increase in energy prices relative to capital and labor leads to some percentage decrease in energy demands. This decrease takes time, and the long-term elasticity of substitution, defined as the above percentage, measures this effect. 
Considerable effort has been put into measuring elasticity of substitution (EMF 1980). One bas is for the estimates is to relate energy consumption to GNP growth. Between 1972 and 1978, for example, U.S. refiner's oil acquisition costs rose by $140 \%$ while the energy/GNP ratio dropped by $8 \%$ (measured in constant dollars of purchasing power). A statistical analysis (Manne and Wilson 1979) of actual experience concluded that reliable estimates of price elasticities cannot be based on these data. This is due in part to controversies over how much of the long-term adjustment had already been completed by 1978 .

Because the price elasticity of substitution is a major factor in energyeconomic estimates and because of the lack of a consensus on its possible value, several alternative values were used in our analysis. First, to estimate the general range of elasticities we polled Energy Modeling Forum participants. This analysis is summarized in Appendix E. For simplicity of communication, respondents were asked to estimate the long-run, primary energy demand elasticity. At constant prices and productivity, this elasticity is equivalent to the elasticity of substitution. These estimates were then averaged and adjusted to account for benchmark economic factors used in this analysis. The result was a set of four elasticities of substitution representing the ranges of elasticities (0.18 to 0.63$)$ used in the model. These were chosen to represent equal probability intervals of the survey results.

In addition to elasticity between the energy sector and the remainder of the economy, there is potential for substitution between alternative energy sources, referred to as interfuel substitution. In ETA-MACRO it is the switching within the energy sector between electric and nonelectric energy sources. This phenomenon is described as electricity's "value share."

Electricity's value share is much less the subject of debate than linkage between the energy sector and the economy. A number of ETA-MACRO experiments have tested the effects of this parameter. The electricity value share used in the model was set at 0.33 . 


\section{Nonelectric Energy}

The model requires specification of the energy sectors, both electric and nonelectric. Potential nonelectric energy resources and technologies included in the model range from the traditional fossil fuels to advanced solar energy systems. Principal fossil fuel resources are coal, $0 i 1$, and gas. $0 i 1$ and gas resources are further divided into domestic resources and imports.

The model assumes 820 quads of domestic $0 i 1$ and gas resources, recoverable at prices of $\$ 2$ to $\$ 6 / \mathrm{milli}$ ion Btu (MBTU). At the current rate of U.S. annual production, 40 quads, this implies a 20-year resource. These resource estimates are based on the Energy Modeling Forum's estimates of U.S. oil resources, and then multiplied by 2 to include natural gas. After 1.980, annual domestic production is limited not only by this resource base but also by a production constraint of 38 quads.

$0 i 1$ import costs are expected to rise at $4 \% / y r$ (over inflation) from $\$ 30 / \mathrm{barre} 1$ or $5.17 \$ /$ MBTU in 1980 . The U.S. is expected to limit crude oil, petroleum products, and LNG imports to $8.5 \mathrm{million}$ barrels/day (MBD) or 17 quads/yr. However, Canadian and Mexican natural gas is assumed to be available up to 1.5 MBD oil equivalent or 3 quads/yr. Actual 1979 energy imports were 19 quads.

Coal is a potentially large domestic resource. For coal, the model assumes maximum practical consumption rates, which are intended to incorporate future possible health, environmental, and climatological constraints. Coal production/ consumption is 1 imited to 40 quads in 2000, approaching a 60-quad limit in the year 2050. These possible constraints in the long term and industry growth in the short term represent the major difficulty of developing this resource. The current production of $737 \mathrm{million}$ ton/yr would need to more than double to meet the assumed 2 billion tons specified as the limit for the year 2000. Coal extraction costs are assumed to increase from $\$ 25 /$ ton $(\$ 1.25 / \mathrm{MBtu}$ ) to higher levels (up to $\$ 50 /$ ton) as lower grades are eventually mined.

Other nonelectric sources specified in the model include coal-based synfuels (liquids and gases), shale oil, coal (direct uses), and backstop 
technologies such as solar heating and cooling, process heat, electrolytic and thermochemical conversion as well as biomass and unconventional petroleum and gas resources. Table C.3 summarizes the costs and introduction rates of synthetic fuels and backstops.

Coal-based synthetic fuels are introduced in the 1990s and allowed to achieve the production shown in Table C.3 by the year 2000 . Thereafter, production is allowed to increase to as many as 50 quads in 2030. Similarly, shale 0 il production is allowed to grow to 12 quads by 2030 . Backstop nonelectric technologies are assumed to cost from $\$ 5$ to $\$ 20 / \mathrm{MBtu}$. Actual production is determined by the economic competitiveness of each alternative technology.

Over the model's time horizon, the potential use of the coal resource represents the principal supply side interaction between the electric and nonelectric sectors. Beyond the year 2000, coal-fired electrical generation may have competition from synfuels.

TABLE C.3. Synthetics and Nonelectric Backstops

\begin{tabular}{lcccc}
\multicolumn{1}{c}{ Source } & $\begin{array}{c}\text { Cost } \\
(\$ / \text { MBtu })\end{array}$ & & \multicolumn{2}{c}{$\begin{array}{l}\text { Quantities of Crude 0il Equi- } \\
\text { valent Available in Year 2000 }\end{array}$} \\
\cline { 1 - 1 } Coal-Based Synthetics & 4.0 & & 3.0 quads & $(1.5 \mathrm{MBD})$ \\
Shale 0il & 6.0 & & 2.0 quads & $(1.0 \mathrm{MBD})$ \\
Backstops & 10.34 & & 3.0 quads & $(1.5 \mathrm{MBD})$
\end{tabular}

\section{Electrical Energy}

Our principal interest is the role of nuclear power in supplying electricity to the U.S. economy, although other technologies used in the specification of the energy sector are considered. Non-nuclear electrical technologies include hydroelectric, fossil fuels, coal-fired electric, and "advanced" technologies such as solar electric or fusion energy. To simplify the model calculations, al ternatives such as geothermal, wind, and electrical generation from refuse have been combined with hydroelectric generation. 
The total contribution from hydroelectric and geothermal energy is fixed outside the model. In 1980 the total generation is $345 \mathrm{billion} \mathrm{kWh}$. This set of technologies is assumed to have an average cost of $33.3 \mathrm{mi} 11 \mathrm{~s} / \mathrm{kWh}$. Total generation is 1 imited to $2.5 \% / y$ growth from the current level, which results in approximately 560 billion $\mathrm{kWh}$ in the year 2000 .

0il-fired electrical generation is defined as being phased out of the economy over the next 30 years. Current (1980) production is specified at 1.5 trillion $\mathrm{kWh}$.

Coal-fired electrical generation is a principal competitor with nucleargenerated electricity. The model specified a coal-produced electricity cost, excluding the resource costs, of $17.2 \mathrm{mills} / \mathrm{kWh}$. This includes operation, maintenance, and capital costs based on $10 \%$ annual fixed charge rate, net of inflation. Capital costs, excluding fuel, are $\$ 750 / \mathrm{kW}$; these costs, levelized at a $65 \%$ capacity factor for 30 years, are $13.2 \mathrm{mills} / \mathrm{kWh}$. Operation and maintenance are $4 \mathrm{mills} / \mathrm{kWh}$. If resource costs are $\$ 1.25 / \mathrm{MBtu}$ or $\$ 12.50 / 1000$ $\mathrm{kWh}$, then total busbar costs are $29.7 \mathrm{mi} 11 \mathrm{~s} / \mathrm{kWh}$. Costs are assumed to increase at $2 \% / y$ from 1980 to account for pollution control, etc.

Table C.4 summarizes the three non-nuclear electrical technologies specified in defining the ETA-MACRO inputs. As with the nonelectric "backstop" technology, an "advanced" electric technology is specified to account for several possible electrical alternatives. This is most likely direct or indirect solar electric conversion, but may also include fusion. In specifying the "advanced" technology, solar electric, for example, was assumed to have a mature cost including storage systems of $100 \mathrm{mills} / \mathrm{kWh}$ with generation of at most 34 billion kWh ( 6 GWe) in 2020 . Its contribution is allowed to grow to at most 2,600 billion kWh by the year 2050 . 
TABLE C.4. Cost Assumptions for Economic Comparison of Base-Load Non-Nuc lear Electricity Plants

\section{Capital \\ Costs Excluding \\ Initial Fuel}

Plant Type

Hydro, Geo-

thermal, etc.

Coal-Fired

(w/scrubbers)

Advanced

(solar, etc.)

\section{Inventories $(\$ / \mathrm{kW})$}

1828

750

5295

\begin{tabular}{|c|c|c|}
\hline & Coa 1 & \\
\hline $\begin{array}{r}\text { Levelized (a) } \\
\text { Capital Cost } \\
\end{array}$ & $\begin{array}{l}\text { Resource } \\
\text { Costs } \\
\end{array}$ & $\begin{array}{c}\text { O\&M } \\
\text { Costs } \\
\end{array}$ \\
\hline
\end{tabular}

32.1

$--$

13.2

93
Total

Busbar

Costs

33.3

29.7

$100.0(d)$

(a) $10 \%$ fixed charge rate, net, of inflation. Includes taxes, insurance, depreciation and utilities ' cost of capital.

(b) Coal at $\$ 1.25 / \mathrm{MBtu}$ at heat rate of $10,000 \mathrm{Btu} / \mathrm{kWh}$.

(c) Includes costs of sludge disposal.

(d) Represents midpoint of a range of estimates from satellite power systems to alternative ground-based systems. 


\section{$\underline{\text { REFERENCES }}$}

Dantzig, G. B., J. J. Connolly, and S. C. Parikh. 1978. Stanford PILOT Energy/Economic Model. EPRI-EA-626, Project 652-1, Electric Power Research Institute, Palo Alto, California.

Economic Report of the President. 1979. U.S. Government Printing Office, Washington, D.C.

Energy Modeling Forum. 1977. "Energy and the Economy." EMF Report 1, Vol., $1 \& 2$. Stanford University, Stanford, California.

Energy Modeling Forum. 1980. "Aggregate Elasticity of Energy Demand." EMF Report 4, Vol. 1. Stanford University, Stanford, California.

Hoffman, K. C. and D. 0. Wood. 1976. "Energy System Modeling and Forecasting." In Annual Review of Energy, Vol. 1, Ed. J. J. Hollander, Annual Reviews, Inc., Palo Alto, California.

Hudson, E. A. and D. W. Jorgenson. 1974. "U.S. Energy Policy and Economic Growth 1975-2000." Bell Journal of Economics 5(2).

Manne, A. S. 1974. "Waiting for the Breeder." Review of Economic Studies Symposium on the Economics of Exhaustible Resources.

Manne, A. S. 1979. "Long-Term Energy Projections for the U.S.A." Presented at the International Conference on Energy Systems Analysis, Dublin, Ireland.

Manne, A. S. and R. G. Richels. 1978. "A Decision Analysis of the U.S. Breeder Reactor Program." In Energy, Vo1. 3. pp. 747-767, Pergammon Press Ltd., New York.

Manne, A. S. and T. F. Wilson. 1979. "The Econometric Experiment of 1973." Working Paper EMF 4.5. Stanford, California.

Riche1s, R. G. 1979. R \& D Under Uncertainty: A Study of the U.S. Breeder Reactor Program. GarTand Publishing Co., New York \& London.

U.S. Department of Energy. 1979. Survey of the Research into Energy-Economic Interactions. Vo1. 1, Survey, HCP/16346-01/1. Washington, D.C.

U.S. Department of Energy. 1980. Month1y Energy Review. Energy Information Association, Washington, D.C.

Wharton E. F. A. Inc. 1978. The Wharton Annual Energy Mode1: Development and Simulation Results. Wharton Econometric Forecasting Associates, Inc. Philadelphia, Pennsylvania. 


\section{APPENDIX D}

PAST ETA-MACRO FBR BENEFIT STUDIES 
APPENDIX D

\section{PAST ETA-MACRO FBR BENEFIT STUDIES}

A wide range of potential FBR benefits have been estimated in past analyses. Manne and Richels (1978) estimated cumulative benefits to 2050 of $\$ 198$ billion discounted at $5 \%$ to 1975 . Their analysis assumed that potential GNP growth was $2.9 \% / \mathrm{yr}$ and $3.7 \mathrm{million}$ short tons of uranium were available at $\$ 45 / 1 \mathrm{~b}(\$ 1975)$. Our study assumes that 6 GWe of FBR technology is available in the year 2000 and the relative LWR and FBR capital costs are 700 and 1000 $\$ /$ kWh respectively. Energy demand growth for this example was $2.9 \% / y r$.

Manne, Richels and Rowen (1978) also performed a sensitivity analys is on uranium resources, energy demand growth, and the cost of advanced nonelectric energy systems. Table D.1 summarizes these results. The relative change in FBR benefits as a function of its availability were also investigated. A second set of scenarios was tested with the FBR ( 6 GWe) first available in 2020. These results are also given in Table D.1.

TABLE D.1. Benefits of Introduc ing 6 GWe of FBR (Manne and Richels 1978)

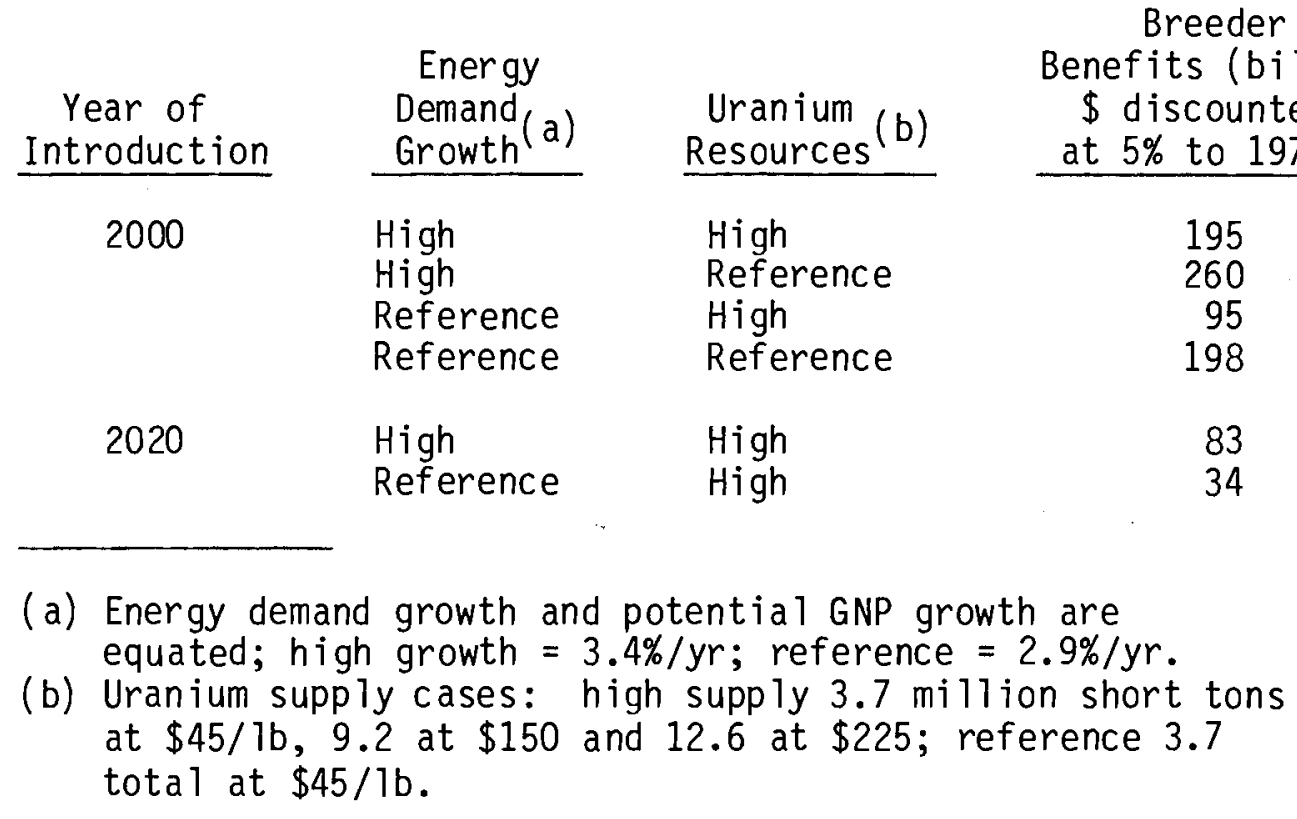


Later, Manne, Richels, and Rowen (1978) presented additional FBR benefit estimates. In this study, nine key questions related to the FBR and advanced nuc lear fuel cycles (ACR) were addressed in ETA-MACRO exercises. Base (reference) case assumptions for these exercises are given in Table D.2.

\section{TABLE D.2. ETA-MACRO Assumptions for Estimating FBR Benefits} (Manne, Richels and Rowen 1978)

\begin{tabular}{|c|c|}
\hline Factor & Value \\
\hline Elasticity of Substitution & 0.25 \\
\hline $\begin{array}{l}\text { Potential GNP Growth } \\
1970-2000 \\
\text { After } 2010\end{array}$ & $\begin{array}{l}3.5 \% / \text { year } \\
2.0 \% / \text { year }\end{array}$ \\
\hline $\begin{array}{l}\text { Import } 0 \text { il Price } \\
\text { (annual increase) }\end{array}$ & $4 \%$ \\
\hline $\begin{array}{l}\text { Coal Production Constraint } \\
\text { in } 2000\end{array}$ & 40 quads \\
\hline LWR Capac ity in 2000 & 300 GWe \\
\hline FBR/LWR Capital Cost Ratio & 1.5 \\
\hline Advanced Electric Cost & $60 \mathrm{mills}$ \\
\hline
\end{tabular}

Manne, Richels, and Rowen (1978) tested the sensitivities in FBR benefits against the available uranium supply, LWR capacity constraints in the year 2000, the effect of advanced LWR or ACR fuel cycles, and introduction dates. Table D.3 summarizes the key scenarios of this study. Note that the estimates in Tables 0.1 and 0.3 are in 1975 dollars. Also note that benefits are discounted cumulative consumption from the year of FBR introduction to the year 2050. This means that in the first set of scenarios (Table D.1) 50 years of FBR benefits are accrued whereas the later availability accrues only 30 years of benefits. If commercially competitive, the FBR would probably remain economically attractive; therefore, benefits should be compared for similar time periods. Ideally, FBR benefits should be estimated into the future as long as discounted benefits can be measured. Our benefits are estimated for a period of 40 years after initial FBR introduction. 
TABLE D.3. Benefits of Introducing 6 GWe of FBR in 2010 (Billions \$ Discounted to 1975 a $5 \% / y r$ )

\begin{tabular}{|c|c|c|c|c|}
\hline $\begin{array}{l}\text { Year of } \\
\text { Introduction }\end{array}$ & $\begin{array}{l}\text { Demand } \\
\text { Growth }\end{array}$ & $\begin{array}{c}\text { Uranium } \\
\text { Supply } \\
\text { (b) }\end{array}$ & $\begin{array}{l}\text { LWR } \\
\text { Capac ity (c) } \\
\text { (year 2000) } \\
\end{array}$ & $\begin{array}{l}\text { Breeder } \\
\text { Benefits (billion } \\
\$ \text { discounted } \\
\text { at } 5 \% \text { to } 1975 \text { ) }\end{array}$ \\
\hline 2010 & $\begin{array}{l}\text { Reference } \\
\text { Reference } \\
\text { Reference } \\
\text { Reference } \\
\text { Reference }\end{array}$ & $\begin{array}{l}\text { Reference } \\
\text { Low } \\
\text { Reference } \\
\text { Low } \\
\text { High }\end{array}$ & $\begin{array}{l}\text { Reference } \\
\text { Reference } \\
\text { High } \\
\text { High } \\
\text { High }\end{array}$ & $\begin{array}{r}78 \\
200 \\
87 \\
196 \\
0\end{array}$ \\
\hline 2020 & $\begin{array}{l}\text { Reference } \\
\text { Reference } \\
\text { Reference } \\
\text { Reference }\end{array}$ & $\begin{array}{l}\text { Reference } \\
\text { Low } \\
\text { Reference } \\
\text { Low }\end{array}$ & $\begin{array}{l}\text { Reference } \\
\text { Reference } \\
\text { High } \\
\text { High }\end{array}$ & $\begin{array}{l}70 \\
89 \\
75 \\
94\end{array}$ \\
\hline
\end{tabular}

(a) Energy demand growth based on elasticity of substitution of 0.25 , actual GNP growth realized $=3.0 \%$ to 2000 .

(b) Uranium supply cases: high supply $10 \mathrm{million}$ short tons at $\$ 50 / 1 \mathrm{~b}$; reference 3.0 at $\$ 50 / 1 \mathrm{~b}$ and 6.0 at $\$ 150 / 1 \mathrm{~b}$; low 1.5 at $\$ 50 / 1 \mathrm{~b}$ and 3.0 at $150 / 1 \mathrm{~b}$.

(c) High - 400 GWe; reference - 300 GWe.

The results shown in Tables $D .1$ and $D .3$ suggest several observations. First, the reference case in Table D.1 shows LWR capacity at 300 GWe in the year 2000; thus, the two tables can be compared on the bas is of LWR capacity. Second, both tables show FBR benefits to increase with a reduction in uranium supply from the high to reference cases. Third, Table D.3 shows that for a high uranium supply, the FBR is not economic and no benefits accrue. Fourth, in both tables, the benefits are reduced with later introduction dates.

Manne, Richels and Rowen (1978) performed an additional sensitivity analys is on the results shown in Table D.3. The elasticity of substitution, which affects general energy demand, was specified at $0.25,0.35$, and 0.50 . The reference case benefits ( $\$ 200$ billion) shown in Table 0.3 for an elasticity of 0.25 are reduced to $\$ 118$ billion for an elasticity of 0.35 and $\$ 52$ billion for 0.50 . 
Figure D.1 summarizes some of the results given in Tables D.1 and D.3. Two factors are shown to increase FBR benefits, general energy demands and decreased uranium supply. The effect of varying LWR capacity was an order of magnitude less than these other effects. An analysis by Manne and Richels (1978) found the principal assumptions affecting FBR benefits to be:

1) energy demands as driven by the elasticity of substitution, 2) uranium supply, and 3) potential GNP. Factors having a lesser effect were coal constraints, FBR capital costs, and assumptions about backstop nonelectric technologies. Low cost solar electric technologies served to reduce FBR benefits but high costs did not significantly improve FBR benefits.

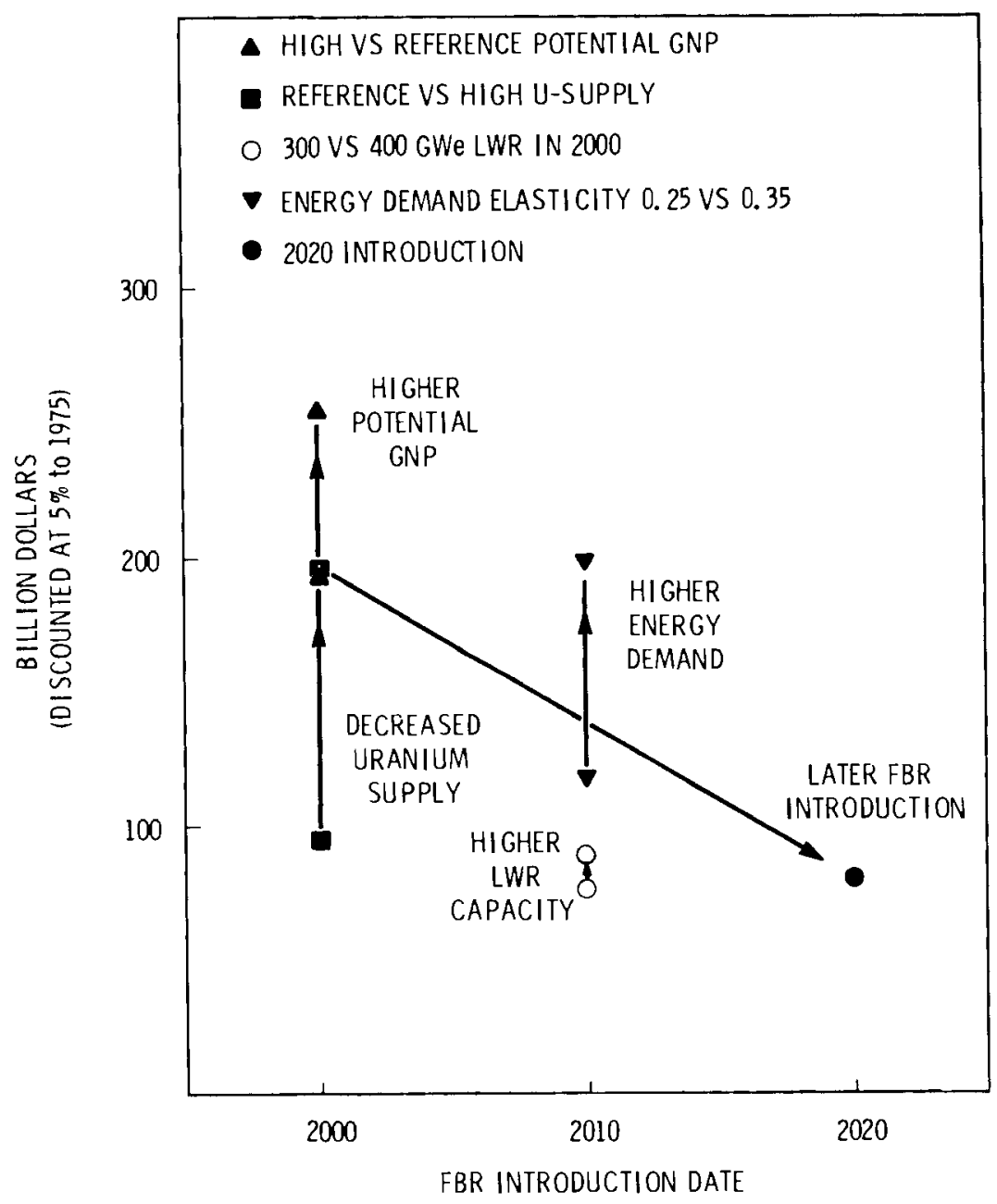

FIGURE D.1. Benefit Sensitivities 


\section{REFERENCES}

Manne, A. S. and R. G. Richels. 1978. "A Decision Analys is of the U.S. Breeder Reactor Program." Energy, Vo1.3.pp. 747-767. Pergammon Press Ltd., New York.

Manne, A. S., R. G. Richels and H. S. Rowen. 1978. "A Decision Analysis of Alternative Nuclear Fuel Cycles." Presented at Nonproliferation Alternative Systems Assessment Program (NASAP) Sumer Study, August 14-16, 1978, Aspen, Colorado. 

APPENDIX E

ENERGY DEMAND ELASTICITIES 


\section{APPENDIX E}

\section{ENERGY DEMAND ELASTICITIES}

In the estimate of FBR benefits, the magnitude and timing of societal benefits were shown to be highly dependent on energy demand. In most energy policy studies, the benefit (or cost) of a given energy policy is estimated by its impact up on the GNP or aggregate consumption. The response of energy demand to changes in energy prices is central to these estimates. To characterize this response, analysts and modelers have developed may approaches to energy demand.

The ETA-MACRO model was selected for the purpose of estimating the economic benefits to society resulting from FBR introduction. ETA-MACRO calculates market equilibrium for the entire energy sector. This is captured by specification of own- and cross-price elasticities of each source of energy. In this way, rising prices for one energy form can be off set by conservation of that fuel and by substitution.

There are two basic elasticities to consider. First, is the primary energy demand elasticity. It is defined as:

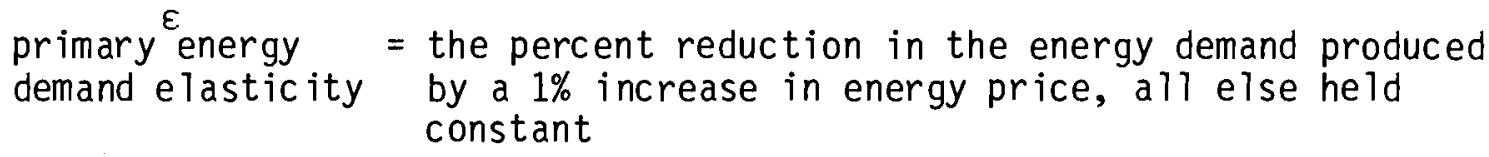
constant

By convention, elasticities are negative whenever price increases lead to decreases in demand.

The elasticity input to ETA-MACRO is a measure of the ease or difficulty of replacing energy with other inputs such as capital and labor into the economy. This elasticity is defined as: 
$\sigma$

elasticity of = the percent change in the ratio of energy to non-energy substitution inputs induced by a $1 \%$ change in their price ratios.

In an early paper Manne (1977) estimated that the elasticity of substitution was on the order of 0.25. Unfortunately, there is a wide margin for error in the econometric estimation of this elasticity parameter. If the elasticity of substitution is very low, the factors of production would not substitute easily with one another. This means that tight energy supplies would lead to reduced output and higher energy prices. For this reason, care was taken in this analysis to determine a range of estimates of this parameter and to test the sensitivity of benefits to its value.

To determine estimates of the energy demand elasticity, Manne, in the spring of 1980, polled the energy analysts who are participants in the Energy Modeling Forum's (a) World 0il Study. The objective was to obtain individual views on the energy demand elasticities and the uncertainties that are involved. Guidelines were based on EMF groundrules for a world oil study exerc ise referred to as EMF-6. As a reference, respondents were asked to base their estimates at a price of $\$ 27$ per barrel of crude $0 i 1$ in 1980 . Each participant was asked to provide elasticity estimates in the form of a cumulative probability distribution. Figure E.1 is a facimile of the questionnaire.

A total of 24 responses to the demand elasticity pol1 were recieved. These are sumarized in Table E.1. Figure E.2 shows a histogram of the average results of the poll. These results are shown in Figure E.3 as a smoothed cumulative distribution function.

(a) The Electric Power Research Institute created the Energy Modeling Forum (EMF) to improve the practical application of energy models to policy issues and planning. Administered by the Stanford University Institute for Energy Studies, the EMF operates through a series of working groups of energy model developers and users conducting comparative tests of a variety of energy models. Different models are examined in the context of important topics in energy decision making. 


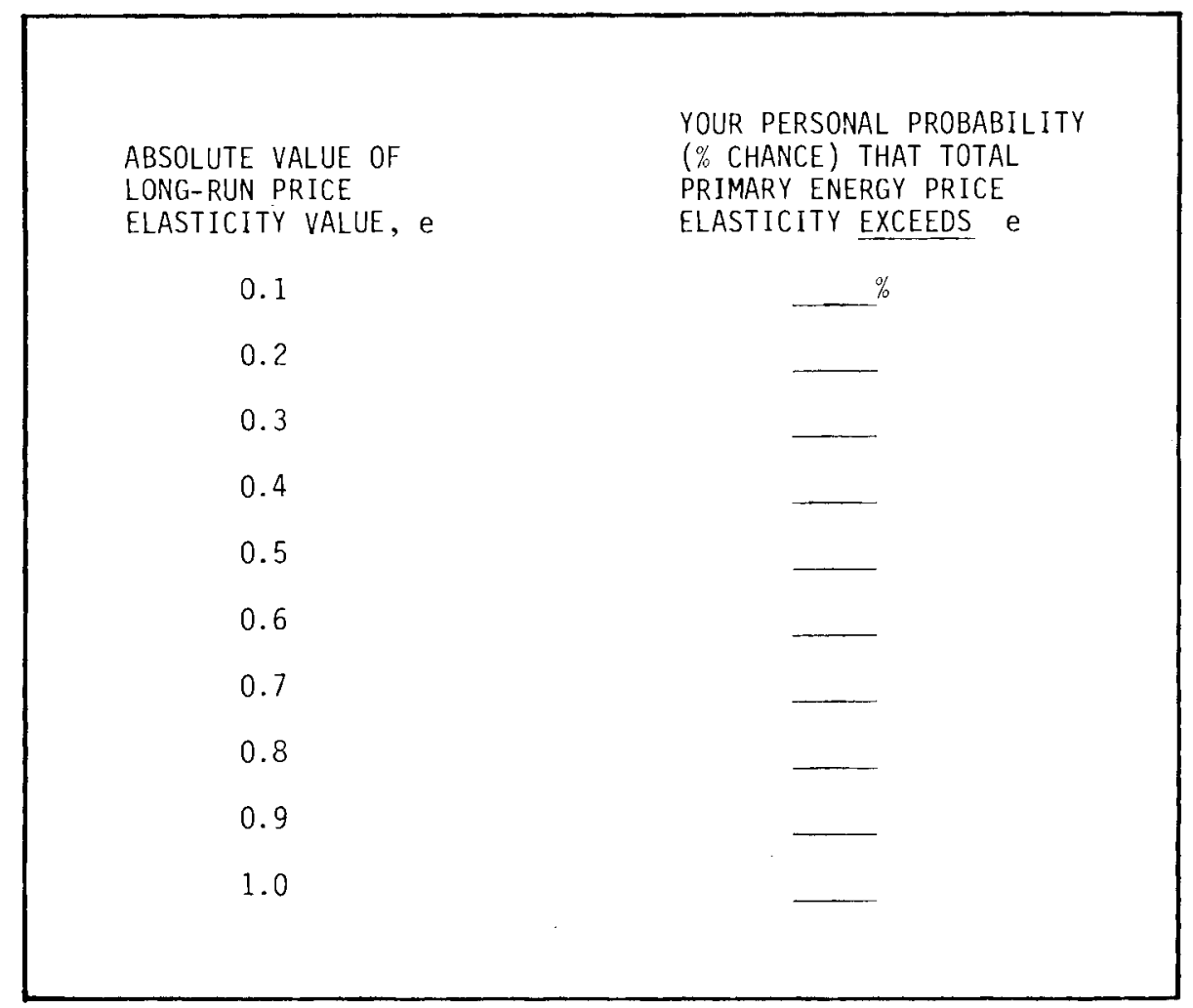

FIGURE E.1. Facsimile of Elasticity Poll

For the assessment of FBR benefits, four representative elasticities were selected to test the sensitivity of the results to demand elasticity. These elasticities were selected to represent equal portions (quartiles) of the survey's results.

$$
\begin{aligned}
& \text { primary demand }=.20, .35, .50, .70 \text {, } \\
& \text { elastic ity }
\end{aligned}
$$

As indicated, ETA-MACRO uses the elasticity of substitution rather than the primary demand elasticity as input. Empirically, these two elasticities are equivalent only to a local approximation, given that primary demand is known with certainty (Hogan and Manne 1979). In other words, two adjustments to the poll's results were required: 
TABLE E.1. Primary Energy Demand Elasticity e

\begin{tabular}{|c|c|c|c|c|c|c|c|c|c|c|c|c|}
\hline Individual Identification Numbers & 1 & 2 & 3 & 4 & 5 & 6 & 7 & 8 & 9 & 10 & 11 & 12 \\
\hline \multicolumn{13}{|l|}{ Probability that e exceeds } \\
\hline .10 & 90 & 99 & 95 & 90 & 99 & 90 & 95 & - & 99 & 85 & 95 & 98 \\
\hline .20 & 60 & 90 & 70 & 70 & 75 & 75 & 85 & - & 95 & 75 & 85 & 90 \\
\hline .30 & 20 & 50 & 45 & 50 & 50 & 50 & 75 & - & 80 & 60 & 60 & 60 \\
\hline .40 & 10 & 20 & 30 & 35 & 40 & 40 & 45 & - & 50 & 50 & 50 & 50 \\
\hline .50 & - & 10 & 25 & 20 & 20 & 20 & $3-$ & - & 40 & 45 & 40 & 40 \\
\hline .60 & - & 1 & 20 & 10 & 5 & 5 & 15 & - & 20 & 30 & 15 & 30 \\
\hline .70 & - & 0 & 15 & 0 & 1 & 1 & 5 & - & 10 & 20 & 5 & 10 \\
\hline .80 & - & 0 & 10 & 0 & .05 & 1 & 1 & - & 5 & 5 & 0 & - \\
\hline \multirow[t]{2}{*}{.90} & - & 0 & 5 & 0 & .01 & 1 & 1 & - & 1 & 0 & 0 & 2 \\
\hline & 13 & 14 & 15 & 16 & 17 & 18 & 19 & 20 & 21 & 22 & 23 & 24 \\
\hline .10 & 90 & 99 & 99 & 100 & 70 & 95 & 90 & 90 & 97 & 100 & 95 & 95 \\
\hline .20 & 80 & 90 & 90 & 80 & 65 & 85 & 80 & 80 & 92 & 98 & 90 & 90 \\
\hline .30 & 65 & 75 & 75 & 70 & 60 & 75 & 70 & 70 & 83 & 90 & 85 & 85 \\
\hline .40 & 50 & 50 & 50 & 55 & 55 & 60 & 60 & 60 & 69 & 70 & 70 & 80 \\
\hline .50 & 40 & 40 & 25 & 45 & 50 & 40 & 50 & 50 & 50 & 50 & 60 & 60 \\
\hline .60 & 30 & 25 & 5 & 30 & 45 & 20 & 40 & 30 & 30 & 30 & 55 & 50 \\
\hline .70 & 20 & 10 & 1 & 25 & 40 & 5 & 30 & 10 & 15 & 15 & 45 & 20 \\
\hline .80 & 15 & 7.5 & .1 & 15 & 35 & - & 20 & 5 & 10 & 5 & 35 & 10 \\
\hline .90 & 10 & 5 & .01 & 10 & 30 & - & 10 & 1 & 5 & 2 & 20 & 5 \\
\hline
\end{tabular}




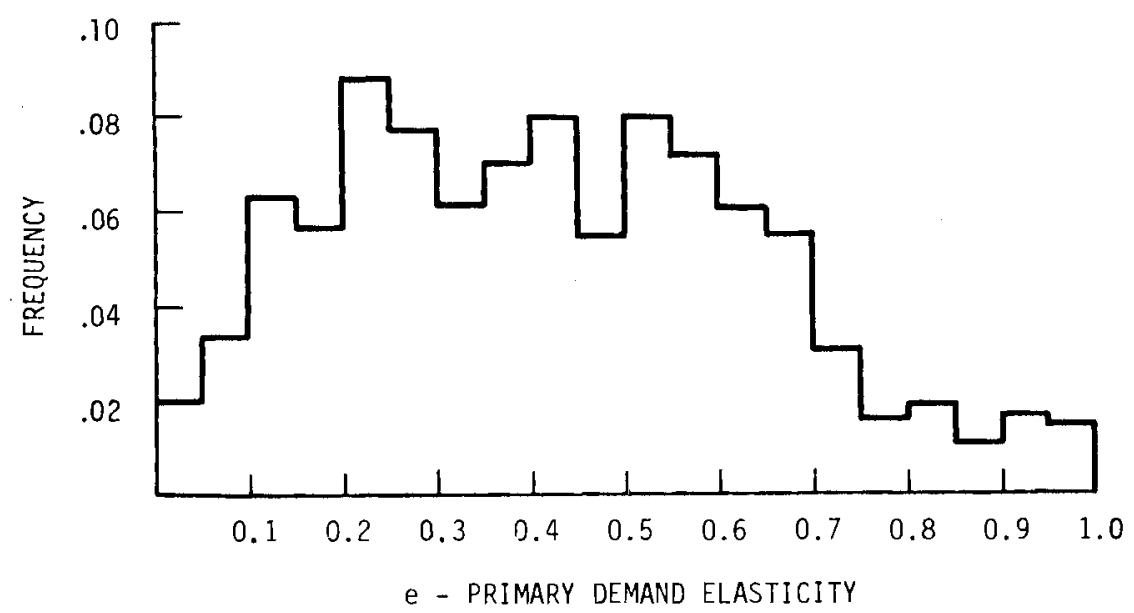

FIGURE E.2. Frequency Histogram of Poll Results

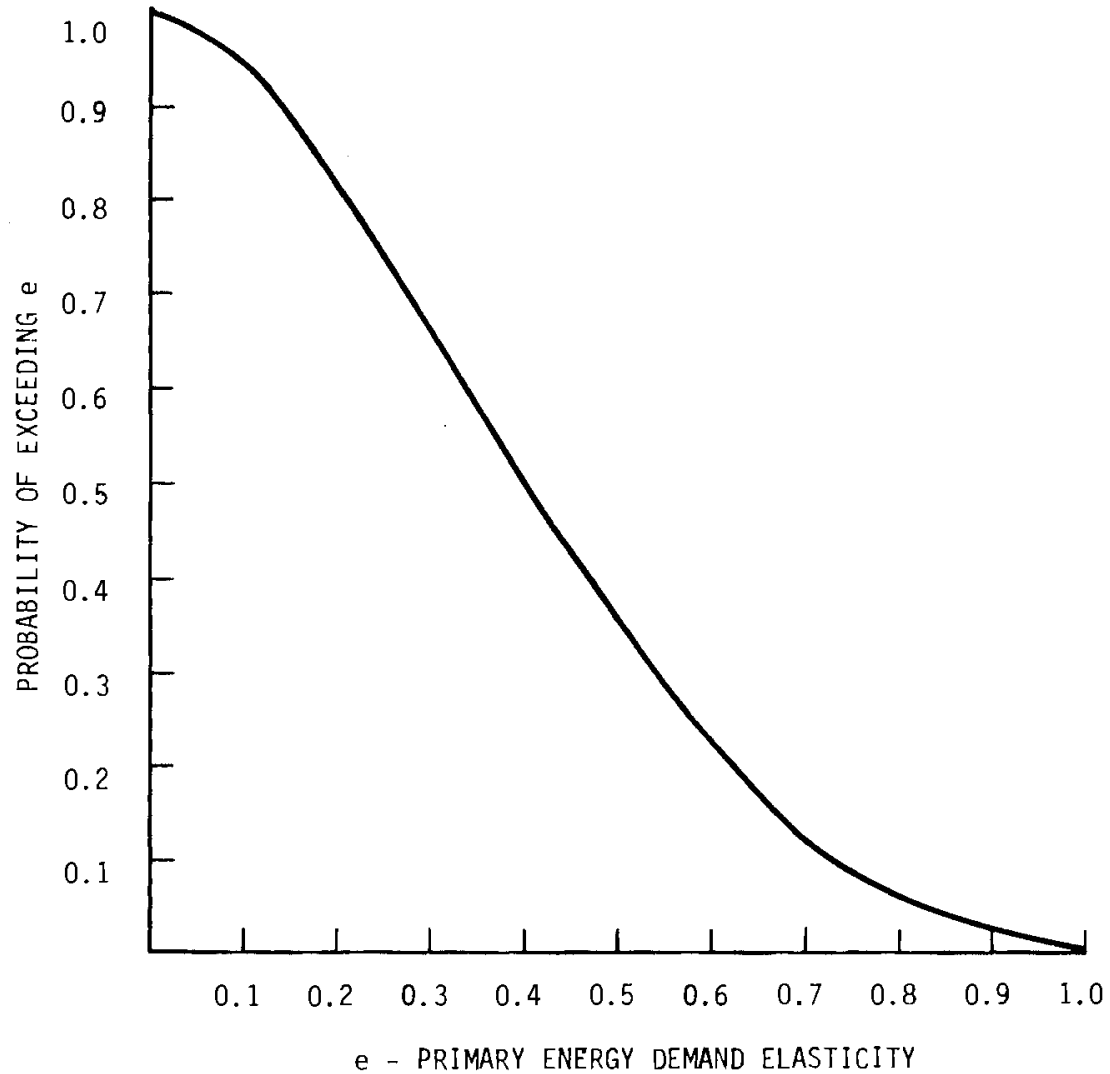

FIGURE E.3. Smoothed Distribution of Poll Results 
1. Account for the benchmark $0 i 1$ price assumed at $\$ 27 / b b l$ for wor 1 d $0 i 1$ versus the domestic price used in the analysis.

2. Transform the primary demand elasticity to the elasticity of substitution.

These two adjustments resulted in the following elasticities of substitution, which were used as inputs to the ETA-MACRO Model for our analysis:

$\begin{array}{lr}\text { Price Elasticity } & \text { Elasticity of Substitution } \\ .2 & .18 \\ .35 & .32 \\ .5 & .45 \\ .7 & .63\end{array}$




\section{REFERENCES}

Hogan, W. W. and A. S. Manne. 1979. "Energy Economy Interactions: The Fable of the Elephant and the Rabbit?" Advances in the Economics of Energy and Resources, Vol I, pp 7-26, JAI Press Inc.

Manne, A. S. 1977. ETA-MACRO: A Model of Energy - Economy Interactions. EPRI-EA-592, Electric Power Research Institute, Palo Alto, California. 
PNL-3598

UC-2,16,

51,78 ,

$79,79 i$

\section{DISTRIBUTION}

No. of

Copies

\section{OFFSITE}

A. A. Churm

DOE Patent Division

9800 South Cass Avenue

Argonne, IL 60439

Gary Boyer

United Nuclear Homestake

P.0. Box 98

Grants, NM 87020

E. M. Craig

Dawn Mining Co.

P.0. Box 25

Ford, WA 99013

Simcha Golan

Bechtel National Inc.

Engineers and Constructors

Fifty Beale Street

P.0 Box 3965

San Francisco, CA 94119

Stanley M. Davies

General Electric Company

310 Deguigne Drive

P.0. Box 508

Sunnyvale, CA 94086

Tom Hand

Westinghouse Electric Corporation

P.0. Box 158

Madison, PA 15663

Tom DiFrancisco

Burns and Roe, Inc.

550 Kinderkamack Raad

Orade 11, NJ 07649
No. of

Copies

John H. Crowley

United Engineers and Constructors

300 South 17 Street

Philadelphia, PA 19101

George Garabedian

Stone and Webster Engineering Corp.

Power Divison

245 Summer Street

Boston, MA 02107

Judy Grange

Science Applications, Inc.

40 Denver Tech Center West

7925 E. Prentice

Englewood, CO 80111

Bob Miller

United Nuclear

Drawer QQ

Gallup, NM 87301

Charles Stanley

Kerr McGee

Box 218

Grants, NM 87020

C. L. Storrs

C-E Power Systems

Combustion Engineering, Inc.

1000 Prospect Hill Road

Windsor, CT 06095

440 DOE Technical Information Service

P.0. Box 62

Oak Ridge, TN 37830 
No. of

Copies

Noe 1 Gonzaga

S. M. Stoller Corporation 1250 Broadway

New York, NY 10001

10 J. P. Thereault

U.S. Department of Energy

Wahington D.C. 20545

W. W. Ballard

U.S. Department of Energy Washington D.C. 20545

S. T. Brewer

U.S. Department of Energy

Washington D.C. 20545

Hugh Kendrick

U.S. Department of Energy Washington D.C. 20545

R. G. Staker

U.S. Department of Energy

Washington D.C. 20545

J. R. Longenecker

U.S. Department of Energy

Washington D.C. 20545

John A. Patterson

U.S. Department of Energy

Washington D.C. 20545

Roger Gagne

U.S. Department of Energy

Washington D.C. 20545

Tom Dillon

U.S. Department of Energy

Washington D.C. 20545

Neal Goldenberg

U.S. Department of Energy

Washington D.C. 20545

Richie Williamson

U.S. Department of Energy

Washington D.C. 20545
No. of

Copies

Dave Bodde

U.S. Department of Energy

Washington D.C. 20545

Bob Bown

U.S. Department of Energy

Washington D.C. 20545

Eli Goodman

U.S. Department of Energy

Washington D.C. 20545

A. J. Snyder

U.S. Department of Energy

Washington D.C. 20545

Ross Humphreys

U.S. Department of Energy

Washington D.C. 20545

Tom Werner

U.S. Department of Energy

Washington D.C. 20545

D. M. Blanchfield

Grand Junction office

U.S. Department of Energy

P.0. Box 2567

Grand Junction, CO 81501

B. Boyer

Grand Junction Office

U.S. Department of Energy

P.0. Box 2567

Grand Junction, CO 81501

M. E. Crew

Grand Junction Office

U.S. Department of Energy

P.0. Box 2567

Grand Junction, CO 81501

D. L. Curry

Grand Junction Office

U.S. Department of Energy

P.0. Box 2567

Grand Junction, CO 81501 
No. of

$\underline{\text { Copies }}$

J. Franco

Grand Junction Office

U.S. Department of Energy

P.0. Box 2567

Grand Junction, CO 81501

P. de Vergi

Grand Junction Office

U.S. Department of Energy

P.0. Box 2567

Grand Junction, CO 81501

D. L. Everhart

Grand Junction Office

U.S. Department of Energy

P.0. Box 2567

Grand Junction, CO 81501

M. Hansen

Grand Junction Office

U.S. Department of Energy

P.0. Box 2567

Grand Junction, CO 81501

R. C. Malan

Grand Junction Office

U.S. Department of Energy

P.0. Box 2567

Grand Junction, CO 81501

L. Kovisars

MET Research

2403 Thomas Avenue

Dallas, TX 75201

R. A. McLaren

Union Carbide Nuclear Divison

P.0. Box P Mail Stop 17

Oak Ridge, TN 37830

C. E. Ford

Union Carbide Nuclear Divison

P.0. Box P Mail Stop 17

Oak Ridge, TN 37830
No. of

Copies

\author{
P. Rogers \\ Bendix Field Engineering Corp. \\ Grand Junction Operations \\ P.0. Box 1569 \\ Grand Junction, CO 81501 \\ Lewis Per 1 \\ National Economic Research \\ Association \\ 5 Wor ld Trade Center \\ New York, NY 10048 \\ Mart in Becker \\ Rensselaer Poly Tech \\ Nuclear Engineering Department \\ Troy, NY 12181 \\ Prof. Deverle P. Harris \\ University of Arizona \\ Department of Mining and \\ Geological Engineering \\ Tucson, AZ 85721 \\ Prof. A. S. Manne \\ 834 Esplanada Way \\ Stanford, CA 94305 \\ Prof. J. Daniel Khazzoom \\ 380 Kensington Way \\ San Francisco, CA 94127 \\ Prof. Wayne J. Davis \\ University of Illinois \\ Dept. of General Engineering \\ Urbana, IL 61801 \\ Dr. Lawrence Droutman \\ Westinghouse Electric Corporation \\ P.0. Box 158 \\ Madison, PA 15663 \\ Randa11 L. Beatty \\ Science Applications, Inc. \\ 800 0ak Ridge Turnpike \\ P.0. Box 843 \\ Oak Ridge, TN 37830
}


No. of

Copies

ONSITE

2 DOE Richland Operations office

P. A. Craig

H. E. Ransom

70 Pacific Northwest Laboratory

C. H. Bloomster

A. J. Boege 1

J. B. Burnham (20)

L L. Clark

M. J. Clausen

B. M. Cole

D. E. Deonigi

D. A. Dingee

C. E. Elderk in

R. L. Engle

R. M. Fleischman (10)

D. L. Hall

C. R. Hann

H. Harty
No. of

Copies

A. J. Haverfield

C. M. Heeb

J. C. King

R. C. Liikala

L. W. Long

J. A. Mahaffey

R. P. Marshall

R. W. McKee

E. T. Merrill

D. F. Newman

R. E. Nightingale

D. E. Olesen

G. F. Piepel

R. J. Sorensen

A. M. Sutey

P. C. Walkup

M. K. White

W. R. Wiley

R. D. Widrig

T. L. Willke

L. D. Williams

Publishing Coordination $\mathrm{Ha}$ (2)

Technical Information (5) 